RAFAEL GARABET AGOPIAN

Estudo morfométrico de rins de primatas

Callithrix jacchus em cativeiro

São Paulo

2010 


\title{
Estudo morfométrico de rins de primatas Callithrix jacchus em cativeiro
}

\author{
Dissertação apresentada ao Programa de \\ Pós-Graduação em Anatomia dos Animais \\ Domésticos e Silvestres da Faculdade de \\ Medicina Veterinária e Zootecnia da \\ Universidade de São Paulo para obtenção \\ de título de Mestre em Ciências
}

Departamento:

Cirurgia

Área de concentração:

Anatomia dos Animais Domésticos e

Silvestres

Orientador:

Prof. Dr. Pedro Primo Bombonato

São Paulo

2010 
Autorizo a reprodução parcial ou total desta obra, para fins acadêmicos, desde que citada a fonte.

DADOS INTERNACIONAIS DE CATALOGAÇÃO-NA-PUBLICAÇÃO

(Biblioteca Virginie Buff D’Ápice da Faculdade de Medicina Veterinária e Zootecnia da Universidade de São Paulo)

Agopian, Rafael Garabet

Estudo morfométrico de rins de primatas Callithrix jacchus em cativeiro I Rafael Garabet Agopian. -- 2010

107 p. : il.

Dissertação (Mestrado) - Universidade de São Paulo. Faculdade de Medicina Veterinária e Zootecnia. Departamento de Cirurgia, São Paulo, 2010.

Programa de Pós-Graduação: Anatomia dos Animais Domésticos e Silvestres

Área de concentração: Anatomia dos Animais Domésticos e Silvestres.

Orientador: Prof. Dr. Pedro Primo Bombonato.

1. Callithrix jacchus. 2. Rim. 3. Morfometria. I. Título. 


\section{Comissão de Ética no uso de animais}

\section{CERTIFICADO}

Certificamos que o Projeto intitulado "Estudo morfométrico de rins de primatas Callithrix jacchus em cativeiro", protocolado sob o no 2051/2010, utilizando amostras de rins de saguis-de-tufo-branco, sob a responsabilidade do Prof. Dr. Pedro Primo Bombonato, está de acordo com os princípios éticos de experimentação animal da "Comissão de Ética no uso de animais" da Faculdade de Medicina Veterinária e Zootecnia da Universidade de São Paulo e foi aprovado em reunião de 27/10/2010.

We certify that the Research "Morphometric study of kidneys in captivity Callithrix jacchus primates", protocol number 2051/2010, under the responsibility Prof. Dr. Pedro Primo Bombonato, agree with Ethical Principles in Animal Research adopted by "Ethic Committee in the use of animals" of the School of Veterinary Medicine and Animal Science of University of São Paulo and was approved in the meeting of day $10 / 27 / 2010$.

São Paulo, 28 de outubro de 2010

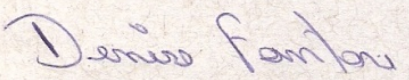

Profa. Dra. Denise Tabacchi Fantoni Presidente 


\section{FOLHA DE AVALIAÇÃO}

Nome: AGOPIAN, Rafael Garabet

Título: Estudo morfométrico de rins de primatas Callithrix jacchus em cativeiro

Dissertação apresentada ao Programa de Pós-Graduação em Anatomia dos Animais Domésticos e Silvestres da Faculdade de Medicina Veterinária e Zootecnia da Universidade de São Paulo para obtenção de título de Mestre em Ciências

Data:

Banca Examinadora

Prof. Dr. Instituição:

Assinatura: Julgamento:

Prof. Dr. Instituição:

Assinatura: Julgamento:

Prof. Dr. Instituição:

Assinatura: Julgamento: 


\section{DEDICATÓRIA}

À minha esposa, minha grande e fiel companheira, meu porto seguro, cúmplice de qualquer êxito alcançado, que tanto me apoiou e sem ela jamais teria conseguido. Minha eterna "querida", que carrega em seu ventre a maior prova do nosso amor, esse também é para você, meu bebê, que mesmo antes de nascer já participa e ajuda a formar o início da nossa grande família. 


\section{AGRADECIMENTOS}

Ao meu orientador, Prof. Dr. Pedro Primo Bombonato, pela confiança, ensinamentos, amizade e por me proporcionar a oportunidade de realizar um grande sonho em minha vida.

Ao Prof. Dr. Edson Aparecido Liberti, pela grande colaboração neste estudo, por me proporcionar grandes ensinamentos e por estar sempre pronto a ajudar.

À minha esposa, pela paciência e ajuda nas horas difíceis, apoio, amor e dedicação. Aos meus pais, João e Lucia, irmãos, Andréia, Marcelo e Luciana, sobrinhos, Gabriel, Leonardo, Vitor, Samira, Gustavo, Matheus, Eloah e "Matheusinho", por estarem sempre presentes em minha vida.

À Dra Cristiane Macedo Dell Rio do Valle, por disponibilizar não só o material deste estudo, mas também toda a sua ajuda e dedicação estando pronta a ajudar a qualquer momento.

Ao meu grande mestre e exemplo, Prof. Dr. Antônio Fernandes Filho, um grande "pai" que foi o responsável por me direcionar a carreira de docência.

À Rosana, pela grande ajuda na análise estatística dos resultados.

Ao Dr. Rodrigo Dell Rio do Valle, pela atenção, disposição e conselhos que me ajudaram a construir este trabalho.

Aos colegas do Departamento de Anatomia dos Animais Domésticos e Silvestres, sempre dispostos a colaborar de alguma forma e com um bom-humor singular, Caio Biasi, Fernanda Agreste, Yiuri Karacas, Camila Ercolini, Miler Rodrigo, Rafael Senos, Marcos Vinícius, Caroline Costola, Luiz Nogueira, Amanda, Matheus, Sarmento, Rodrigo Barreto, Vivian e todos aqueles que conviveram comigo durante este período.

À Renata Fernades pela grande ajuda e principal responsável pelo meu contato com o departamento.

Aos colegas do "VQM" por me receberem em seu ambiente de trabalho, sempre bem humorados e dispostos a me orientar quanto ao uso dos equipamentos e ajuda com meu estudo chegando a disponibilizar seus horários nos equipamentos, Ricardo, Regina, Paulo Henrique, Thiago e Valquíria.

Aos meus grandes amigos, Arthur e Raquel, sempre apoiando e me tirando do sufoco, obrigado pelos momentos alegres e descontraídos, estaremos sempre juntos em nossa caminhada. 
Aos técnicos Ronaldo, Índio e Diogo pela atenção e suporte técnico laboratorial. Aos secretários sempre dispostos a ajudar Maicon e Jaqueline.

À coordenadora e os professores do Departamento de Anatomia dos Animais Domésticos e Silvestres, $\operatorname{Prof}^{\mathrm{a}} \mathrm{Dr}^{\mathrm{a}}$ Maria Angélica Miglino, $\operatorname{Prof}^{\mathrm{a}}$. $\mathrm{Dr}^{\mathrm{a}}$. Paula Papa e Prof. Dr. José Roberto Kfoury.

Aos meus colegas e exemplos profissionais Prof Paneta, Prof. Lucci, Prof. Celso, Prof $^{a}$ Adriana, Prof ${ }^{a}$ Acácia, Prof ${ }^{a}$ Renata, Prof ${ }^{a}$ Katia e Prof ${ }^{a}$ Andréia. Deixo aqui registrada minha profunda admiração e respeito.

Aos meus queridos alunos, combustível que alimenta a minha busca por conhecimento. 


\section{RESUMO}

AGOPIAN, R. G. Estudo morfométrico de rins de primatas Callithrix jacchus em cativeiro. [Morphometric study of kidneys in captivity Callithrix jacchus primates]. 2010. 107 f. Dissertação (Mestrado em Ciências) - Faculdade de Medicina Veterinária e Zootecnia, Universidade de São Paulo, São Paulo, 2010.

Atualmente, os primatas de pequeno e médio porte, em especial os sagüis, têm grande destaque em estudos experimentais, pois são usados frequentemente como modelo para estudos comparativos de várias doenças em humanos, entretanto vários aspectos básicos de sua anatomia ainda estão por serem estudados. Com esta motivação, rins de 20 Callithrix jacchus da colônia do DPZ (Centro de Primatas da Alemanha), foram utilizados para sua caracterização morfométrica macro e microscópica, onde os parâmetros relativos à mensuração anatômica, comprimento, altura, largura, peso e volume dos rins foram estabelecidos, bem como a quantificação de glomérulos e mensuração da área glomerular, com a finalidade de se comparar a influência de fatores como simetria bilateral, sexo, idade e condição sanitária, nestes parâmetros. Com base nos resultados concluiu-se que todos os parâmetros mensurados não são influenciados pelo sexo ou pela simetria. Os rins dos animais com alteração nos exames apresentaram maior tamanho (comprimento, altura e largura), peso e volume, e também, maior área glomerular que os rins dos animais sadios. Nos animais mais jovens, o número de glomérulos quantificados foi maior e a área glomerular média foi menor, que em animais mais velhos.

Palavras-chave: Callithrix jacchus. Rim. Morfometria. 


\begin{abstract}
AGOPIAN, R. G. Morphometric study of kidneys in captivity Callithrix jacchus primates. [Estudo morfométrico de rins de primatas Callithrix jacchus em cativeiro]. 2010. 107 f. Dissertação (Mestrado em Ciências) - Faculdade de Medicina Veterinária e Zootecnia, Universidade de São Paulo, São Paulo, 2010.
\end{abstract}

Currently, the primates of small and medium size, especially the marmosets, have great prominence in experimental studies, they are often used as a model for comparative studies of various diseases in humans, but several basic aspects of their anatomy are still being studied. With this motivation, the kidneys of 20 Callithrix jacchus in the colony of DPZ (German Primate Center), were used to characterize their macroscopic and microscopic morphometry, where the parameters for anatomical measurements, length, height, width, weight and volume of the kidneys were established, as well as quantification of glomeruli and measurement of glomerular area in order to compare the influence of factors such as bilateral symmetry, sex, age and health condition in these parameters. Based on the results concluded that all measured parameters are not affected by sex or by symmetry. The kidneys of animals with changes in the examinations of larger size (length, width and height), weight and volume, and also a greater area than the glomerular kidney of healthy animals. In younger animals, the number of glomeruli was higher and the mean glomerular area was smaller than in older animals.

Keywords: Callithrix jacchus. Kidney. Morphometry. 


\section{LISTA DE FIGURAS}

Figura 1- Espécime de Callithrix jacchus da colônia do Centro de Primatas da Alemanha - DPZ

Figura 2- $\quad$ Tipos de néfrons de mamíferos. (A) Néfron justamedular. (B) Néfron cortical.

Figura 3- Imagem das edificações de recintos internos do Centro de Primatas da Alemanha - DPZ. Goettingen - 2005. 36

Figura 4- Colocação de plástico coletor de urina em gaiolas de Callithrix jacchus no DPZ. 38

Figura 5- $\quad$ Fitas reagentes Multistix 10 SG - Bayer ${ }^{\circledR}$ e aparelho Cliniteck Status Bayer $^{\circledR}$ utilizados na avaliação de proteínas e hemácias na urina 39

Figura 6- Esquema representativo de inclusão ou exclusão de glomérulos na contagem final. 45

Figura 7- Ilustração indicando esquema da seqüência de numeração glomerular iniciada da margem superior para a inferior e da margem esquerda para a direita.

Figura 8- $\quad$ Aspectos da cloração da urina de Callithrix jacchus sem alteração nos exames (esquerda) e com alteração nos exames (direita).

Figura 9- Coleta sanguínea em Callitrix jacchus para realização de bioquímica sérica (uréia e creatinina) e curva glicêmica. .50

Figura 10- Corte histológico de rim de Callithrix jacchus com escore total $=0$. Coloração HE, animal Nicoletta. .50

Figura 11- Corte histológico de rim de Callithrix jacchus com escore total $=1$. Coloração HE, animal Blanche. 
Figura 12- Corte histológico de rim de Callithrix jacchus com escore total $=2$. Coloração HE, animal Ariberta.

Figura 13- Imagem de Callithrix jacchus com peso $>400$ gramas 55

Figura 14- Imagem de Callithrix jacchus com peso $<400$ gramas .55

Figura 15- Necropsia de Callithrix jacchus sem alteração nos exames, demonstrando o tamanho, o posicionamento dos rins e a quantidade de gordura na cavidade abdominal. Animal - Southern 68

Figura 16- Necropsia de Callithrix jacchus com alteração nos exames, demonstrando o tamanho, o posicionamento dos rins e a quantidade de gordura na cavidade abdominal. Neste caso o rim direito encontrava-se encoberto pelo fígado aumentado de tamanho. Animal Karla. .68

Figura 17- Rim de Callithrix jacchus sem alteração nos exames, demonstrando tamanho e forma. Animal - Southern.

Figura 18- Rim de Callithrix jacchus com alteração nos exames, demonstrando tamanho e forma. Animal - Karla. .68

Figura 19- Rim de Callithrix jacchus sem alteração nos exames, demonstrando morfologia interna. Animal - Southern. .68

Figura 20- Rim de Callithrix jacchus com alteração nos exames, demonstrando morfologia interna. Animal - Karla.. .68

Figura 21- Corte histológico de rim de Callithrix jacchus demonstrando quantificação glomerular. .78

Figura 22- Corte histológico de rim de Callithrix jacchus demonstrando mensuração da área glomerular. 


\section{LISTA DE TABELAS}

Tabela 1-

Valores referentes à idade (anos) dos machos e fêmeas de Callithrix jacchus dos grupos 1 e 2 - Goettingen. 48

Tabela 2-

Valores referentes ao peso $(\mathrm{g})$ dos machos e fêmeas de Callithrix jacchus dos grupos 1 e 2 - Goettingen - 2006. .53

Tabela 3-

Valores referentes ao peso (g) dos Callithrix jacchus com alteração nos exames ( $\operatorname{sim}$ ) e sem alteração nos exames (não) Goettingen - 2006 . .54

Tabela 4-

Valores referentes ao comprimento $(\mathrm{cm})$ dos rins direito e esquerdo dos Callithrix jacchus machos e fêmeas dos grupos 1 e 2 - Goettingen - 2009 e 2006 .58

Tabela 5-

Valores referentes ao comprimento $(\mathrm{cm})$ dos rins direito e esquerdo dos Callithrix jacchus com alteração nos exames (sim) e sem alteração nos exames (não) dos grupos 1 e 2 - Goettingen 2009 e 2006

Tabela 6-

Valores referentes à altura $(\mathrm{cm})$ dos rins direito e esquerdo dos Callithrix jacchus machos $(M)$ e fêmeas $(F)$ dos grupos 1 e 2 Goettingen - 2009 e 2006 60

Tabela 7-

Valores referentes à altura $(\mathrm{cm})$ dos rins direito e esquerdo dos Callithrix jacchus com alteração nos exames (sim) e sem alteração nos exames (não) dos grupos 1 e 2 - Goettingen - 2009 e 2006

Tabela 8- $\quad$ Valores referentes à largura $(\mathrm{cm})$ dos rins direito e esquerdo de Callithrix jacchus machos $(\mathrm{M})$ e fêmeas $(F)$ dos grupos 1 e 2 Goettingen - 2009 e 2006 
Tabela 9-

Valores referentes à largura $(\mathrm{cm})$ dos rins direito e esquerdo de Callithrix jacchus com alteração nos exames (sim) e sem alteração nos exames (não) dos grupos 1 e 2 - Goettingen - 2009 e 2006

Tabela 10-

Valores referentes ao peso $(\mathrm{g})$ dos rins direito e esquerdo de Callithrix jacchus machos $(M)$ e fêmeas $(F)$ dos grupos 1 e 2 Goettingen - 2009 e 2006 64

Tabela 11-

Valores referentes ao peso $(\mathrm{g})$ dos rins direito e esquerdo de Callithrix jacchus com alteração nos exames (sim) e sem alteração nos exames (não) dos grupos 1 e 2 - Goettingen - 2009 e 2006 .65

Tabela 12- $\quad$ Valores referentes ao volume $\left(\mathrm{cm}^{3}\right)$ dos rins direito e esquerdo de Callithrix jacchus machos $(\mathrm{M})$ e fêmeas $(F)$ dos grupos 1 e 2 Goettingen - 2009 e 2006

Tabela 13- Valores referentes ao volume $\left(\mathrm{cm}^{3}\right)$ dos rins direito e esquerdo de Callithrix jacchus com alteração nos exames (sim) e sem alteração nos exames (não) dos grupos 1 e 2 - Goettingen - 2009 e 2006 .

Tabela 14- Valores referentes ao número de glomérulos em 30 campos de $1,51 \mathrm{~mm}^{2}$, dos rins direito e esquerdo de Callithrix jacchus machos (M) e fêmeas $(F)$ dos grupos 1 e 2 - São Paulo 2010 .70

Tabela 15- Valores referentes ao número de glomérulos em 30 campos de $1,51 \mathrm{~mm}^{2}$, dos rins direito e esquerdo de Callithrix jacchus com alteração nos exames (sim) e sem alteração nos exames (não)

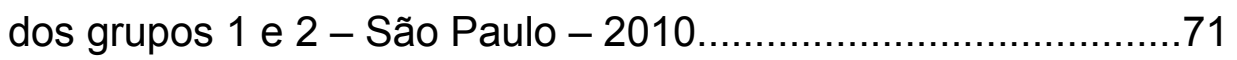

Tabela 16- Valores referentes à densidade glomerular $\left(\mathrm{n}^{\circ} / \mathrm{mm}^{2}\right)$, dos rins direito e esquerdo de Callithrix jacchus machos (M) e fêmeas (F) dos grupos 1 e 2 - São Paulo - 2010. 
Tabela 17- Valores referentes à densidade glomerular $\left(\mathrm{n} \% \mathrm{~mm}^{2}\right)$, dos rins direito e esquerdo de Callithrix jacchus com alteração nos exames (sim) e sem alteração nos exames (não) dos grupos 1 e 2 - São Paulo - 2010 . .73

Tabela 18- Valores referentes à área glomerular média $\left(\mu \mathrm{m}^{2}\right)$, dos rins direito e esquerdo de Callithrix jacchus machos $(M)$ e fêmeas $(F)$ dos grupos 1 e 2 - São Paulo - 2010. 74

Tabela 19- Valores referentes à área glomerular média $\left(\mu \mathrm{m}^{2}\right)$, dos rins direito e esquerdo de Callithrix jacchus com alteração nos exames (S) e sem alteração nos exames $(\mathrm{N})$ dos grupos 1 e 2 - São Paulo 2010 .75 


\section{LISTA DE GRÁFICOS}

Gráfico 1- Valores referentes ao peso $(\mathrm{g})$ dos machos e fêmeas de Callithrix

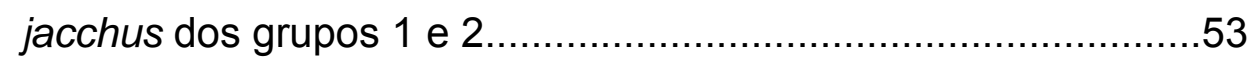

Gráfico 2- Valores referentes ao peso (g) dos Callithrix jacchus com alteração nos exames (sim) e sem alteração nos exames (não) .54

Gráfico 3- Valores referentes ao comprimento $(\mathrm{cm})$ dos rins direito e esquerdo dos Callithrix jacchus machos e fêmeas dos grupos 1 e 2. .58

Gráfico 4- Valores referentes ao comprimento $(\mathrm{cm})$ dos rins direito e esquerdo dos Callithrix jacchus com alteração nos exames (sim) e sem alteração nos exames (não) dos grupos 1 e $2 \ldots \ldots \ldots \ldots \ldots \ldots . . . . .59$

Gráfico 5- Valores referentes à altura $(\mathrm{cm})$ dos rins direito e esquerdo dos Callithrix jacchus machos e fêmeas dos grupos 1 e 2 .60

Gráfico 6- $\quad$ Valores referentes à altura $(\mathrm{cm})$ dos rins direito e esquerdo dos Callithrix jacchus com alteração nos exames (sim) e sem alteração nos exames (não) dos grupos 1 e 2

Gráfico 7- Valores referentes à largura $(\mathrm{cm})$ dos rins direito e esquerdo de Callithrix jacchus machos e fêmeas dos grupos 1 e 2 . 62

Gráfico 8- $\quad$ Valores referentes à largura $(\mathrm{cm})$ dos rins direito e esquerdo de Callithrix jacchus com alteração nos exames (sim) e sem alteração nos exames (não) dos grupos 1 e $2 \ldots \ldots \ldots \ldots \ldots \ldots \ldots \ldots . . . . . . .63$

Gráfico 9- Valores referentes ao peso (g) dos rins direito e esquerdo de Callithrix jacchus machos e fêmeas dos grupos 1 e 2 . .64 
Gráfico 10- Valores referentes ao peso $(\mathrm{g})$ dos rins direito e esquerdo de Callithrix jacchus com alteração nos exames (sim) e sem alteração nos exames (não) dos grupos 1 e 2 . 65

Gráfico 11- Valores referentes ao volume $\left(\mathrm{cm}^{3}\right)$ dos rins direito e esquerdo de Callithrix jacchus machos e fêmeas dos grupos 1 e 2 . .66

Gráfico 12- Valores referentes ao volume $\left(\mathrm{cm}^{3}\right)$ dos rins direito e esquerdo de Callithrix jacchus com alteração nos exames (sim) e sem alteração nos exames (não) dos grupos 1 e 2 .

Gráfico 13- Valores referentes ao número de glomérulos em 30 campos de $1,51 \mathrm{~mm}^{2}$, dos rins direito e esquerdo de Callithrix jacchus

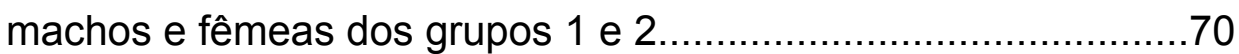

Gráfico 14- Valores referentes ao número de glomérulos em 30 campos de $1,51 \mathrm{~mm}^{2}$, dos rins direito e esquerdo de Callithrix jacchus com alteração nos exames (sim) e sem alteração nos exames (não) dos grupos 1 e 2

Gráfico 15- Valores referentes à densidade glomerular $\left(\mathrm{n} \% \mathrm{~mm}^{2}\right)$, dos rins direito e esquerdo de Callithrix jacchus machos e fêmeas dos grupos 1 e 2 . .72

Gráfico 16- Valores referentes à densidade glomerular $\left(\mathrm{n} / \mathrm{mm}^{2}\right)$, dos rins direito e esquerdo de Callithrix jacchus com alteração nos exames (sim) e sem alteração nos exames (não) dos grupos 1 e $2 \ldots \ldots \ldots . . .73$

Gráfico 17- Valores referentes à área glomerular média $\left(\mu \mathrm{m}^{2}\right)$, dos rins direito e esquerdo de Callithrix jacchus machos e fêmeas dos grupos $1 \mathrm{e}$ 2 .

Gráfico 18- Valores referentes à área glomerular média $\left(\mu \mathrm{m}^{2}\right)$, dos rins direito e esquerdo de Callithrix jacchus com alteração nos exames (sim) e sem alteração nos exames (não) dos grupos 1 e 2....................74 
Gráfico 19- Valores referentes à distribuição de freqüência (\%) da área glomerular média $\left(\mu \mathrm{m}^{2}\right)$, dos rins direito e esquerdo de Callithrix jacchus machos e fêmeas do grupo 1...........................................76

Gráfico 20- Valores referentes à distribuição de freqüência (\%) da área glomerular média $\left(\mu \mathrm{m}^{2}\right)$, dos rins direito e esquerdo de Callithrix jacchus machos e fêmeas do grupo 2 ..........................................76

Gráfico 21- Valores referentes à distribuição de freqüência (\%) da área glomerular média $\left(\mu \mathrm{m}^{2}\right)$, dos rins direito e esquerdo de Callithrix jacchus com alteração nos exames (sim) e sem alteração nos exames (não) do grupo 1 ........................................................77

Gráfico 22- Valores referentes à distribuição de freqüência (\%) da área glomerular média $\left(\mu \mathrm{m}^{2}\right)$, dos rins direito e esquerdo de Callithrix jacchus com alteração nos exames (sim) e sem alteração nos exames (não) do grupo 2...........................................................77 


\section{LISTA DE ANEXOS}

Anexo A Protocolo de coloração para Hematoxilina-Eosina, diafanização e montagem das lâminas

Anexo B Divisão dos grupos de estudo. .96

Anexo C Dados referentes ao sexo, idade (anos), peso (g) e ausência ou presença de alteração nos exames dos animais dos grupos $1 \mathrm{e}$ 2

Anexo D

Valores da mensuração anatômica, comprimento, altura, largura $(\mathrm{cm})$, volume $\left(\mathrm{cm}^{3}\right)$ e peso $(\mathrm{g})$, dos rins direito e esquerdo dos animais do grupo 1 e 2 . .98

Anexo E Representação esquemática dos formulários para contagem glomerular .99

Anexo F

Valores referentes à contagem glomerular em 30 campos, média de glomérulos por campo, área do campo $\left(\mathrm{mm}^{2}\right)$ e densidade glomerular (glomérulos $/ \mathrm{mm}^{2}$ ) dos rins direito e esquerdo dos animais do grupo 1 e 2 100

Anexo G Representação esquemática dos formulários para mensuração da área glomerular. 101

Anexo $\mathrm{H} \quad$ Valores referentes à média da área glomerular $\left(\mu \mathrm{m}^{2}\right)$ de 25 glomérulos mensurados em cada rim, direito e esquerdo, dos animais do grupo 1 e 2 102

Anexo I

Valores referentes à bioquímica sérrica (uréia e creatinina $(\mathrm{mg} / \mathrm{dl})$ ) dos animais do grupo 1 e 2 . 103 
Anexo J Valores de parâmetros urinários, proteína e sangue, mensurados por meio de testes de fita $(+)$, albumina $(\mathrm{mg} / \mathrm{dl})$, creatinina $(\mathrm{mg} / \mathrm{dl})$ e relação albumina/creatinina, mensurados em laboratório, dos 3 exames realizados nos animais do grupo

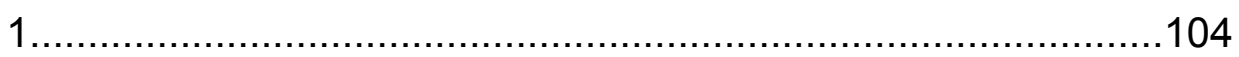

Anexo K Valores de parâmetros urinários, proteína e sangue, mensurados por meio de testes de fita $(+)$, albumina $(\mathrm{mg} / \mathrm{dl})$, creatinina $(\mathrm{mg} / \mathrm{dl})$ e relação albumina/creatinina, mensurados em laboratório, dos 3 exames realizados nos animais do grupo 2 105

Anexo $\mathrm{L} \quad$ Valores das taxas de glicose sanguínea $(\mathrm{mg} / \mathrm{dl})$ do exame da curva glicêmica antes da sobrecarga de glicose e 20 minutos após a sobrecarga para sangue venoso $(\mathrm{V})$ e periférico $(P)$, e 10, 40, $60,80,100,120$ e 140 minutos após a sobrecarga para sangue periférico, dos animais do grupo 1 e 2 ..................................106

Anexo M Escore morfológico e classificação final (total) do exame

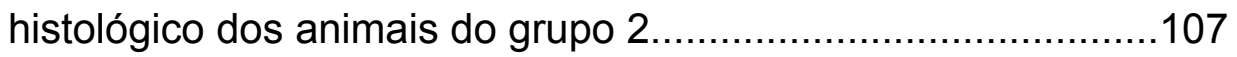




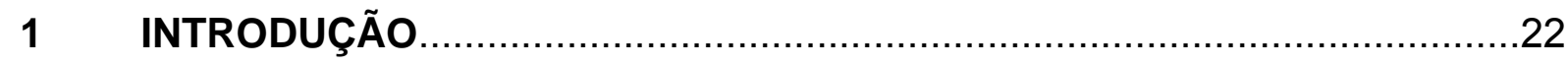

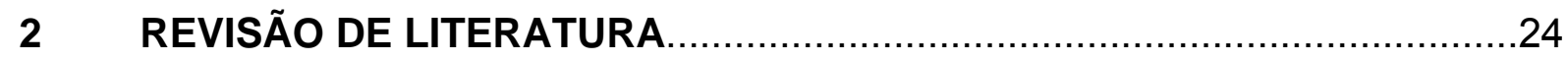

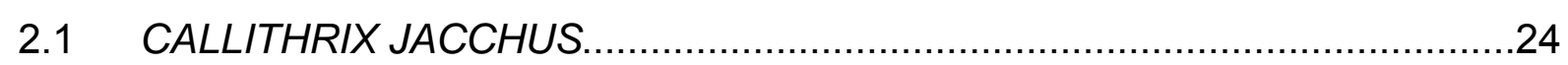

2.2 ASPECTOS ANATOMOFISIOLÓGICOS DOS RINS...................................28

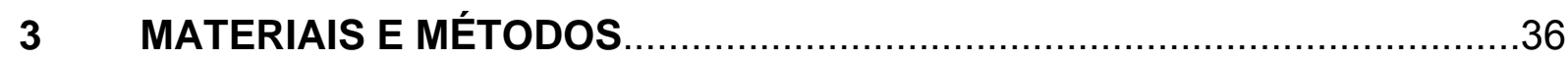

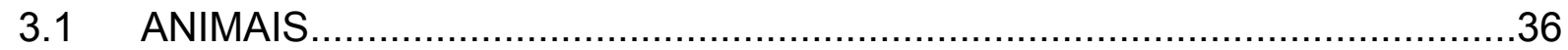

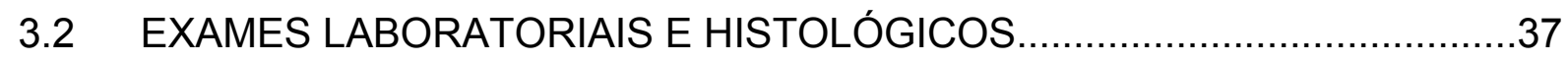

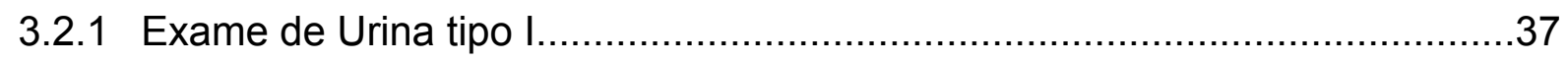

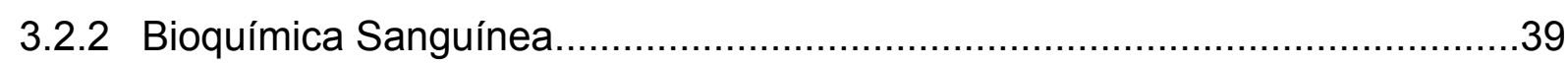

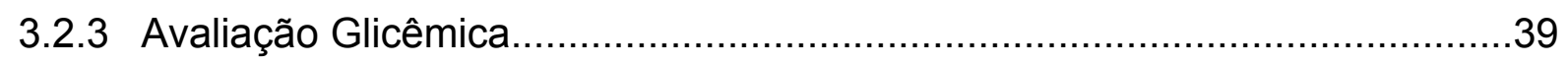

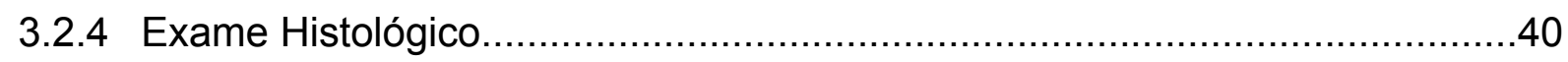

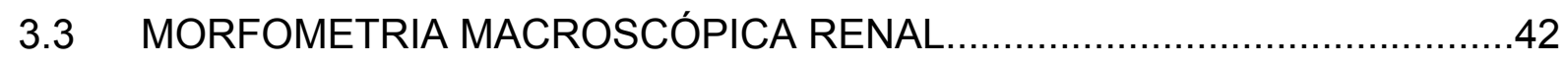

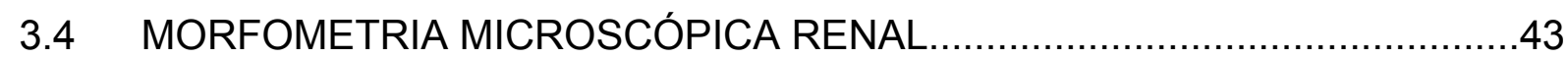

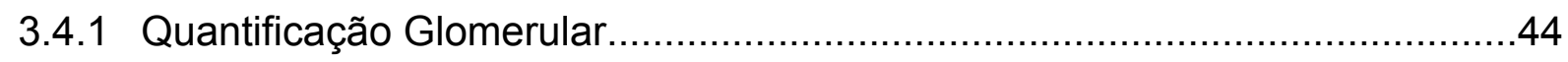

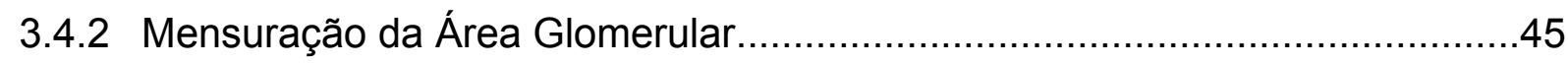

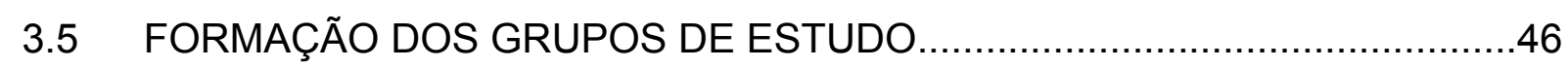

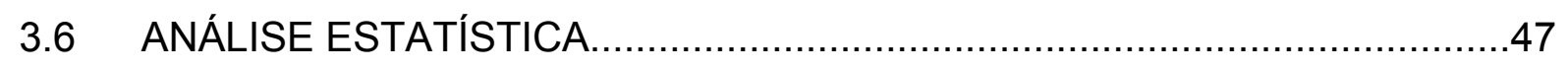

4 RESULTADOS

4.1 EXAMES LABORATORIAIS E HISTOLÓGICO .......................................48

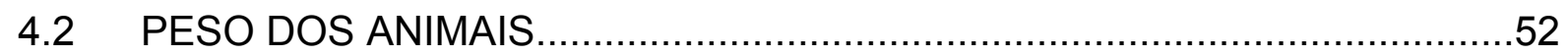

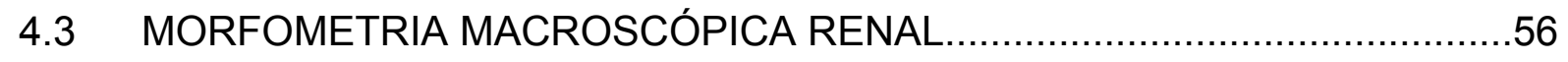

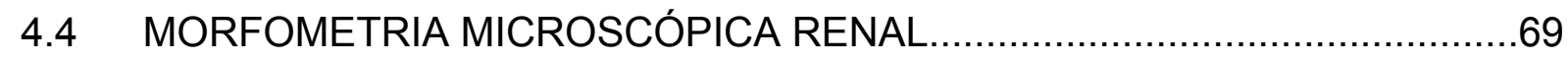

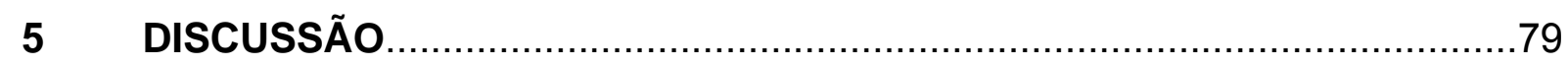

6 CONCLUSÃO

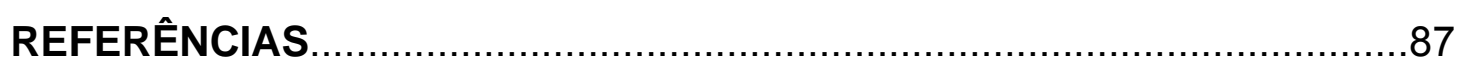

ANEXOS 


\section{INTRODUÇÃO}

De há muito tempo os animais são utilizados em pesquisas biomédicas, como por exemplo, no desenvolvimento de vacinas e estudos farmacológicos. É incalculável a contribuição dos animais às novas descobertas para prevenção e tratamento de desordens orgânicas. Para tanto, essa contínua evolução do conhecimento, especialmente o da biologia, tanto na medicina humana quanto na veterinária, repercute no desenvolvimento de ações envolvendo a criação e a experimentação animal, implicando na necessidade de uma constante atualização de suas técnicas e procedimentos (ANDRADE, 2002).

Nas últimas três décadas o estudo com primatas tem recebido grande atenção, possivelmente devido a sua semelhança anatômica, fisiológica e etológica com a espécie humana, e a medida que estes estudos se desenvolveram muito se descobriu sobre a distribuição destas espécies e o ambiente onde vivem, além de revelações sobre alimentação, reprodução, habitat e distribuição geográfica (AURICHIO, 1995).

No Brasil existe a maior diversidade de primatas do mundo, constando mais de 70 espécies. Este fato deve-se as características climáticas e geográficas do país e faz com que a sua extensão territorial explique o grande número de endemismo (AURICHIO, 1995).

Atualmente, os primatas de pequeno e médio porte têm grande destaque em estudos experimentais, pois são tomados como modelo para várias doenças em humanos. Em especial os Sagüis, têm muitas vantagens como animal de laboratório, já que sua pequena dimensão e elevado nível de reprodução em cativeiro, além do fácil manuseio, pequena quantidade de alimentação e boa adaptabilidade a novos ambientes são características importantes na criação desta espécie o que facilita a sua utilização em pesquisas envolvendo estudos metabólicos e infecciosos (GUIMARÃES, 1994; OLIVEIRA et al. (2004).

Segundo Horacek, Earle e Gilmore (1986) os primatas do gênero Callithrix são muito utilizados como modelos para elucidar aspectos da fisiologia humana, em especial, aspectos relacionadas ao funcionamento dos rins.

Poucos estudos em ciências, tidas como básicas são relatadas para primatas, e esta carência se refere principalmente a aspectos que abordam a morfologia de 
diferentes tecidos incluindo, estudos anatômicos macroscópicos, microscópicos e topográficos de órgãos e sistemas utilizando técnicas de imagem (VALLE, 2008).

As informações sobre a morfologia normal do corpo, bem como 0 conhecimento das estruturas que compõem um organismo, em especial dos primatas, é fundamental para o aprendizado e com isso conseguir avançar em todas as áreas da ciência médica (SCHAEFFTER, 1996).

Os espécimes utilizados neste estudo são originados do Centro de Primatas da Alemanha - DPZ localizado na cidade de Goettingen, Alemanha, que possui uma colônia de primatas não humanos de 4 espécies, os quais são manejados e reproduzidos sob condições controladas, para pesquisas biomédicas. Atualmente este centro conta com um plantel de aproximadamente 600 animais da espécie Callithrix jacchus, alojados em recintos internos, sendo esta colônia constituída apenas de animais nascidos em cativeiro a várias gerações na Europa.

Apesar da crescente utilização de Callithrix jacchus como modelos de primatas em pesquisas biomédicas, Abbot et al. (2003) concluíram que sua história de vida, comportamento e fisiologia não são bem conhecidos e segundo Valle (2008), pode-se incluir a falta de estudos anatômicos envolvendo os sistemas e órgãos, em particular os rins, no que se refere a biometria do sistema urinário.

Contudo, para que a contribuição destes animais na busca de conhecimento com novas descobertas ocorra de fato, torna-se relevante, estudos que viabilizem informações sobre a espécie, não somente em virtude da freqüente utilização destes primatas em experimentação biomédica, mas também pela escassez de informações sobre as características anatômicas e histológicas em destaque relacionada aos rins.

O presente estudo propõe a caracterização biométrica dos rins de Callithrix jacchus criados em cativeiro, tanto para mensurações anatômicas, morfometria macroscópica (comprimento, altura, largura, peso e volume), como para microscópica (quantificação e mensuração da área glomerular), a fim de se comparar os dados para a verificação de possíveis diferenças decorrentes de idade, sexo, lado (rim direito e rim esquerdo) e estado de saúde dos animais. 


\section{REVISÃO DE LITERATURA}

Atualmente os sagüis têm grande destaque em estudos experimentais, entretanto vários aspectos básicos de sua anatomia ainda estão por serem estudados (ABBOT, et al. 2003).

\subsection{CALLITHRIX JACCHUS}

Dos vários tipos de sagüis, o Callithrix jacchus, também chamado de sagüide-tufo-branco, sagüi comum, "common marmoset" (ing.), é o mais comum e conhecido dos sagüis, original do nordeste brasileiro, que divergiu evolutivamente junto com outros callitriquídeos dos demais primatas das Américas a cerca de 18 milhões de anos e é considerado e espécie mais recente da sua família (AURICHIO, 1995; NEUSSER, 2001; ABBOT, 2003).

Segundo Diniz (1997), estes animais podem ser encontrados em vida livre no Brasil, na região Nordeste, Centro-Oeste até o norte de São Paulo, e Aurichio (1995) acrescenta outras regiões de mata brasileira como a Serra da Carioca e Tijuca no Rio de Janeiro além da introdução desta espécie em parques da cidade de São Paulo.

Os animais desta espécie (Figura 1) apresentam tufo de pelos brancos circum-auriculares e ápice castanho escuro, com mancha branca na região nasal e frontal, pelagem longa, densa, de coloração cinza rajado e cauda, com faixas transversais com comprimento maior que a cabeça mais o corpo, que existe para garantir o equilíbrio do animal, não possuindo preensibilidade. Todos os dedos, com exceção do hálux, possuem unhas em forma de garras, o que possibilita a captura de insetos em frestas e escaladas em troncos de árvores (STENVENSON; RYLANDS, 1988; AURICHIO, 1995; DINIZ, 1997). 
Schneider (1996) classifica taxonomicamente estes animais como:

\section{Classe}

Mammalian

\section{Ordem}

Primate

\section{Infraordem}

Platyrhini

\section{Família}

Cebidae

\section{Subfamília}

Callitrichinae

\section{Gênero}

Callithrix (Erxleben, 1777)

\section{Espécie}

Callithrix jacchus (Linnaeus, 1758)

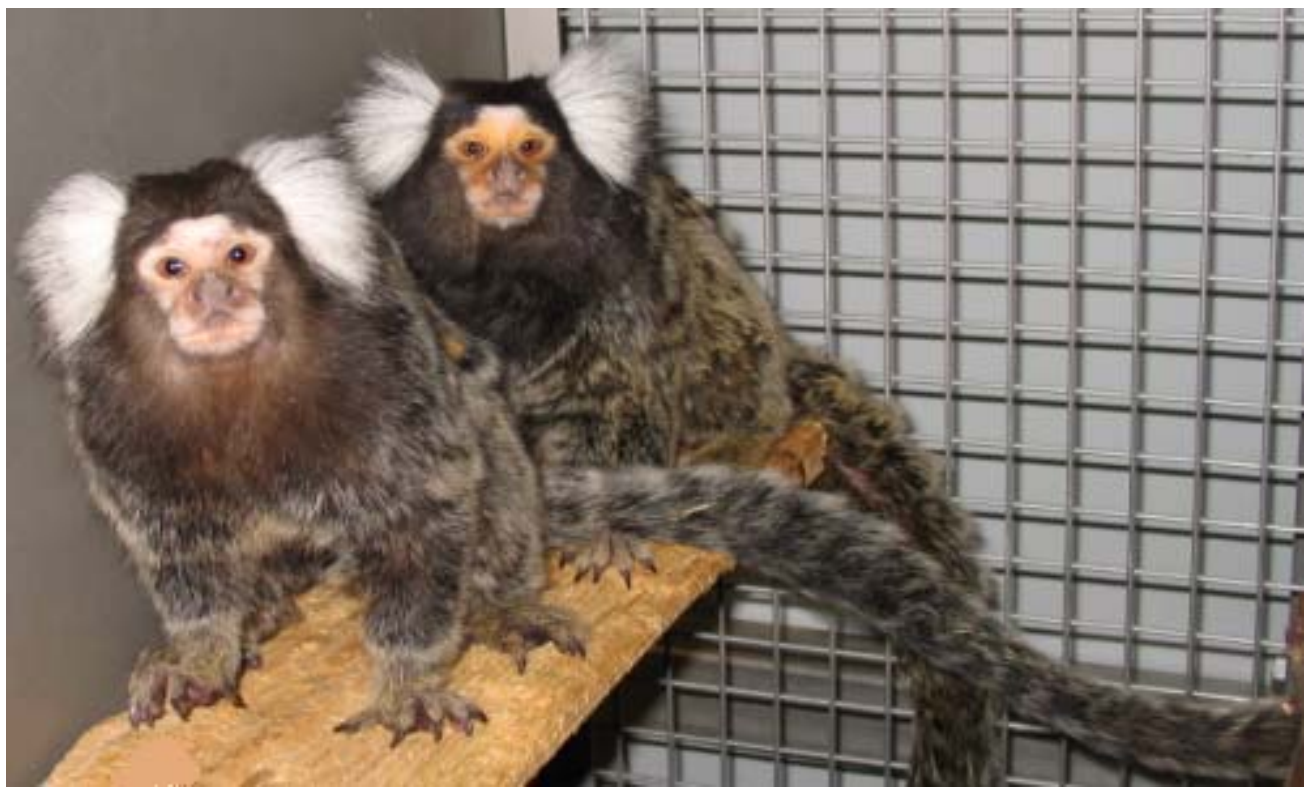

Figura 1 - Espécime de Callithrix jacchus da colônia do Centro de Primatas da Alemanha - DPZ 
Estes animais apresentam pequeno porte com peso entre 200 e $400 \mathrm{~g}$ e tamanho entre 20 e 30 cm (STENVENSON; RYLANDS, 1988; AURICHIO, 1995; DINIZ, 1997).

Existem alguns estudos que relacionam o peso da espécie com a criação em cativeiro comparado com vida livre e entre sexo. Segundo Araújo et al. (2000), em seu estudo para verificar esta diferença de peso, 243 indivíduos em 15 grupos em vida livre da floresta Nísia - Natal foram comparados com 138 indivíduos da Universidade Federal do Rio Grande do Norte criados em cativeiro. Foi relatado que em vida livre os machos pesaram entre 282,8 a $352 \mathrm{~g}$ e as fêmeas pesaram entre 281,6 a $362,4 \mathrm{~g}$ e em cativeiro os machos pesaram entre 317,1 a $378,1 \mathrm{~g}$ e as fêmeas pesaram entre 309,3 a $410,1 \mathrm{~g}$.

Em outro estudo, com 24 callitriquídeos em cativeiro a média de peso dos machos adultos foi de $361,25 \mathrm{~g}$, variando de 260 a $450 \mathrm{~g}$ e das fêmeas foi de 338,75 variando de 330 a 400g (BOERE et al. 2005).

Em nenhum destes estudos existiu diferença significante entre machos e fêmeas, mas os indivíduos em cativeiro são mais pesados do que na vida livre e sugerem que as diferenças entre cativeiro e vida livre não são de constituição corpórea, mas devidas a dieta e atividade física (ARAÚJO et al., 2000; BOERE et al. 2005).

No Centro de Primatas da Alemanha, Valle et al. (2005) relataram que $70 \%$ dos animais se encontravam com peso superior a $400 \mathrm{~g}$, o que foge aos padrões encontrados para espécie em vida livre (DINIZ, 1997).

Os Callithrix jacchus são basicamente insetívoros-guminívoros, e para a extração da goma, os incisivos inferiores são longos e estreitos e os caninos são dotados de densa camada de esmalte dando resistência aos dentes, o que facilita o roer dos troncos de árvores gumíferas (AURICHIO, 1995; DINIZ, 1997).

No que se refere à alimentação de primatas, muitos estudos giram em torno da família Callithrichidea, foram determinados vários níveis nutricionais por eles exigidos. Primatas da África e Ásia necessitam de 15\% de proteína ao passo que os calitriquídeos necessitam de $25 \%$ de proteína de alto valor biológico, este fato devese em razão de que parte do aporte energético utilizados por estes animais vem do metabolismo protéico (COIMBRA-FILHO, SILVA; PISSINATI, 1981).

Além de gomas, estes animais em vida livre também se alimentam de grande variedade de matéria vegetal, incluindo folhas, frutos e sementes, e animal, incluindo 
artrópodes, moluscos e ovos (STENVENSON; RYLANDS, 1988; AURICHIO, 1995; DINIZ, 1997).

Habitam originalmente a caatinga e o cerrado em formações arbóreas baixas, se adaptam tanto em vegetações primárias quando em áreas degradadas, são considerados de hábitos diurnos e forma grupos de 7 a 15 indivíduos em uma área de uso de aproximadamente $50.000 \mathrm{~m}^{2}$ por grupo. Os animais marcam suas árvores com urina e secreções (glândulas de cheiro), já que habitam uma área relativamente pequena, e com isso conseguem amenizar a competição intra-específica por goma, que em alguns casos corresponde a $50 \%$ da sua alimentação (STENVENSON; RYLANDS, 1988; AURICHIO, 1995; DINIZ, 1997).

A regra nestes grupos sociais é de casamentos monogâmicos, porém ocorrem casamentos poliândricos com dois ou três machos para uma fêmea reprodutora. Esta dominância por uma fêmea inibe a ovulação das demais, porém para esta espécie podem existir exceções, onde já foi observado dois casais ativos no mesmo grupo, com baixa competição por posição social (AURICHIO, 1995).

Estes animais possuem temperatura corpórea de aproximadamente $36,5^{\circ} \mathrm{C}$, podendo variar de 38 a $39^{\circ} \mathrm{C}$, de acordo com o estresse a que este é submetido. Sua longevidade é de aproximadamente 10 anos, os animais são considerados adultos a partir de 15 meses, pois neste período já atingiram sua maturidade sexual, a gestação é de 138 a 170 dias, podendo nascer de 1 a 3 filhotes, porém a gemiparidade ocorre na maioria dos casos (DINIZ, 1997).

Através da introdução destes grupos em região de Mata Atlântica no sudeste, - Callithrix jacchus assumiu o mesmo nicho ecológico de outras espécies do seu gênero em especial, o Callithrix penicillata. Isto fez com que as colônias nativas destas regiões se tornassem mistas, em um processo de acasalamento interespecífico que gerou híbridos férteis. Atualmente estes híbridos ameaçam a soberania do Callithrix penicillata que também sofre com outros processos como a degradação ambiental (RUIZ-MIRANDA, 2006). 


\subsection{ASPECTOS ANATOMOFISIOLÓGICOS DOS RINS}

Nos rins são filtrados os produtos do metabolismo orgânico, assim como as substâncias não degradáveis no sangue, os quais são eliminados na urina. Para a realização deste processo o rim recebe cerca de $25 \%$ do débito cardíaco, isto faz com que grande quantidade de líquidos oriundos do plasma sanguíneo passe pelos rins, referindo a este órgão a função de controlar a quantidade de fluídos eletrólitos a serem eliminados através da urina conferindo aos rins a manutenção do equilíbrio hidroeletrolítico do organismo (COTRAN; KUMAR; ROBBINS, 1996; JONES, 2000; AUGHEY; FRYE, 2001; KONIG, 2004; REECE, 2008).

No processo de manutenção do meio interno, os rins recebem uma grande quantidade de sangue da artéria renal, que é uma artéria originada diretamente da aorta abdominal. Esse grande aporte sanguíneo faz com que seja produzida uma grande quantidade de urina em uma primeira fase, denominada pré-urina ou urina primária. Em seqüência os elementos deste primeiro filtrado são reutilizados pelo organismo através de uma filtração seletiva ocorrida no processo final de formação da urina, agora mais hipertônica (DYCE, 2004).

Além da função homeostática, os rins desempenham funções endócrinas, através da secreção de renina, a qual atua na regulação da pressão arterial, produção de eritropoetina, através do qual estimula a produção de eritrócitos, e metabólitos ativos da vitamina D (BANKS, 1991; JONES, 2000; AUGHEY; FRYE, 2001; KONIG, 2004; REECE, 2008).

Os rins, nos animais, são órgãos pareados suspensos na parede abdominal dorsal por uma prega peritoneal e vasos que os irrigam, seu posicionamento é adjacente à coluna vertebral situados na região sublombar, e vão desde a região lombar até o segmento intratorácico da cavidade abdominal sob as últimas costelas (KONIG, 2004; REECE, 2008).

Como estão separados da cavidade abdominal pelo seu envoltório de peritônio, são considerados órgãos retroperitoneais (REECE, 2008).

O rim direito, na maioria das espécies, salvo algumas exceções como os suínos, está em posição mais cranial que o rim esquerdo, mantendo contato com o processo caudado do fígado e o lobo lateral direito, o que determina uma impressão 
renal nestes lobos hepáticos, e dessa maneira torna-se mais estável em relação ao seu posicionamento do que o rim esquerdo (KONIG, 2004; REECE, 2008).

O posicionamento renal pode variar, pelo comprimento de meia vértebra, durante os movimentos respiratórios devido a movimentação do diafragma (DYCE, 2004).

Cada rim fica colocado dentro de uma fenda da fáscia sublombar, a qual contém uma quantidade de gordura que varia de acordo com cada espécie, esta é suficiente em alguns casos para encobrir totalmente o rim. Esta camada de tecido adiposo, conhecido como cápsula adiposa perirrenal, serve para proteger estes órgãos de pressões sofridas por órgãos adjacentes (DYCE, 2004; KONIG, 2004).

Nos humanos, os rins também estão situados no espaço retroperitoneal, na porção posterior do abdome, lateralmente a coluna vertebral, mas ao contrário da maioria das espécies animais, o direito é levemente mais caudal que o esquerdo (TISHER; MADSEN, 1996).

Os rins possuem um extremidade voltado para o diafragma, denominada extremidade cranial, e outra voltada para a pelve, denominada extremidade caudal; uma margem voltada para a parede abdominal, margem lateral, e uma margem voltada para o plano mediano da cavidade abdominal, margem medial; uma face apoiada na parede dorsal do abdome, face dorsal e outra voltada para a parede ventral de abdome, face ventral. Através do conhecimento da topografia renal, referenciado por estas descrições, podemos orientar seu posicionamento na cavidade abdominal e mensurar suas dimensões (KONIG, 2004).

Mensurações dos rins podem também ser obtidas pela ultra-sonografia com alto grau de precisão e reprodutibilidade, refletindo as verdadeiras dimensões dos rins analisados à necropsia (BARR, 1990). Estudos realizados em humanos confirmam que a mensuração do comprimento renal é altamente confiável, sugerindo ser bom indicador do tamanho dos rins (ABLETT et al., 1995; EMAMIAN et al., 1995).

Além disso, o volume renal pode ser calculado usando-se as mensurações ultra-sonográficas (HRICAK; LIETO, 1983; JONES et al., 1983). Barr (1990) considerou a forma dos rins como aproximadamente elipsóide e concluiu que essa forma é bom indicador do seu verdadeiro volume.

As dimensões dos rins em humanos podem ser descritas da seguinte maneira: sua extremidade cranial está relacionada com a $12^{\circ}$ vértebra torácica e a 
extremidade caudal com a $3^{\circ}$ vértebra lombar; o peso de cada órgão em um homem adulto pode variar de 125 a $170 \mathrm{~g}$, já na mulher adulta esta variação é de 115 a 155 g; o comprimento é de aproximadamente 11 a $12 \mathrm{~cm}$; a largura é de 5 a 7,5 e a espessura é de 2,5 a $3 \mathrm{~cm}$ (TISHER; MADSEN, 1996).

Nos gorilas o rim esquerdo fica em situação mais caudal que o direito e a extremidade cranial deste rim, se encontra relacionado com o $12^{\circ}$ arco costal ao passo que a extremidade cranial do rim esquerdo se relaciona com o $13^{\circ}$ arco costal (RAVEN et al., 1950).

Nos cães e gatos, os rins em condições normais, posicionam-se retoperitoneais e assimétricos (direito mais caudal), colocados na parede dorsocranial do abdome. Para os cães, estes órgãos são relativamente grandes, alcançando $1 / 500$ a $1 / 200$ do peso corporal e o esquerdo normalmente mais pesado que o direito (ELLENPORT, 1986; OWENS; BIERY, 1998; KEALY; MCALLISTER, 2005).

Alterações uni ou bilaterais na forma e tamanho dos rins freqüentemente representam importantes sinais clínicos de distúrbios renais (FORREST et al., 1998). A nefrite intersticial crônica e a estenose da artéria renal, por exemplo, freqüentemente resultam no decréscimo do tamanho dos rins, enquanto a pielonefrite aguda, a doença policística e a hidronefrose podem levar ao aumento do tamanho dos rins (FINCO et al., 1971; MAHAFFEY; BARBER, 1992). A deteç̧ão dessas alterações pode ser fundamental para o diagnóstico e prognóstico da doença. A mensuração renal é, portanto, uma informação clínica fundamental (BARR; HOLT; GIBBS, 1990; FELKAI et al., 1992).

O formato dos rins varia de acordo com cada espécie, mas para a maioria das espécies apresentam-se lisos, com tamanho e forma similares para ambos os órgãos, variando de um formato clássico denominado "feijão", como no caso dos cães, podendo até ser mais arredondados, como no caso dos gatos. Apresentam-se com coloração marrom-avermelhada (ELLENPORT, 1975; OWENS; BIERY, 1998; DYCE, 2004; KONIG, 2004).

Localizado na margem medial do rim existe o hilo renal, que se caracteriza por uma fenda por onde a artéria renal, a veia renal, a pelve renal os plexos nervosos e linfáticos alcançam o seio renal. Como revestimento externo o órgão recebe uma cápsula fibrosa denominada cápsula renal, que em condições normais é 
facilmente removida do órgão para inspeção do seu parênquima (TISHER; MADSEN, 1996; AUGHEY; FRYE, 2001; KONIG, 2004).

A arquitetura interna dos rins pode ser a primeira vista descrita, pela identificação de duas regiões na superfície de corte do órgão. Uma região mais pálida, externa, denominada córtex e uma região mais escura, interna, denominada medular (TISHER; MADSEN, 1996; AUGHEY; FRYE, 2001).

O córtex renal apresenta-se como porção marginal do parênquima renal, possui coloração vermelho-escuro, finamente granulado com estrias delgadas que alojam as artérias interlobulares as quais delimitam os lóbulos corticais (KONIG, 2004; JUNQUEIRA, 2008).

A medula renal é constituída de uma zona periférica escura, da qual uma zona central com estrias radiais alcança a pelve renal. A região medular é formada por pirâmides medulares que em algumas espécies se unem em uma crista renal formando um rim unipiramidal e em outras permanecem separadas com seu ápice apontado para os cálices renais formando as papilas renais (KONIG, 2004; JUNQUEIRA, 2008).

Em humanos a zona medular é composta de 8 a 18 pirâmides medulares, sendo classificado como multipiramidal ou multipapilar. A base de cada pirâmide é voltada para o córtex e o ápice voltado para a pelve, onde formam as papilas renais que escoam a urina produzida para os cálices renais, nesta região de papila renal abrem-se de 10 a 25 pequenos canalículos por papila, que representam a porção distal dos túbulos coletores, e estas formam a área crivosa (TISHER; MADSEN, 1996; JUNQUEIRA, 2008).

Em comparação com humanos os primatas apresentam diferenças anatômicas relacionadas principalmente com posicionamento dos rins, onde ao contrário dos humanos os primatas possuem o rim direito mais cranial que o esquerdo, e com a classificação decorrente de sua arquitetura interna, onde os primatas possuem uma apresentação unipiramidal e os humanos uma apresentação multipiramidal (ROBERTS, 1972), com exceções de algumas espécies tais como o macaco aranha (Ateles geoffroyi), que possui um rim anatômica e fisiologicamente semelhante ao dos humanos (GOODMAN; WOLF; ROBERTS, 1977) e os gorilas (Gorilla gorilla) que em alguns casos podem apresentar pirâmides renais divididas em subpirâmides (RAVEN et al., 1950). 
Para os Callithrix jacchus, a classificação renal é expressa da seguinte maneira: rins unilobares (liso), em forma de feijão cobertos por uma fina cápsula fibrosa com poucas fibras elásticas, e de acordo com a arquitetura interna, é classificado como unipiramidal (MIRAGLIA; ROSSI; MOREIRA, 1968).

O rim é constituído pela associação de néfrons (Figura 2), onde estes são considerados a unidade funcional deste órgão. O néfron é formado por um conjunto de túbulos coletores que se conectam entre si, corpúsculo renal, túbulo contorcido proximal, porção delgada e espessa da alça do néfron ou de Henle e pelo túbulo contorcido distal (KONIG, 2004; JUNQUEIRA, 2008; REECE, 2008).

A distribuição dos componentes do néfron pelo parênquima renal se apresenta com os corpúsculos renais e os túbulos contorcidos (distal e proximal), na região cortical e as duas porções da alça do néfron na região medular. Os néfrons com corpúsculos nos córtices externo e médio são denominados de néfrons corticais ou corticomedulares e os néfrons com corpúsculos renais próximos a medula são denominados néfrons justamedulares (JUNQUEIRA, 2008; REECE, 2008).

O primeiro segmento do sistema tubular de canalículos do néfron é o túbulo contorcido proximal, este se encontra justaposto ao corpúsculo renal e dá início ao pólo urinário. A alça do néfron continua após a porção sinuosa do túbulo proximal e consiste de um segmento inicial descendente mais dilatado, o túbulo reto proximal, seguido de uma porção mais estreita, o túbulo delgado, o qual forma a alça capilar, a partir desta alça, um segmento dilatado e ascendente e em direção reta ao córtex é formado, o túbulo reto distal, encerrando assim a alça do néfron e começando a partir desta porção o túbulo contorcido distal, que volta a se aproximar do corpúsculo renal e se une ao túbulo coletor, o qual recebe a drenagem de mais de um túbulo contorcido distal e conseqüentemente de mais de um néfron, que desemboca nos ductos papilares na pelve renal (KONIG, 2004). 


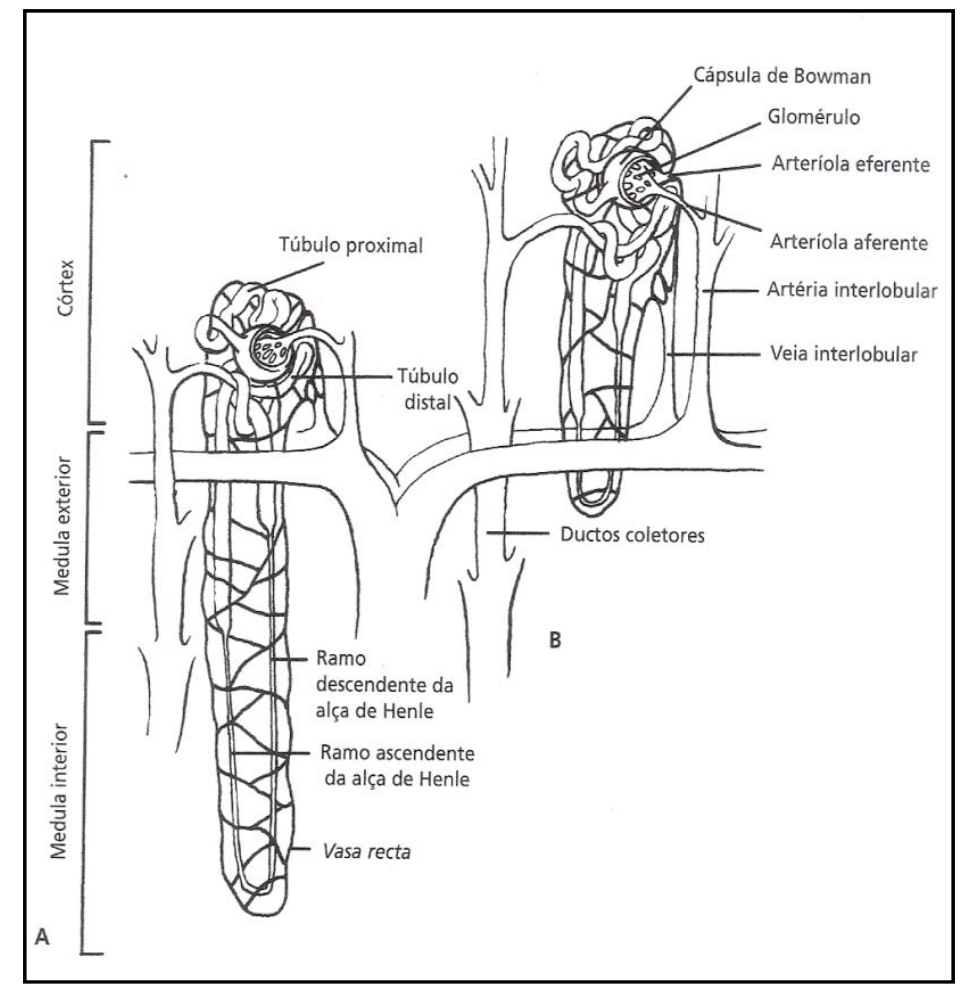

Figura 2 - Tipos de néfrons de mamíferos. (A) Néfron justamedular. (B) Néfron cortical

O corpúsculo renal é formado por um conjunto de 30 a 50 alças capilar, denominado glomérulo, e uma cápsula de dupla parede, denominada cápsula glomerular ou de Bowman, a qual forma os limites do corpúsculo (KONIG, 2004; JUNQUEIRA, 2008).

O espaço entre os dois folhetos, visceral e parietal da cápsula glomerular acolhe a urina primária ou pré-urina. A camada interna ou visceral da cápsula glomerular contém células denominadas podócitos, as quais detêm prolongamentos que se relacionam com uma membrana basal, entre estes prolongamentos existem espaços denominados fendas de filtração. Estes podócitos revestem a superfície externa dos capilares glomerulares e a relação das células endoteliais destes capilares com os podócitos formam a principal barreira de filtração glomerular, denominada barreira hemato-úrica. (JUNQUEIRA, 2008).

A perfusão de sangue nos rins em um cão adulto de grande porte chega a 2 mil litros em um dia, este sangue atinge o parênquima renal onde é distribuído para os néfrons, por uma rede arterial renal, onde, no pólo vascular, através de uma arteríola aferente atinge um enovelado de alças capilares, glomérulo, seguindo por uma arteríola eferente, sendo produzida durante esta passagem de sangue pelo 
glomérulo, em média 300 litros de urina primária, que será reduzida mais tarde, em 2 litros de urina após a passagem da pré-urina, pelo sistema tubular de canalículos do néfron (KONIG, 2004).

Os rins de mamíferos são capazes de controlar a concentração de fluidos corporais e alguns pequenos mamíferos adaptados a regiões áridas são eficientes na concentração da urina, a fim de se reduzir a perda de água (DIAZ; OJEDA, 1999).

Medições das porções dos néfrons são propostas para verificar as diferenças entre os rins dos animais, segundo a sua capacidade de concentração urinária e por fim relacioná-las com o seu habitat (DIAZ; OJEDA, 1999).

Conforme o modelo de contracorrente multiplicador, a capacidade de concentrar a urina depende do comprimento das alças de Henle e ductos coletores que atravessam a medula renal (SCHMIDT-NIELSEN, O'DELL, 1961). O comprimento máximo da alça de Henle é diretamente proporcional à espessura medular (BEUCHAT, 1990) e, portanto esta mensuração pode ser utilizada para propor os índices de desempenho renal que segundo Diaz e Ojeda (1999) os índices mais altos foram encontrados em pequenos roedores do deserto.

Em relação à contagem glomerular é proposto que os cães possuam em média em cada rim cerca de 400 mil glomérulos, os gato cerca de 500 mil, os suínos cerca de 1 milhão, os bovinos até 4 milhões e os eqüinos até 2,7 milhões (KONIG, 2004).

Em humanos o número total de glomérulos possui uma variação muito grande dependendo da população em questão, estudos envolvendo populações de três continentes relataram uma diferença de até 8 vezes com média de 900 mil glomérulos por rim podendo chegar a 2 milhões (MCNAMARA et al., 2009).

A contagem e mensuração glomerular bem como, a obtenção de seu volume, podem servir como ferramentas para estudos de populações. McNamara et al. (2009) concluiu que a variação no número e volume glomerular são fatores importantes que contribuem para a determinação de uma maior ou menor carga de doença renal crônica no futuro desta população.

Em seu estudo com a população de países do oeste Africano, McNamara et al. (2008) realizaram a contagem e volume glomerular em 81 rins necropsiados. Nesta população á média glomerular foi de 924 mil glomérulos para cada rim 
variando de 536 mil a 1,394 milhões e volume glomerular variou 2,5 vezes com média de $5,74 \mu \mathrm{m}^{3} \times 10^{6}$.

Outros estudos também relatam uma grande variação no tamanho normal dos glomérulos em humanos, como relataram Douglas-Denton et al. (2006), que encontraram em rins necropsiados de norte americanos adultos, um intervalo de 5,2 vezes no volume glomerular médio, variando de 3,29 a 16,99 $\mu^{3} \times 10^{6}$.

A doença renal é também associada com mudanças no volume glomerular, já que a hipertrofia glomerular se faz presente na glomeruloesclerose segmentar focal, na nefropatia diabética, na glomerulonefrite membranosa, na hipertensão arterial e nas nefropatias relacionadas à obesidade (HUGHSON et al., 2002; KAMBHAM et al., 2001).

O número total de glomérulos é um fator determinante proposto na etiologia multifatorial da hipertensão arterial. Indivíduos com baixo número glomerular são sujeitos para estar em risco aumentado de hipertensão e doença progressiva dos rins em uma fase posterior da vida (MCNAMARA et al., 2009). 


\section{MATERIAIS E MÉTODOS}

Toda descrição anatômica adotada neste estudo foi baseada no posicionamento quadrupedal dos animais utilizados.

\subsection{ANIMAIS}

Foram utilizados, neste estudo, 20 animais da espécie Callithrix jacchus (Sagui-de-tufo-branco), sendo 10 machos e 10 fêmeas com idade variando entre 1 e 8 anos, oriundos da colônia do Centro de Primatas da Alemanha - DPZ (Figura 3).

A colônia do DPZ está localizada na cidade Alemã de Goettingen e consiste de animais exclusivamente nascidos em cativeiro na Europa há várias gerações. Os animais estavam alojados em recintos internos com dimensões de acordo com o tamanho de cada grupo de animais, sob condições controladas de luz (12h), umidade $(55 \pm 10 \%)$ e temperatura $\left(25 \pm 3^{\circ} \mathrm{C}\right)$. A dieta era variada e baseada em alimentação fresca consistindo de carne bovina e frango, ração peletizada para primatas, ração peletizada para gatos, frutas da estação, legumes, verduras, pão, leite, água filtrada ad libidum e suplementação vitamínica, além de larvas de tenébrio que eram oferecidas em duas ocasiões por semana.

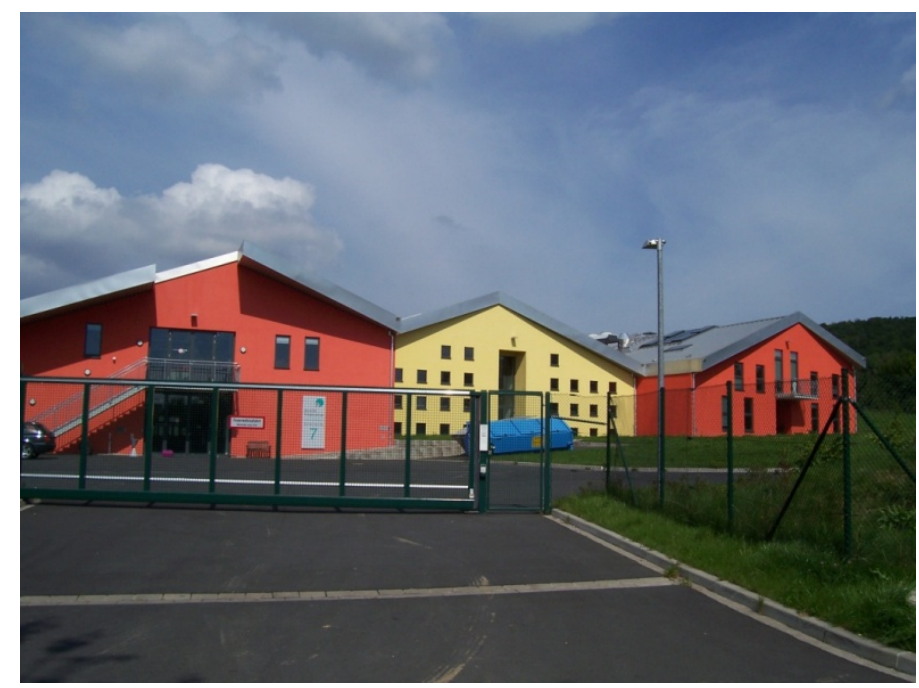

Figura 3 - Imagem das edificações de recintos internos do Centro de Primatas da Alemanha - DPZ. Goettingen - 2005 
Os animais passaram por estudos prévios de ultrassonografia abdominal que constataram não haver nenhuma fêmea prenhe utilizada neste estudo.

Estes animais foram pesados com o auxílio de uma balança digital e para tal, foram sedados com cloridrato de cetamina, na dose de $20 \mathrm{mg} / \mathrm{kg}$, segundo protocolo recomendado por Tamara ${ }^{1}$ (2005), veterinária responsável pelo DPZ, a qual realizou este procedimento.

\subsection{EXAMES LABORATORIAIS E HISTOLÓGICO}

Foi realizada uma sequência de exames laboratoriais compreendendo exame de urina tipo I, albumina e creatinina urinária, bioquímica sanguínea (uréia e creatinina) e curva glicêmica para verificar a condição de sanidade dos 20 animais. Também foi realizado exame histológico do rim para 10 animais, divididos em 5 machos e 5 fêmeas, após procedimento de eutanásia no DPZ devido a outros estudos.

Para glicemia e bioquímica sanguínea os animais foram submetidos a jejum prévio de alimentos sólidos por 12 horas, com água à vontade.

\subsubsection{Exame de Urina tipo I}

Para este exame os animais foram separados e foi colocado um plástico coletor sob a gaiola possibilitando a colheita de urina sem contato com as fezes, conforme ilustra a figura 4. Este procedimento ocorreu durante a noite e a coleta de urina, que ficou armazenada no plástico coletor, procedida pela manhã.

\footnotetext{
${ }^{1}$ Informação fornecida por Tamara em Goettinger, em 2005.
} 


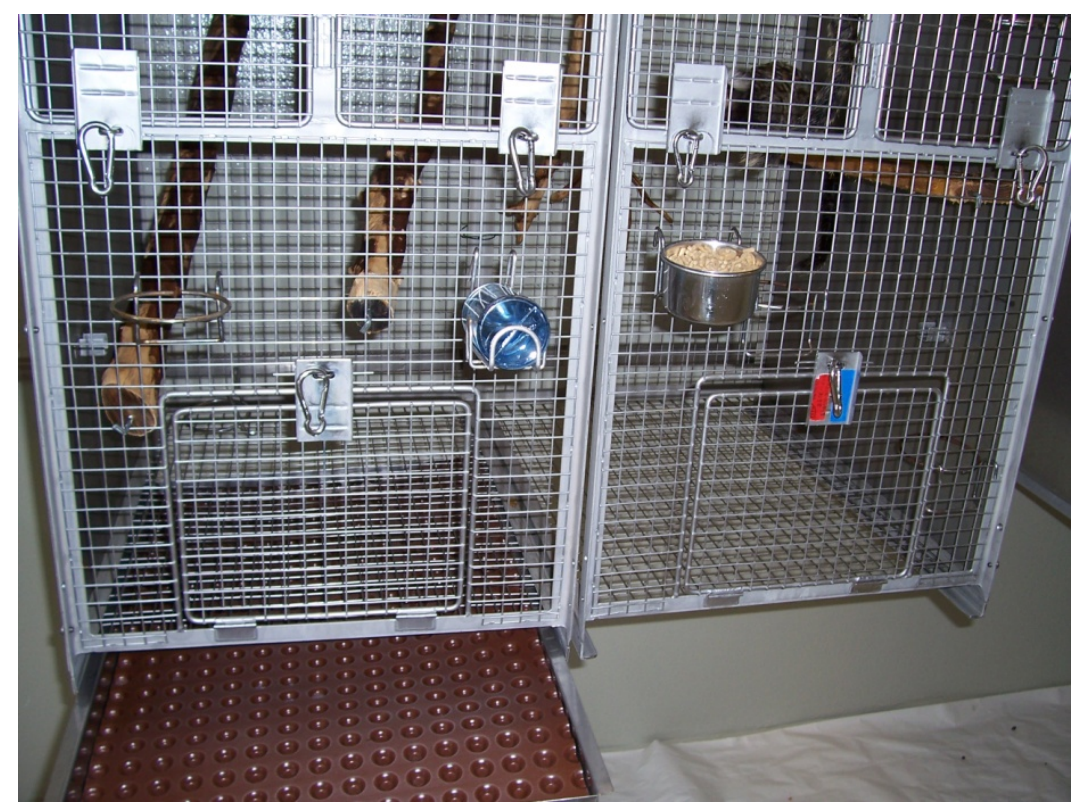

Figura 4 - Colocação de plástico coletor de urina em gaiolas de Callithrix jacchus no DPZ

O objetivo dos exames de urina eram detectar possíveis alterações renais, principalmente através da quantidade de proteína e sangue (hemácias) presentes na urina.

Para esta avaliação foram utilizadas fitas reagentes da marca Multistix 10 SG - Bayer ${ }^{\circledR}$ utilizando um aparelho para sua leitura (Clinitek Status - Bayer ${ }^{\circledR}$ ) (Figura 5).

Uma alíquota da urina foi encaminhada ao laboratório para a realização do exame da albumina e creatinina urinária. A albumina urinária foi mensurada através do kit ALB plus da Roche ${ }^{\circledR}$ e o equipamento Roche/Hitachi ${ }^{\circledR} /$ MODULAR:ACN 413 e a creatinina urinária foi mensurada através do kit Crea Plus - Cobas $^{\circledR}$ no equipamento Roche/Hitachi ${ }^{\circledR}$.

Para este experimento foram realizadas 3 colheitas de urina com intervalos de 4 a 5 meses. 


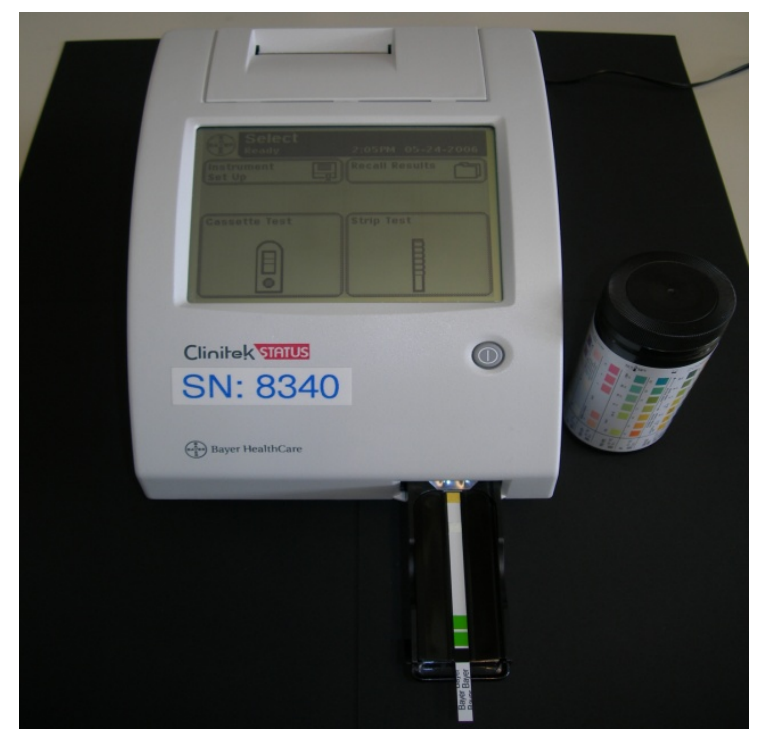

Figura 5 - Fitas reagentes Multistix 10 SG Bayer $^{\circledR}$ e aparelho Cliniteck Status Bayer $^{\circledR}$ utilizados na avaliação de proteínas e hemácias na urina

\subsubsection{Bioquímica Sanguínea}

Para a realização da bioquímica sérica foram colhidos $0,5 \mathrm{ml}$ de sangue da veia femoral que foi acondicionado em tubo tipo "Vacuntainer" sem anticoagulante.

Após a coleta o sangue foi encaminhado para o laboratório do Hospital Universitário de Goettingen para análise.

\subsubsection{Avaliação Glicêmica}

A avaliação glicêmica foi realizada de duas maneiras diferentes. Um método foi para avaliar a glicemia no sangue venoso e outro método para a avaliação em sangue periférico.

Para sangue venoso a análise foi realizada no laboratório do Hospital Universitário de Goettingen, com sangue $(0,5 \mathrm{ml})$ colhido da veia femoral (item 3.2.2). 
Para sangue periférico, a glicemia capilar foi mensurada por meio do aparelho Accu-Check Compact Blood Glucose Meter - Roche ${ }^{\circledR}$ do DPZ, Também através desta metodologia foi determinada a curva glicêmica, que é a determinação seriada das glicemias durante um período de até 2 horas após a administração de uma sobrecarga de glicose.

Após jejum prévio de 12 horas para alimentos sólidos, foi realizada a primeira mensuração antes da sobrecarga de glicose para glicemia capilar e venosa. A seguir foi oferecido ao animal $4 \mathrm{ml} / \mathrm{kg}$ de solução de glicose (Solução - 0,5 g glicose $/ \mathrm{ml}$ ), por via oral. Após este procedimento, foram realizadas mais duas mensurações com intervalos de 10 minutos para sangue periférico e no mesmo tempo da segunda mensuração também foi coletado sangue venoso para mensuração de glicose. A partir deste intervalo foram realizadas mensurações a cada 20 minutos com aparelho Accu-Check Compact Blood Glucose Meter - Roche ${ }^{\circledR}$ (sangue periférico) até completar 2 horas. Em 1 animal o exame se estendeu até 140 minutos.

Os dados foram analisados em forma de curva e os animais que apresentaram valor máximo acima de $150 \mathrm{mg} / \mathrm{dl}$ foram considerados intolerantes a glicose.

\subsubsection{Exame Histológico}

Para a realização do exame histológico utilizamos 10 animais do DPZ que foram submetidos à eutanásia, em conformidade com os protocolos da instituição, em decorrência de outros experimentos, o que tornou possível a coleta e análise histológica dos rins destes animais. Não foi realizado nenhum procedimento que pudesse ocasionar alterações na função renal destes animais. Os animais foram pesados em conformidade com a descrição anterior (item 3.1).

Os rins foram fotografados, pesados, mensurados e seccionados para fixação em solução aquosa de formol a 10 , e em seguida processados para a inclusão em parafina.

Foram realizados cortes de $5 \mu \mathrm{m}$ para a confecção das lâminas, estas ficaram 30 minutos em temperatura ambiente para secagem depois foram levadas a estufa a 
$60^{\circ} \mathrm{C}$ durante 2 horas, após este procedimento as lâminas foram coradas com HE, Hematoxilina-Eosina, (Anexo A).

Para a avaliação histológica do parênquima renal, foram adotados critérios que foram divididos em três partes e depois foram convertidos em escores:

Parâmetro glomerular: celularidade, espessamento do mesângio, espaço glomerular, lobulação, presença de sinéquia, formação de crescente e espessamento da membrana basal;

Parâmetro interstício: intensidade do processo inflamatório, células inflamatórias presentes, intensidade e distribuição de fibrose e intensidade de alterações circulatórias;

Parâmetro tubular: dilatação, epitélio regenerativo, hiperplasia epitelial, presença de cilindros hialinos e granulosos e necrose.

\section{- Critérios morfológicos:}

Escore 0 - ausência de comprometimento glomerular e de cilindros hialinos. Observa-se mínimo infiltrado inflamatório intersticial de linfócitos, plasmócitos, macrófagos e neutrófilos. Ausência de fibrose.

Escore 1 - presença de glomerulopatia segmentar multifocal, discreto número de túbulos com cilindros hialinos, discreto infiltrado inflamatório intersticial de linfócitos, plasmócitos e neutrófilos. Edema intersticial e ausência de fibrose intersticial.

Escore 2 - presença de glomerulopatia segmentar a global multifocal, sinéquia glomerular, redução do espaço glomerular, moderado número de túbulos com cilindros hialinos; moderado infiltrado inflamatório intersticial multifocal de linfócitos, plasmócitos e neutrófilos e discretos focos de fibrose intersticial.

Escore 3 - presença de glomerulopatia global generalizada, formação de crescente, sinéquia glomerular, glomeruloesclerose; grande número de túbulos com cilindros 
hialinos, severo infiltrado inflamatório intersticial de linfócitos, plasmócitos e neutrófilos; múltiplos focos a focos coalescentes de fibrose intersticial.

Com a avaliação morfológica baseada nos parâmetros e escores previamente definidos, os animais podem ser classificados em escores que variaram entre 0 e 3 :

0 - indivíduo com pelo menos dois padrões dentro da normalidade. Indivíduo normal.

1 - indivíduo com pelo menos dois parâmetros com alterações discretas ou mínimas. Variando o terceiro parâmetro em ausência de alterações com moderada alteração. Ex: $0-1-1=1$ ou $2-1-1=1$ ou 1-1-1=1. Indivíduo clinicamente normal e com alterações laboratoriais mínimas ou intercorrentes.

2 - indivíduo com pelo menos dois parâmetros com alterações moderadas. Ex: 2-21=2 ou 2-2-2=2 ou 2-2-3=2. Indivíduo clinicamente normal e com alterações laboratoriais permanentes ou moderadas.

3 - indivíduo com pelo menos dois parâmetros com alterações severas. Ex: 3-3-2=3 ou 3-3-3=3. Indivíduo clinicamente doente e com alterações laboratoriais marcantes.

\subsection{MORFOMETRIA MACROSCÓPICA RENAL}

A morfometria macroscópica dos rins foi realizada nos 20 exemplares de Callithrix jacchus deste experimento, que foi possibilitado após coleta dos rins em conseqüência do procedimento de eutanásia, em razão de outros estudos ocorridos no DPZ, conforme citado no item anterior.

Após a retirada dos rins direito e esquerdo da cavidade abdominal, estes foram pesados com o auxílio de balança digital, e em seguida foram realizadas as mensurações macroscópicas (comprimento, altura e largura), com o auxílio de paquímetro digital Mitutoyo ${ }^{\circledR}$ modelo CD-8” CX-B. 
Para a obtenção do comprimento renal foi tomado como referência a mensuração entre as extremidades cranial e caudal do rim. A mensuração da altura dos rins foi baseada na medição entre o hilo renal e o ponto médio na margem lateral do rim. As medidas da largura dos rins foram tomadas referenciando a medida entre o ponto médio na face ventral com o ponto médio da face dorsal, considerando este ponto, como a metade da medida entre a margem lateral e o hilo em cada face renal.

A volumetria foi realizada após a obtenção das medidas de comprimento, altura e largura de cada rim, onde foi adotada a seguinte fórmula para o cálculo do volume de cada rim:

Área maior $=(($ Comprimento do Rim / 2) $\times($ Altura do Rim / 2) $) \times 3,14$
Área menor $=(($ Comprimento do Rim / 2) $\times($ Largura do Rim / 2) $) \times 3,14$
Volume $=($ Área maior $/ 2)+($ Área menor $/ 2) \times$ Comprimento do Rim

\subsection{MORFOMETRIA MICROSCÓPICA RENAL}

Para o estudo microscópico foram coletados fragmentos de secções transversais dos rins direito e esquerdo dos 20 animais deste estudo, que foram processados segundo procedimentos convencionais de histologia e corados com Hematoxilina-Eosina (Anexo A), para estudo morfométrico microscópico glomerular.

Após a coleta de fragmentos renais já fixados em solução de formol $10 \%$, estes foram então desidratados, diafanizados e incluídos em blocos de parafina. Desta forma obtivemos 2 fragmentos renais emblocados por animal, 1 para rim esquerdo e 1 para rim direito. Para cada bloco de cada animal, foram selecionados 10 cortes com $5 \mu \mathrm{m}$ de espessura e assim foram confeccionadas 5 lâminas contendo 2 cortes cada, para rim direito e esquerdo de cada animal. A confecção dos cortes histológicos e das lâminas não obedeceu nenhum padrão seqüencial, sendo totalmente aleatória. Após a confecção das lâminas os cortes foram corados com Hematoxilina-Eosina e estes foram então utilizados para quantificação glomerular e mensuração da área glomerular. 
O estudo microscópico renal foi realizado com o auxílio do microscópico óptico Axioscópio Zeiss $®$ e as imagens processadas em um microcomputador utilizando programa de morfometria específico Axiovision $4.8 \circledast$, segundo o processo de captação da imagem, calibração do equipamento, engenharia da imagem, mensuração dos campos, listagem dos dados e comparação dos resultados.

\subsubsection{Quantificação Glomerular}

Para a quantificação glomerular foi padronizado a leitura de 3 campos aleatórios para cada corte de cada rim de cada animal, com este método foram obtidos 30 campos para rim direito mais 30 campos para rim esquerdo de cada um dos 20 Callithrix jacchus utilizados neste estudo.

Após a calibragem do programa de imagem utilizado foi possível mensurar a área do campo utilizado na quantificação dos glomérulos e por fim, após os dados desta quantificação, obter a densidade glomerular, através da seguinte fórmula:

$D G=(N G / N C) / A C$

Onde:

DG = Densidade glomerular;

NG = Número de glomérulos quantificados;

$\mathrm{NC}=$ Número de campos quantificados;

$\mathrm{AC}=$ Área do campo.

A realização da quantificação glomerular pelo método acima descrito foi auxiliada através do preenchimento de 40 formulários como exemplificado no Anexo E.

Ficou adotado que durante a quantificação os glomérulos que se apresentaram encostados na margem esquerda ou inferior do campo foram incluídos e os glomérulos que estiveram na margem superior ou direita foram excluídos como mostra a figura 6: 


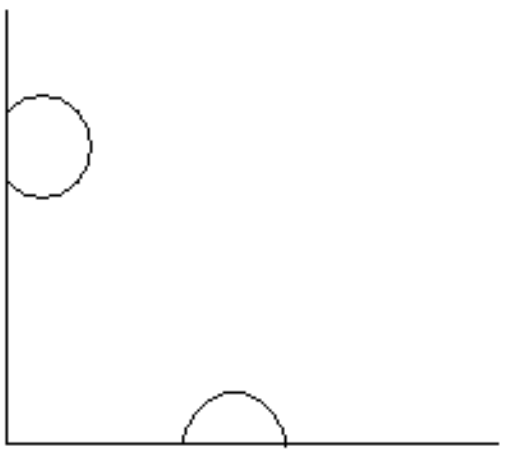

INCLUÍDOS

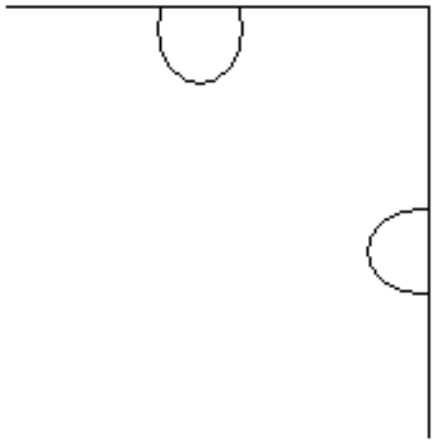

EXCLUÍDOS

Figura 6 - Esquema representativo de inclusão ou exclusão de glomérulos na contagem final

\subsubsection{Mensuração da Área Glomerular}

Para se obter a área glomerular foi padronizado a mensuração de 25 glomérulos para cada rim de cada animal. Após a quantificação (item 3.4.1), estes glomérulos foram numerados para que pudessem ser identificados e assim mensurados.

A escolha dos 25 glomérulos de cada rim dos Callithrix jacchus, ocorreu de forma aleatória em sistema de sorteio numérico através de uma urna contendo fichas identificadas desde o número 1 até o último número correspondente a quantificação glomerular em cada rim. Em seqüência ao sorteio os 25 glomérulos foram identificados e mensurados através do processamento, no programa Axiovision $4.8 \circledR$, das imagens obtidas no microscópio óptico Axioscópio Zeiss $®$.

A numeração dos glomérulos obedeceu a seguinte regra: numeração iniciada da margem superior para a inferior e da margem esquerda para a direita, como mostra a figura 7 .

O preenchimento do formulário exemplificado no Anexo G auxiliou na identificação dos glomérulos a serem mensurados e na descrição da mensuração glomerular realizada de acordo com o método descrito. 
Com a obtenção da área de cada um dos 25 glomérulos de cada rim foi estabelecido à área glomerular média através da seguinte fórmula:

$A G M=A G T / N G M$

Onde:

AGM = Área glomerular média

AGT = Somatória das áreas dos glomérulos mensurados;

$\mathrm{NC}=$ Número glomérulos mensurados .

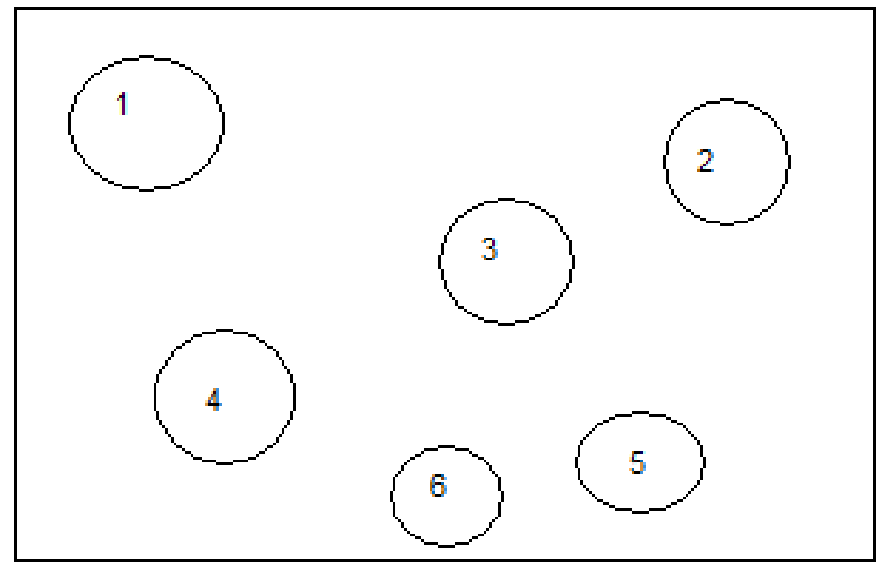

Figura 7 - Ilustração indicando esquema da seqüência de numeração glomerular iniciada da margem superior para a inferior e da margem esquerda para a direita

\subsection{FORMAÇÃO DOS GRUPOS DE ESTUDO}

Os 20 Callithrix jacchus utilizados neste trabalho foram divididos em dois grupos (1 e 2) separados pelo critério idade, onde o grupo 1 foi composto de 10 animais com idade entre 1 e 3 anos e o grupo 2 foi composto por 10 animais com idade entre 6 e 8 anos. Nestes 2 grupos foi também estabelecido o mesmo número de machos e fêmeas, distribuídos de forma igualitária entre os grupos, ou seja, 5 machos e 5 fêmeas para cada grupo, sempre respeitando o critério idade (Anexo B).

A partir dos resultados dos exames laboratoriais, foi possível classificar os animais de ambos os grupos em animais com alteração nos exames e animais sem alteração nos exames, onde no grupo 1 dos 10 animais, 5 foram classificados como 
sem alteração nos exames e 5 foram classificados em com alteração nos exames, já para o grupo 2, a divisão ficou em 3 animais sem alteração nos exames e 7 animais com alteração nos exames (Anexo $\mathrm{C}$ ).

O critério para esta seleção se baseou principalmente nos exames de proteinúria (mais de duas cruzes em pelo menos 1 dos 3 exames), hematúria (presença de sangue na urina), relação albumina e creatinina urinária (acima de 0,025) e curva glicêmica (pico de glicose acima de $150 \mathrm{mg} / \mathrm{dl}$ ). Os animais foram considerados com alteração nos exames aqueles que apresentaram alteração em pelo menos 3 dos exames citados.

\subsection{ANÁLISE ESTATÍSTICA}

Os dados de peso dos animais, morfometria macroscópica do renal (comprimento, altura, largura, peso e volume) e morfometria microscópica renal (quantificação, densidade e mensuração da área glomerular) estão apresentados por média, desvio padrão, mediana e erro padrão.

Os dados foram abordados estatisticamente de duas maneiras: na primeira abordagem foi considerado o fator sexo e na segunda abordagem foi considerado $o$ fator alteração nos exames Nas duas abordagens também foi considerado o fator grupo: animais de 1 a 3 anos (grupo 1) e animais de 6 a 8 anos (grupo 2) e o fator lado: considerando rim direito e rim esquerdo.

Para cada uma das variáveis de interesse, empregou-se análise de variância - ANOVA com três fatores em cada uma das abordagens: grupo, lado (considerado medida obtida no mesmo animal) e sexo ou alteração nos exames. A homogeneidade da variância foi verificada e, quando necessário, empregaram-se transformações nos dados. Foram consideradas diferenças significativas valores de $p<0,05$. 


\section{RESULTADOS}

Nos animais estudados verificamos que a idade (anos) variou conforme a tabela 1 (valores de idade - Anexo C):

Tabela 1 - Valores referentes à idade (anos) dos machos e fêmeas de Callithrix jacchus dos grupos 1 e 2 - Goettingen - 2006

\begin{tabular}{llllll} 
& & \multicolumn{4}{c}{ IDADE } \\
\cline { 2 - 6 } & & Média \pm DP & Mediana & EP & Mínimo - Máximo \\
\hline \hline \multirow{2}{*}{ GRUPO 1 } & Machos & $2,2 \pm 0,76$ & 2,5 & 0,34 & $1,0-3,0$ \\
\cline { 2 - 6 } & Fêmeas & $2,1 \pm 0,74$ & 2,0 & 0,33 & $1,0-3,0$ \\
\hline \multirow{2}{*}{ GRUPO 2 } & Machos & $7,1 \pm 0,55$ & 7,0 & 0,24 & $6,5-8,0$ \\
\cline { 2 - 6 } & Fêmeas & $6,9 \pm 1,02$ & 6,5 & 0,46 & $6,0-8,0$ \\
\hline \hline
\end{tabular}

G1 $\mathbf{n}=$ 10: Machos $n=5$, Fêmeas $n=5 ;$ G2 $\mathbf{n}=10$ : Machos $n=5$, Fêmeas $n=5$.

\subsection{EXAMES LABORATORIAIS E HISTOLÓGICO}

Foi realizada uma série de exames laboratoriais nos animais deste estudo, que permitiram a distinção destes animais dentro de seus grupos em animais com alteração nos exames e animais sem alteração nos exames.

Para os 20 Callithrix jacchus deste trabalho foram obtidos os valores de bioquímica sanguínea para uréia e creatinina, que se mantiveram dentro dos padrões de normalidade segundo Yarbrougth et al. (1984) (Anexo I).

Destes 20 animais, 12 tiveram resultados alterados nos exames de urina como proteinúria e hematúria e presença de albumina e creatinina urinária em grande quantidade segundo Agarwal et al. (2004) (Anexo J e K). 
$\mathrm{Na}$ avaliação glicêmica, 10 animais apresentaram resultados da curva glicêmica com pico de glicose acima de 200 mg/dl (Anexo L).

Foi realizado exame histológico para os 10 animais do grupo 2, onde 9 apresentaram alterações (5 machos e 4 fêmeas), destes 9 animais, 7 apresentaram alteração nos exames laboratoriais (4 machos e 3 fêmeas). O único animal (1 fêmea) deste grupo que não apresentou alterações no exame histológico, também não apresentou alteração nos exames laboratoriais.

Dos 10 animais utilizados para o exame histológico; 1 fêmea apresentou escore total 0; 4 (3 machos e 1 fêmea) apresentaram escore total 1; 5 (2 machos e 3 fêmeas) apresentaram escore total 2 e nenhum apresentou escore total 3 (Anexo $\mathrm{M})$.

A figura 8 demonstra a diferença de coloração da urina de Callithrix jacchus sem alteração nos exames e com alteração nos exames e a figura 9 a coleta sanguínea para realização de exames laboratoriais:

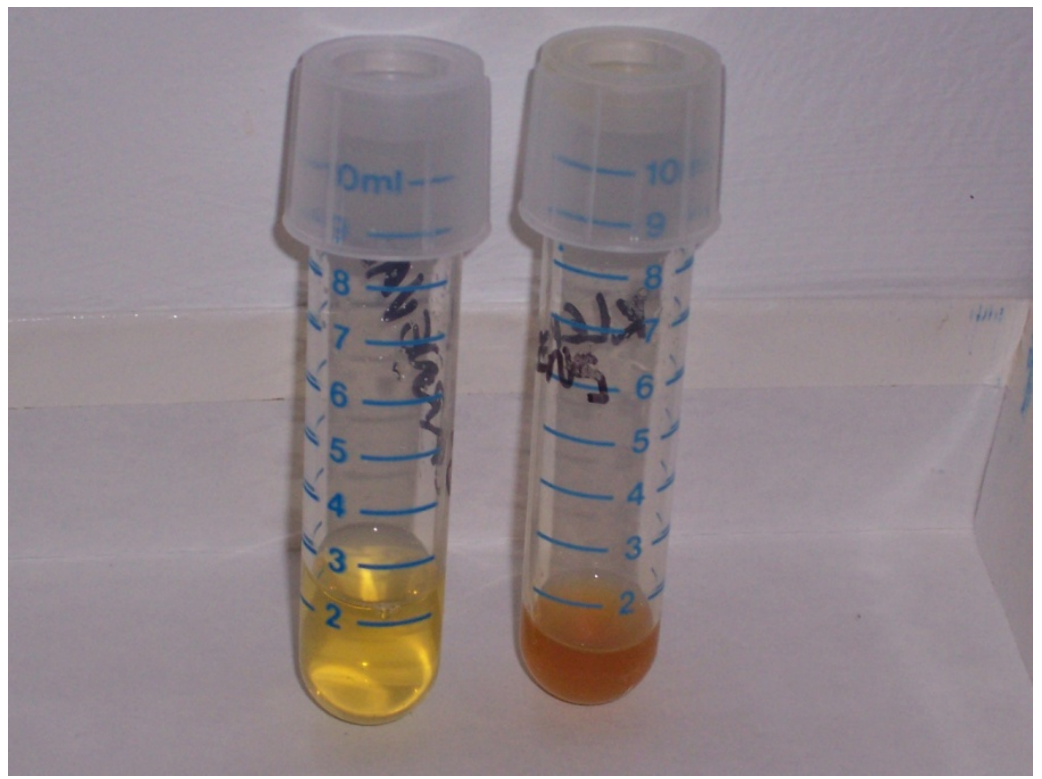

Figura 8 - Aspectos da cloração da urina de Callithrix jacchus sem alteração nos exames (esquerda) e com alteração nos exames (direita) 


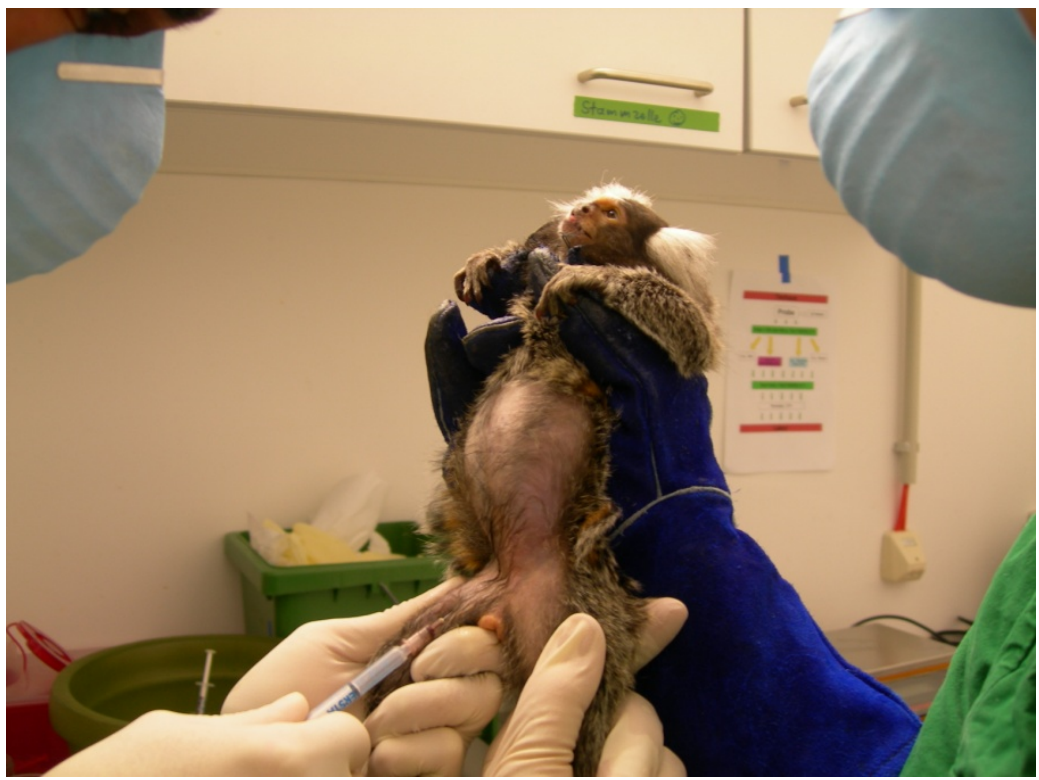

Figura 9 - Coleta sanguínea em Callitrix jacchus para realização de bioquímica sérica (uréia e creatinina) e curva glicêmica

As figuras 10, 11 e 12 representam os cortes histológicos para avaliação do escore dos animais do grupo 2 :

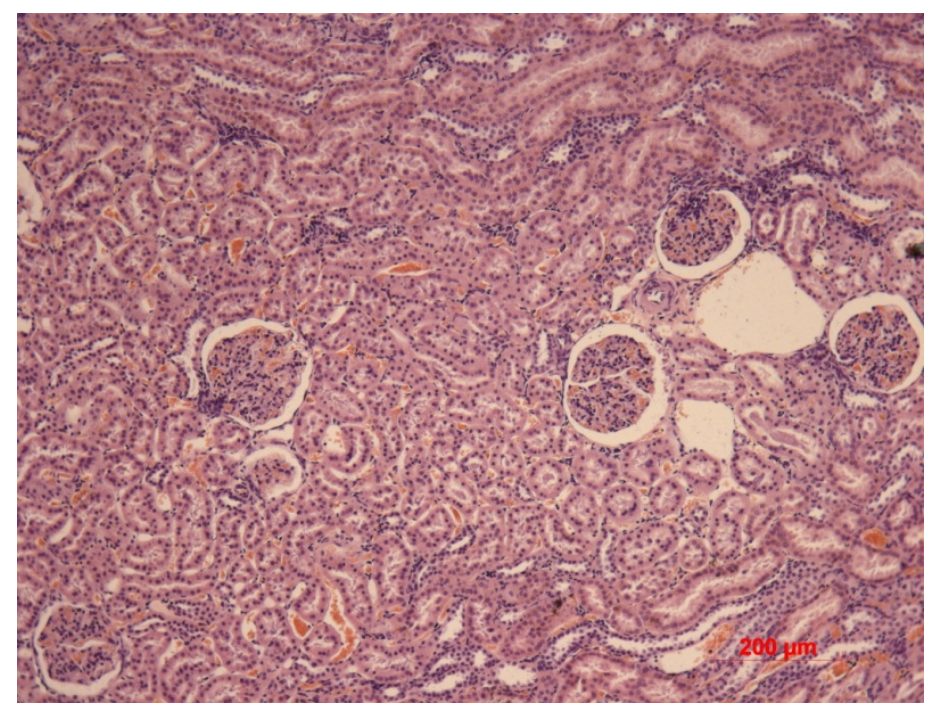

Figura 10 - Corte histológico de rim de Callithrix jacchus com escore total $=0$. Coloração $\mathrm{HE}$, animal Nicoletta 


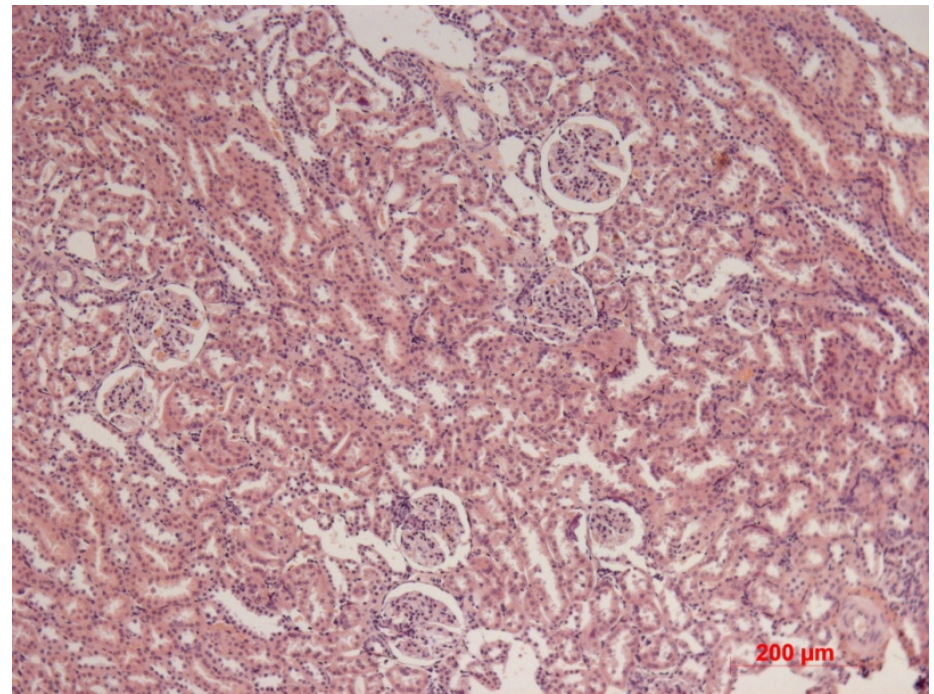

Figura 11 - Corte histológico de rim de Callithrix jacchus com escore total $=1$. Coloração $\mathrm{HE}$, animal Blanche

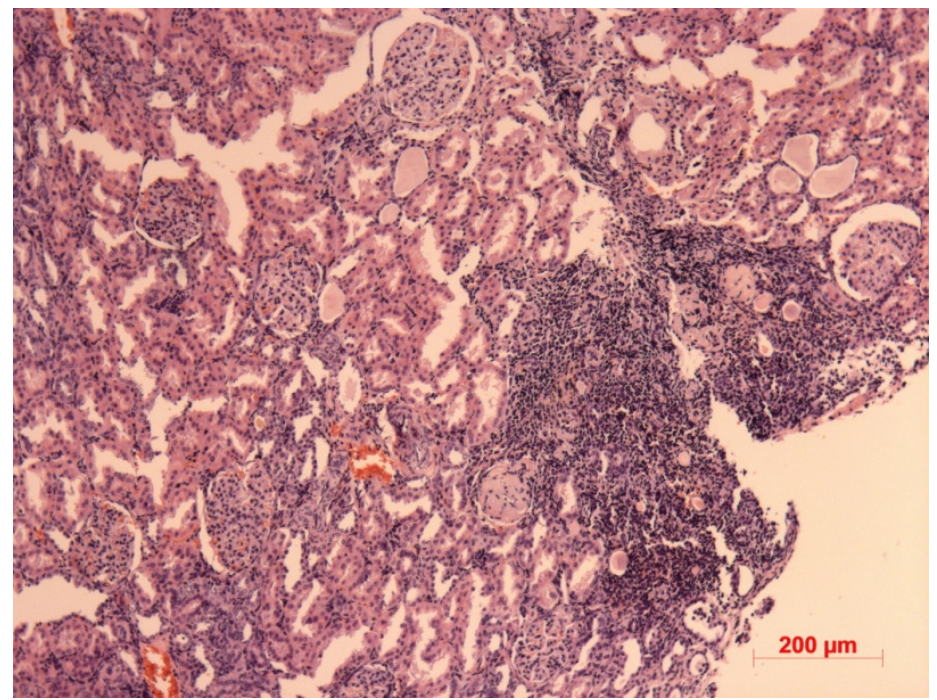

Figura 12 - Corte histológico de rim de Callithrix jacchus com escore total $=2$. Coloração $\mathrm{HE}$, animal Ariberta 


\subsection{PESO DOS ANIMAIS}

Para a avaliação estatística os animais do grupo 1 e 2 foram submetidos a duas abordagens diferentes. Na primeira abordagem foi considerado o fator sexo e estes foram subdivididos dentro de seus respectivos grupos em machos e fêmeas, na segunda abordagem foi considerado o fator saúde dos animais e para a avaliação do peso vivo, estes foram divididos em animais com alteração nos exames e sem alteração nos exames, não levando em consideração a formação dos grupos 1 e 2.

A análise de variância não indica haver diferença significativa quando considerados o peso dos animais em relação aos grupos de estudo $(p=0,454)$ e sexo $(p=0,170)$, também não demonstra efeito de interação entre grupo e sexo ( $p=$ 0,779). Estes resultados estão expressos na tabela 2 e gráfico 1.

Quando considerado a saúde dos animais em relação ao peso, estes são divididos em animais com e sem alteração nos exames laboratoriais, e a análise de variância não indica haver diferença significativa entre estes grupos ( $p=0,082)$, conforme demonstrado na tabela 3 e gráfico 2 .

Valores de peso descritos no Anexo C. 
Tabela 2 - Valores referentes ao peso (g) dos machos e fêmeas de Callithrix jacchus dos grupos $1 \mathrm{e}$ 2 - Goettingen - 2006

\begin{tabular}{cccccc}
\cline { 3 - 6 } & & \multicolumn{4}{c}{ PESO } \\
\cline { 3 - 6 } & & Média \pm DP & Mediana & EP & Mínimo - Máximo \\
\hline \hline \multirow{2}{*}{ GRUPO 1 } & Machos & $396,6 \pm 57,00$ & 420 & 25,49 & $319-464$ \\
\cline { 2 - 6 } & Fêmeas & $427,6 \pm 44,05$ & 440 & 19,70 & $365-477$ \\
\hline \multirow{2}{*}{ GRUPO 2 } & Machos & $409,6 \pm 14,25$ & 407 & 6,37 & $390-425$ \\
\cline { 2 - 6 } & Fêmeas & $456,0 \pm 95,53$ & 460 & 42,72 & $301-552$ \\
\hline \hline
\end{tabular}

G1 $\mathbf{n}=10$ : Machos $\mathrm{n}=5$, Fêmeas $\mathrm{n}=5 ;$ G2 $\mathbf{n}=$ 10: Machos $\mathrm{n}=5$, Fêmeas $\mathrm{n}=5$.

Grupo $(p=0,454)$; Sexo $(p=0,170)$.

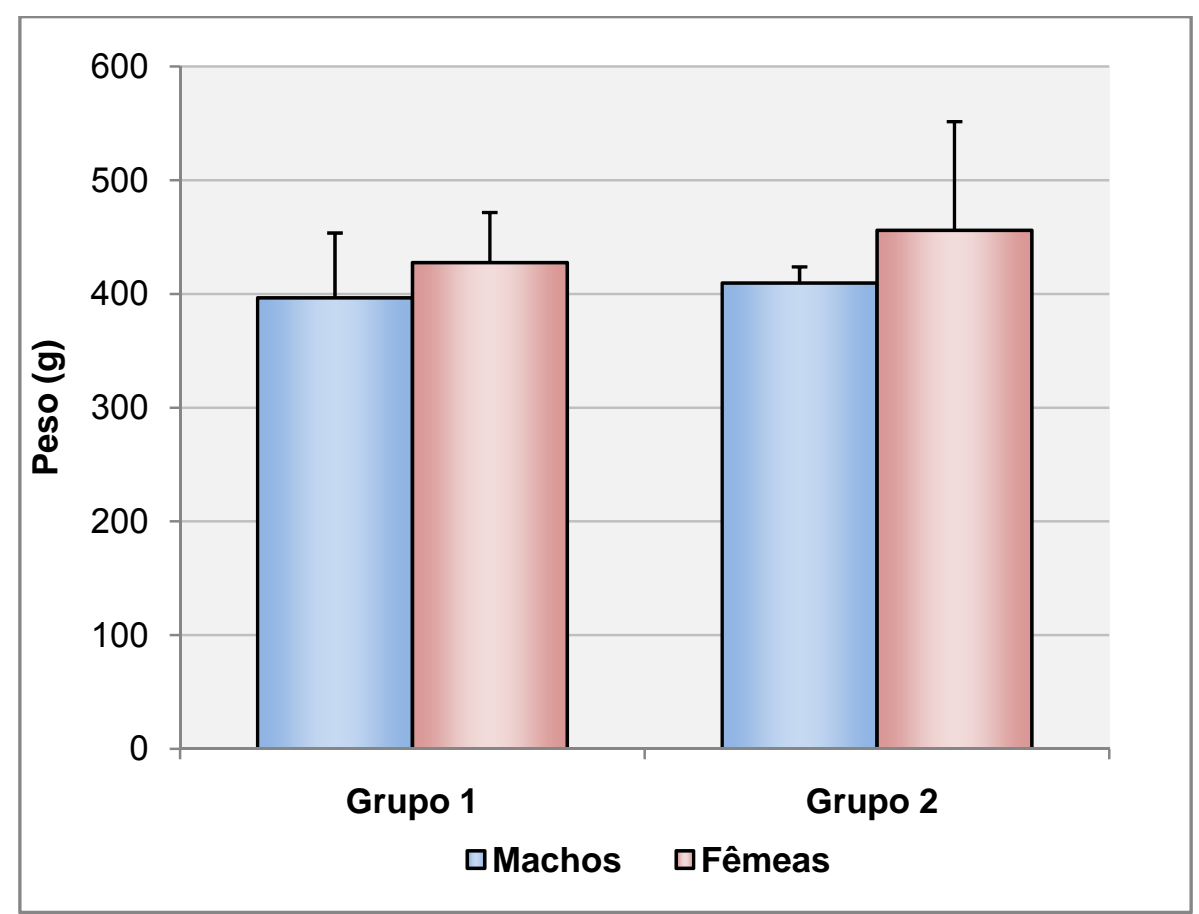

Gráfico 1 - Valores referentes ao peso (g) dos machos e fêmeas de Callithrix jacchus dos grupos 1 e 2 
Tabela 3 - Valores referentes ao peso $(\mathrm{g})$ dos Callithrix jacchus com alteração nos exames (sim) e sem alteração nos exames (não) - Goettingen - 2006

\begin{tabular}{ccccc}
\cline { 2 - 4 } & \multicolumn{4}{c}{ PESO } \\
\cline { 2 - 5 } & Média \pm DP & Mediana & EP & Mínimo - Máximo \\
\hline \hline NÃO & $394 \pm 62,43$ & 405,0 & 22,07 & $301-477$ \\
\hline SIM & $441 \pm 52,17$ & 432,5 & 15,06 & $360-552$ \\
\hline \hline
\end{tabular}

Não: $n=8 ;$ Sim: $n=12 ;(p=0,082)$.

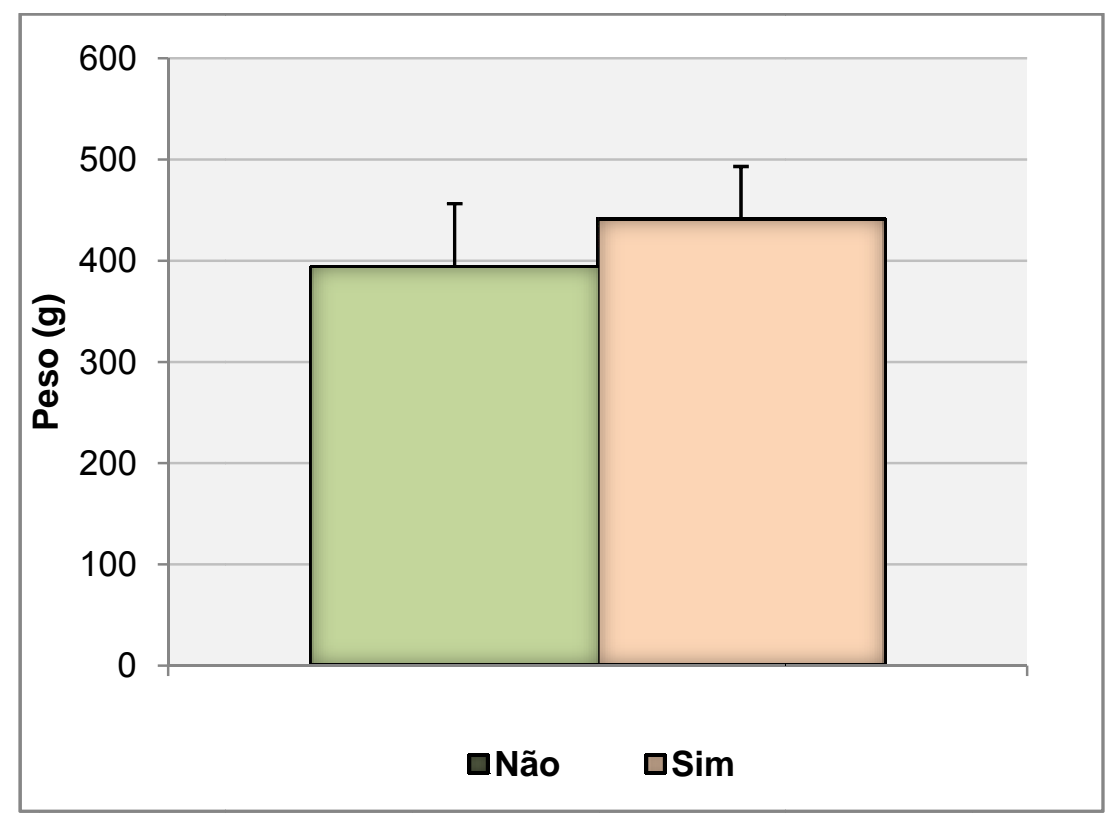

Gráfico 2 - Valores referentes ao peso (g) dos Callithrix jacchus com alteração nos exames (sim) e sem alteração nos exames (não) 
As figuras 13 e 14 representam Callithrix jacchus dos grupos 1 e 2 com peso superior e inferior a 400 gramas:

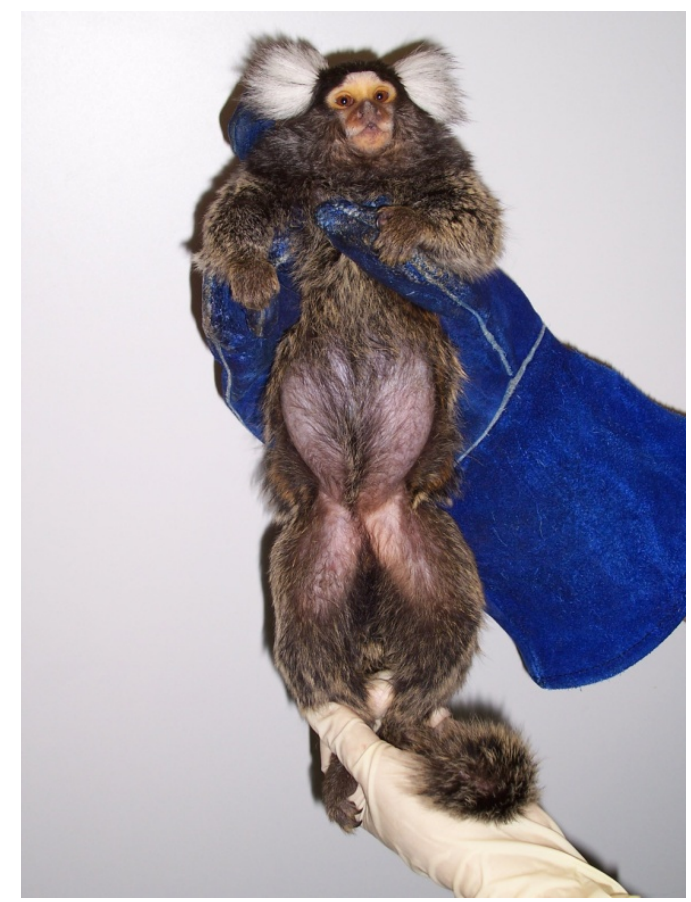

Figura 13 - Imagem de Callithrix jacchus com peso $>400$ gramas

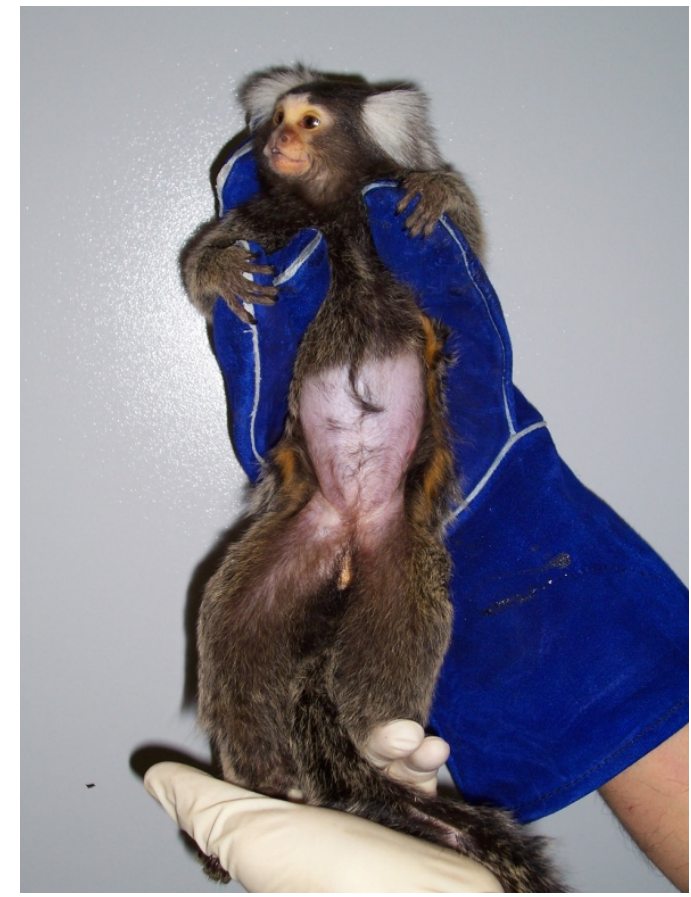

Figura 14 - Imagem de Callithrix jacchus com peso < 400 gramas 


\subsection{MORFOMETRIA MACROSCÓPICA RENAL}

A ANOVA com três fatores foi empregada considerando-se os fatores grupo (grupo 1 e grupo 2), lado (rim direito e rim esquerdo) e sexo na primeira abordagem estatística e posteriormente considerou-se, ao invés do fator sexo, o fator saúde dos animais (com alteração nos exames e sem alteração nos exames).

Em nenhuma das duas abordagens a análise de variância indica haver diferença significativa quando considerado o lado, rim direito e rim esquerdo, para comprimento, altura, largura, peso e volume dos rins $(p>0,05)$.

Quando se considera o sexo em relação à mensuração anatômica, a análise de variância indica não haver diferença significativa no comprimento, altura, peso e volume dos rins, para os fatores grupo e sexo $(p>0,05)$, como demonstram as tabelas 4, 6, 10 e 12 e gráficos 3, 5, 9, e 11, com exceção da largura dos rins, na qual a diferença significativa foi detectada entre grupo 1 e 2 ( $p=0,004)$, mas não entre os sexos ( $p=0,278)$, conforme a tabela 8 e gráfico 7 .

Entretanto, quando se considera a saúde dos animais em relação aos parâmetros macroscópicos, foi detectada diferença significativa na altura dos rins, entre grupo 1 e grupo 2 ( $p=0,010)$ e entre animais com alteração nos exames e sem alteração nos exames ( $p=0,001)$; na largura dos rins, diferença entre grupo 1 e $2(p=0,005)$ e entre animais com alteração nos exames e sem alteração nos exames ( $p=0,004$ ); no peso dos rins, diferença entre animais com alteração nos exames e sem alteração nos exames ( $p=0,008$ ); no volume dos rins, diferença entre com alteração nos exames e sem alteração nos exames $(p=0,006)$. As tabelas $7,9,11$ e 13 e os gráficos $6,8,10$ e 12 expressam os resultados destas análises.

Já em relação ao comprimento dos rins, ainda considerando a sanidade dos animais, a análise de variância mostra uma indicação de diferença entre animais com alteração nos exames e sem alteração nos exames ( $p=0,064$ ), que foi confirmada após a retirada do animal Asko da análise $(p=0,010)$.

Sua retirada da análise foi preconizada, pois este animal se apresentava muito fora do padrão em relação ao restante dos componentes de seu grupo, já que seu comprimento renal é de $1,20 \mathrm{~cm}$ para o rim direito e $1,8 \mathrm{~cm}$ para o rim esquerdo 
ao passo que a média do grupo é de $2,15 \pm 0,25$ para rim direito e 2,07 $\pm 0,25$ para rim esquerdo.

Os resultados das análises do comprimento renal podem ser visualizados na tabela 5 e no gráfico 4 .

$\mathrm{Na}$ análise da altura do rim, considerando-se o fator sexo, não foi possível detectar a diferença significativa entre os grupos 1 e 2 em função da variabilidade dos dados em relação ao sexo, mas essa diferença foi significativa quando considera-se a saúde dos animais.

Em nenhuma das análises realizadas para macroscopia renal foi verificado efeito de interação entre os fatores considerados (grupo, lado e sexo ou alteração nos exames). 
Em relação à morfologia renal (mensuração anatômica) o comprimento $(\mathrm{cm})$ dos rins direito e esquerdo variou de acordo com as tabelas 4 e 5 e gráficos 3 e 4 (valores do comprimento renal - Anexo D):

Tabela 4 - Valores referentes ao comprimento $(\mathrm{cm})$ dos rins direito e esquerdo dos Callithrix jacchus machos (M) e fêmeas (F) dos grupos 1 e 2 - Goettingen - 2009 e 2006

\begin{tabular}{|c|c|c|c|c|c|c|c|}
\hline \multicolumn{8}{|c|}{ COMPRIMENTO DOS RINS } \\
\hline \multicolumn{2}{|c|}{ Média \pm DP } & \multicolumn{2}{|c|}{ Mediana } & \multicolumn{2}{|c|}{ EP } & \multicolumn{2}{|c|}{ Mínimo - Máximo } \\
\hline RD & RE & RD & RE & RD & RE & RD & RE \\
\hline $1,74 \pm 0,55$ & $1,79 \pm 0,39$ & 1,60 & 1,8 & 0,25 & 0,18 & $1,20-2,50$ & $1,15-2,20$ \\
\hline $1,96 \pm 0,13$ & $1,95 \pm 0,17$ & 1,90 & 2,00 & 0,06 & 0,08 & $1,80-2,10$ & $1,65-2,10$ \\
\hline $1,84 \pm 0,12$ & $1,77 \pm 0,11$ & 1,88 & 1,76 & 0,53 & 0,47 & $1,65-1,95$ & $1,64-1,90$ \\
\hline $1,97 \pm 0,16$ & $1,91 \pm 0,13$ & 2,00 & 2,00 & 0,07 & 0,06 & $1,80-2,20$ & $1,75-2,00$ \\
\hline
\end{tabular}

G1 $\mathbf{n}=10$ : Machos $n=5$, Fêmeas $n=5 ; \mathbf{~} \mathbf{n}=\mathbf{1 0}$ : Machos $n=5$, Fêmeas $n=5$.

Grupo $(p=0,911)$; Sexo $(p=0,158)$; Lado $(p=0,645)$.

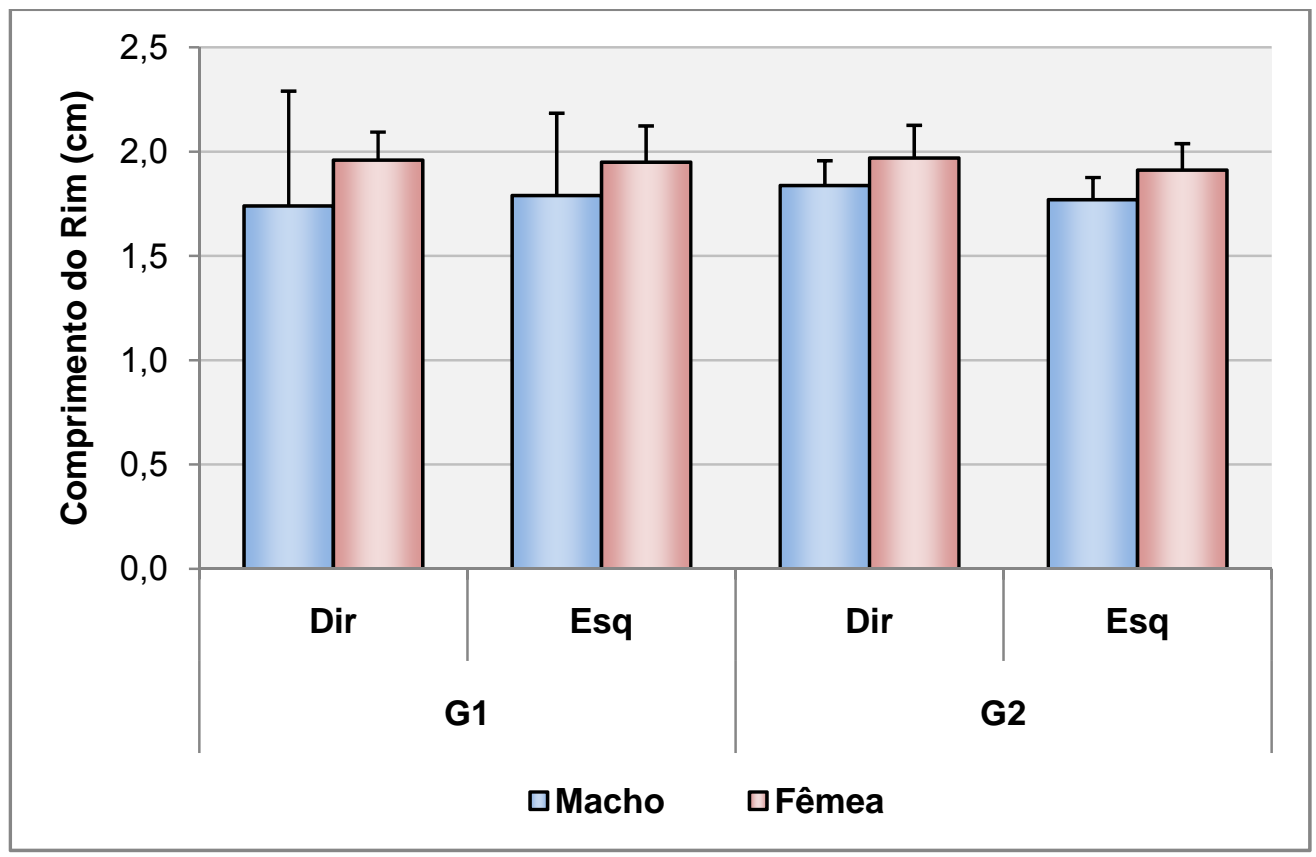

Gráfico 3 - Valores referentes ao comprimento $(\mathrm{cm})$ dos rins direito e esquerdo dos Callithrix jacchus machos e fêmeas dos grupos 1 e 2 
Tabela 5 - Valores referentes ao comprimento $(\mathrm{cm})$ dos rins direito e esquerdo dos Callithrix jacchus com alteração nos exames (sim) e sem alteração nos exames (não) dos grupos 1 e 2 Goettingen - 2009 e 2006

\begin{tabular}{|c|c|c|c|c|c|c|c|}
\hline \multicolumn{8}{|c|}{ COMPRIMENTO DOS RINS } \\
\hline \multicolumn{2}{|c|}{ Média \pm DP } & \multicolumn{2}{|c|}{ Mediana } & \multicolumn{2}{|c|}{ EP } & \multicolumn{2}{|c|}{ Mínimo - Máximo } \\
\hline RD & RE & RD & RE & RD & RE & RD & RE \\
\hline $1,74 \pm 0,30$ & $1,72 \pm 0,35$ & 1,80 & 1,80 & 0,14 & 0,16 & $1,30-2,10$ & $1,15-2,00$ \\
\hline $1,96 \pm 0,48$ & $2,02 \pm 0,15$ & 2,10 & 2,00 & 0,21 & 0,07 & $1,20-2,50$ & $1,80-2,20$ \\
\hline $1,77 \pm 0,10$ & $1,73 \pm 0,81$ & 1,80 & 1,75 & 0,06 & 0,05 & $1,65-1,85$ & $1,64-1,80$ \\
\hline $1,96 \pm 0,13$ & $1,89 \pm 0,12$ & 1,95 & 1,90 & 0,05 & 0,05 & $1,80-2,20$ & $1,70-2,00$ \\
\hline
\end{tabular}

G1 $\mathbf{n}=10$ : Não $\mathbf{n}=5$, Sim $\mathbf{n}=5$; $\mathbf{G 2} \mathbf{n}=10$ : Não $n=3$, Sim $\mathbf{n}=7$.

Grupo $(p=0,837)$; Alt. Exames $(p=0,064)^{*}$; Lado $(p=0,714)$.

*Retirando o animal Asko $(p=0,010)$.

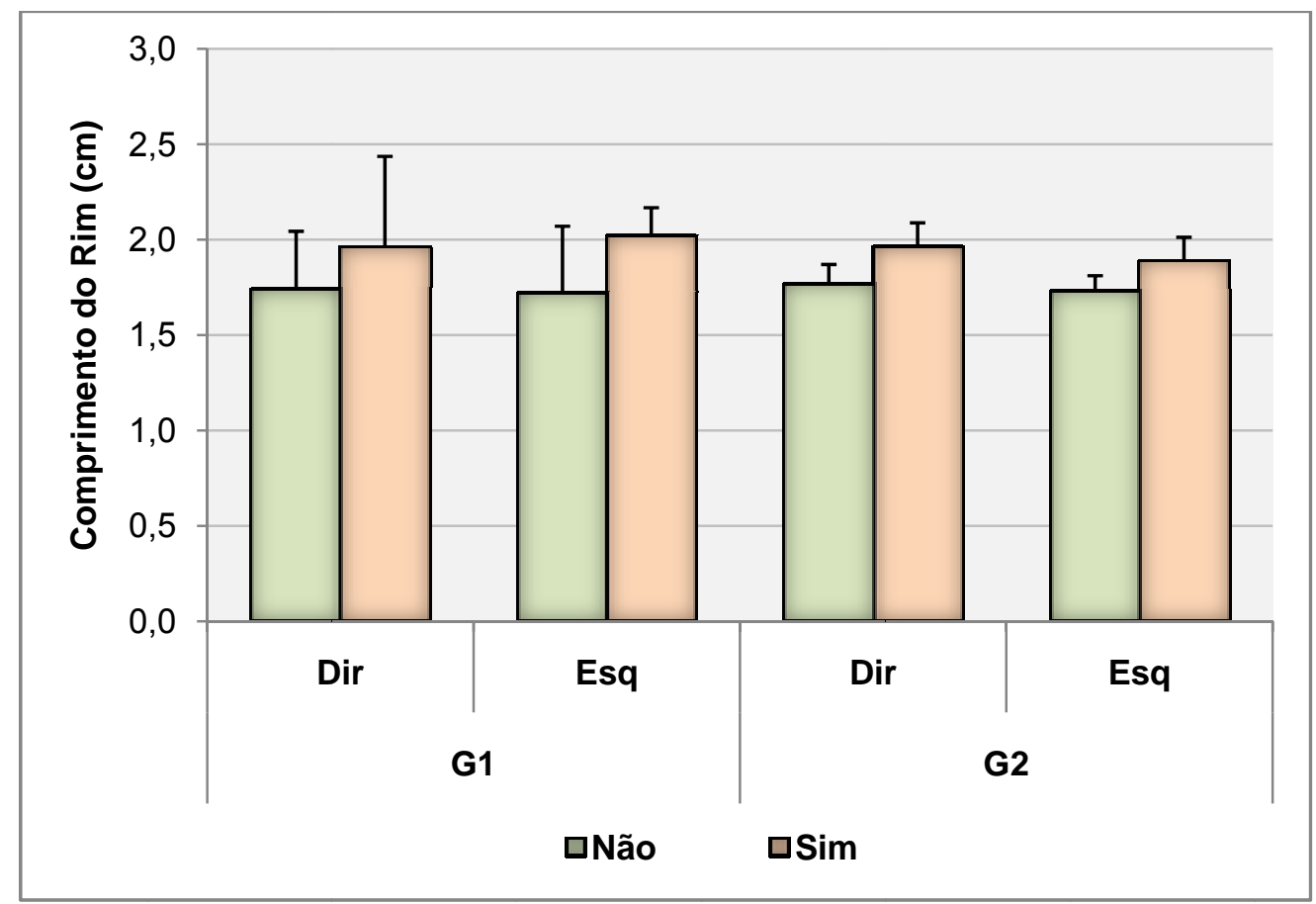

Gráfico 4 - Valores referentes ao comprimento $(\mathrm{cm})$ dos rins direito e esquerdo dos Callithrix jacchus com alteração nos exames (sim) e sem alteração nos exames (não) dos grupos 1 e 2 
Em relação à morfologia renal (mensuração anatômica) a altura $(\mathrm{cm})$ dos rins direito e esquerdo variou de acordo com as tabelas 6 e 7 e gráficos 5 e 6 (valores da altura renal - Anexo D):

Tabela 6 - Valores referentes à altura $(\mathrm{cm})$ dos rins direito e esquerdo dos Callithrix jacchus machos (M) e fêmeas $(F)$ dos grupos 1 e 2 - Goettingen - 2009 e 2006

ALTURA DOS RINS

\begin{tabular}{|c|c|c|c|c|c|c|c|}
\hline \multicolumn{2}{|c|}{ Média \pm DP } & \multicolumn{2}{|c|}{ Mediana } & \multicolumn{2}{|c|}{ EP } & \multicolumn{2}{|c|}{ Mínimo - Máximo } \\
\hline RD & RE & RD & RE & RD & RE & RD & RE \\
\hline
\end{tabular}

\begin{tabular}{llllllllll}
$\mathbf{G} 1$ & $\mathbf{M}$ & $1,35 \pm 0,40$ & $1,53 \pm 0,31$ & 1,40 & 1,45 & 0,18 & 0,14 & $0,85-1,90$ & $1,20-1,90$ \\
\cline { 2 - 9 } & $\mathbf{F}$ & $1,40 \pm 0,21$ & $1,24 \pm 0,15$ & 1,40 & 1,25 & 0,10 & 0,07 & $1,20-1,75$ & $1,00-1,40$ \\
\hline $\mathbf{G} 2$ & $\mathbf{M}$ & $1,18 \pm 0,18$ & $1,18 \pm 0,08$ & 1,21 & 1,20 & 0,08 & 0,04 & $0,96-1,40$ & $1,10-1,30$ \\
\cline { 2 - 9 } & $\mathbf{F}$ & $1,26 \pm 0,15$ & $1,23 \pm 0,10$ & 1,30 & 1,20 & 0,07 & 0,04 & $1,00-1,40$ & $1,10-1,35$
\end{tabular}

G1 $\mathbf{n}=$ 10: Machos $n=5$, Fêmeas $n=5 ; \mathbf{G 2} \mathbf{n}=10$ : Machos $n=5$, Fêmeas $n=5$. Grupo $(p=0,118)$; Sexo $(p=0,903)$; Lado $(p=0,910)$.

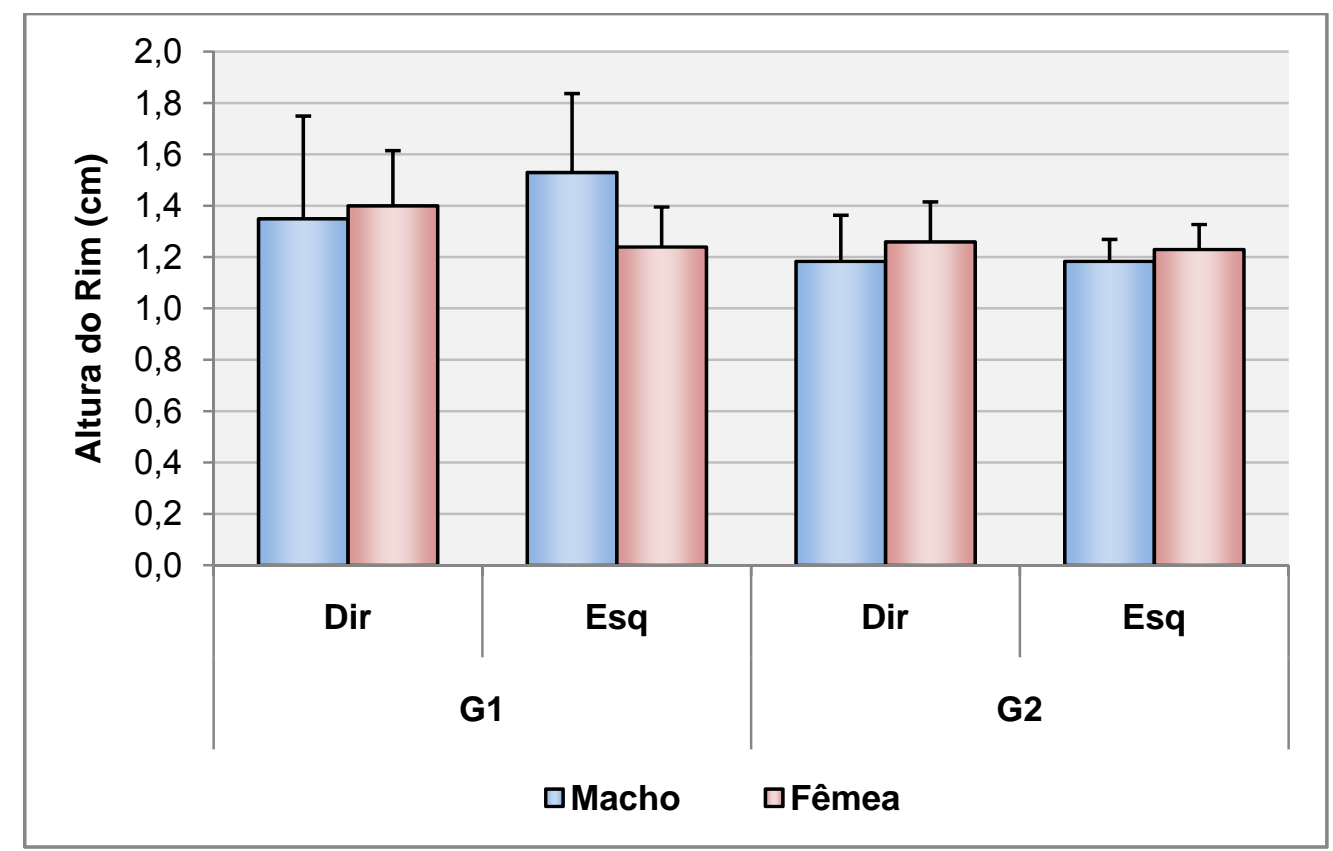

Gráfico 5 - Valores referentes à altura $(\mathrm{cm})$ dos rins direito e esquerdo dos Callithrix jacchus machos $(M)$ e fêmeas $(F)$ dos grupos 1 e 2 
Tabela 7 - Valores referentes à altura $(\mathrm{cm})$ dos rins direito e esquerdo dos Callithrix jacchus com alteração nos exames (sim) e sem alteração nos exames (não) dos grupos 1 e 2 Goettingen - 2009 e 2006

\begin{tabular}{|c|c|c|c|c|c|c|c|}
\hline \multicolumn{8}{|c|}{ ALTURA DOS RINS } \\
\hline \multicolumn{2}{|c|}{ Média \pm DP } & \multicolumn{2}{|c|}{ Mediana } & \multicolumn{2}{|c|}{ EP } & \multicolumn{2}{|c|}{ Mínimo - Máximo } \\
\hline RD & RE & RD & RE & RD & RE & RD & RE \\
\hline $1,16 \pm 0,20$ & $1,22 \pm 014$ & 1,20 & 1,25 & 0,09 & 0,06 & $0,85-1,40$ & $1,00-1,35$ \\
\hline $1,59 \pm 0,22$ & $1,55 \pm 0,29$ & 1,50 & 1,45 & 0,10 & 0,13 & $1,40-1,90$ & $1,20-1,90$ \\
\hline $1,09 \pm 0,19$ & $1,13 \pm 0,06$ & 1,00 & 1,10 & 0,11 & 0,03 & $0,96-1,30$ & $1,10-1,20$ \\
\hline $1,28 \pm 0,12$ & $1,24 \pm 0,08$ & 1,30 & 1,22 & 0,05 & 0,03 & $1,05-1,40$ & $1,10-1,35$ \\
\hline
\end{tabular}

Grupo $(p=0,010)$; Alt. Exames $(p=0,001)$; Lado $(p=0,898)$.

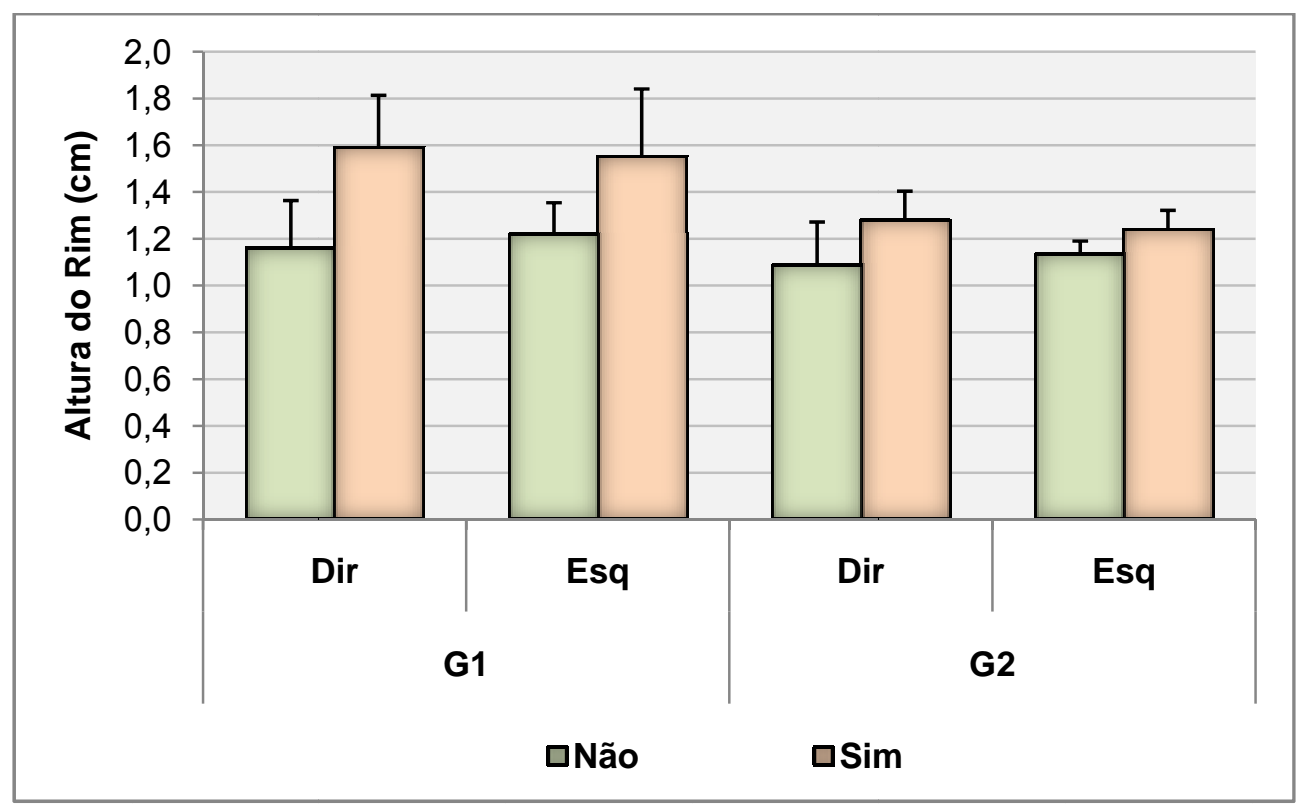

Gáfico 6 - Valores referentes à altura $(\mathrm{cm})$ dos rins direito e esquerdo dos Callithrix jacchus com alteração nos exames (sim) e sem alteração nos exames (não) dos grupos 1 e 2 
Em relação à morfologia renal (mensuração anatômica) a largura $(\mathrm{cm})$ dos rins direito e esquerdo variou de acordo com as tabelas 8 e 9 e gráficos 7 e 8 (valores da largura renal - Anexo D):

Tabela 8 - Valores referentes à largura $(\mathrm{cm})$ dos rins direito e esquerdo de Callithrix jacchus machos (M) e fêmeas $(F)$ dos grupos 1 e 2 - Goettingen - 2009 e 2006

LARGURA DOS RINS

Média \pm DP $\quad$ Mediana $\quad$ MP $\quad$ Mínimo - Máximo

\begin{tabular}{llllllll}
\hline \hline RD & RE & RD & RE & RD & RE & RD & RE
\end{tabular}

\begin{tabular}{llllllllll}
\hline \hline $\mathbf{G} 1$ & $\mathbf{M}$ & $1,01 \pm 0,15$ & $0,98 \pm 0,16$ & 1,10 & 0,90 & 0,07 & 0,07 & $0,80-1,15$ & $0,80-1,20$ \\
\cline { 2 - 9 } & $\mathbf{F}$ & $1,05 \pm 0,11$ & $1,14 \pm 0,15$ & 1,05 & 1,10 & 0,05 & 0,07 & $0,90-1,20$ & $1,00-1,40$ \\
\hline \multirow{2}{*}{$\mathbf{G} 2$} & $\mathbf{M}$ & $1,20 \pm 0,1$ & $1,28 \pm 0,10$ & 1,19 & 1,25 & 0,04 & 0,05 & $1,10-1,30$ & $1,20-1,45$ \\
\cline { 2 - 9 } & $\mathbf{F}$ & $1,28 \pm 0,19$ & $1,29 \pm 0,23$ & 1,25 & 1,35 & 0,09 & 0,10 & $1,10-1,55$ & $1,00-1,55$
\end{tabular}

G1 $\mathbf{n}=10$ : Machos $n=5$, Fêmeas $n=5 ; \mathbf{~} \mathbf{n}=10$ : Machos $n=5$, Fêmeas $n=5$.

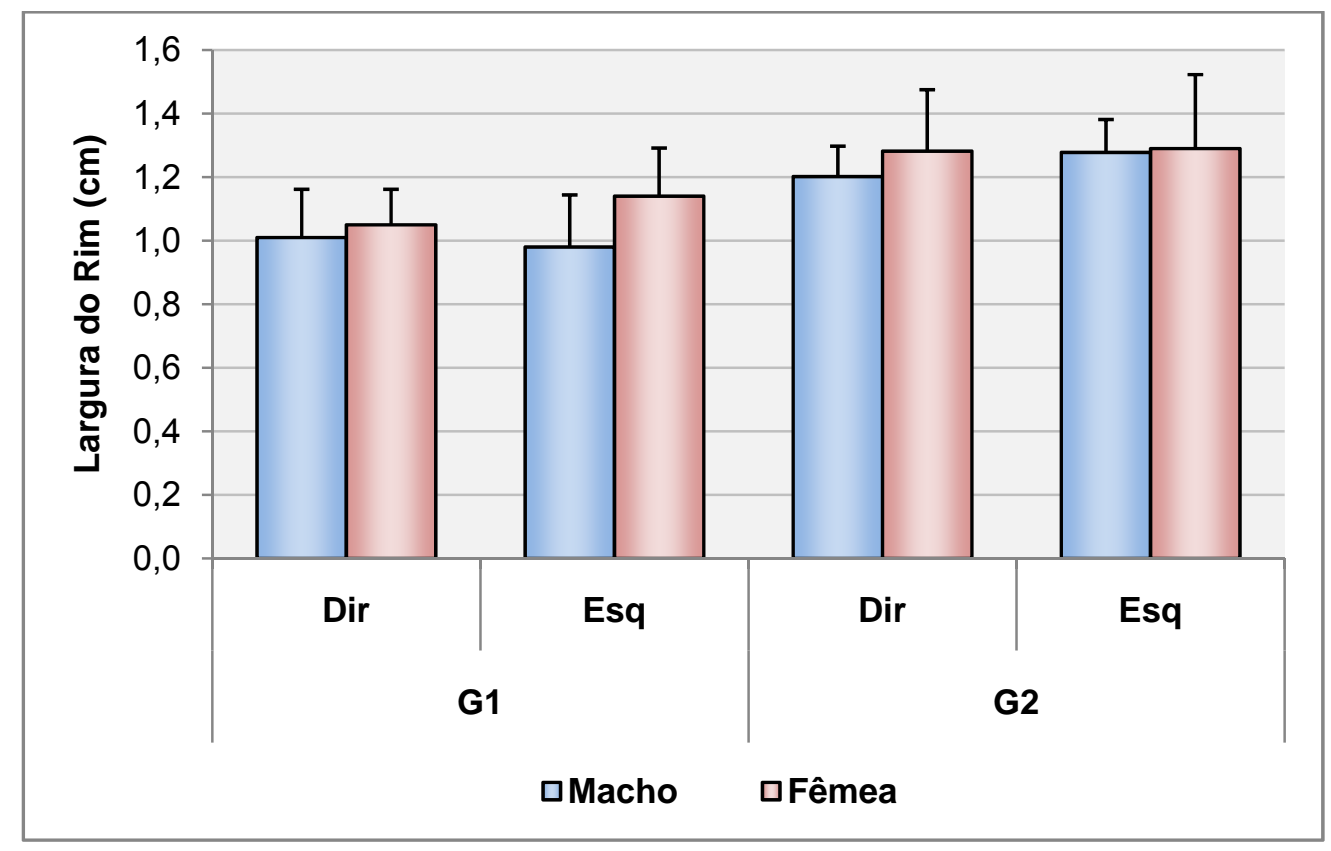

Gráfico 7 - Valores referentes à largura $(\mathrm{cm})$ dos rins direito e esquerdo de Callithrix jacchus machos e fêmeas dos grupos 1 e 2 
Tabela 9 - Valores referentes à largura $(\mathrm{cm})$ dos rins direito e esquerdo de Callithrix jacchus com alteração nos exames (sim) e sem alteração nos exames (não) dos grupos 1 e 2 Goettingen - 2009 e 2006

\section{LARGURA DOS RINS}

\begin{tabular}{ccccccccc}
\hline \hline \multicolumn{2}{c}{ Média \pm DP } & Mediana & EP & & Mínimo - Máximo \\
\hline \hline RD & RE & RD & RE & RD & RE & RD & RE \\
\hline $0,97 \pm 0,12$ & $0,98 \pm 0,13$ & 1,00 & 1,00 & 0,05 & 0,06 & $0,80-1,10$ & $0,80-1,10$ \\
\hline $1,09 \pm 0,11$ & $1,14 \pm 0,18$ & 1,10 & 1,10 & 0,05 & 0,08 & $0,90-1,20$ & $0,90-1,40$ \\
\hline $1,11 \pm 0,01$ & $1,10 \pm 0,10$ & 1,11 & 1,10 & 0,01 & 0,06 & $1,10-1,12$ & $1,00-1,20$ \\
\hline $1,30 \pm 0,15$ & $1,36 \pm 0,13$ & 1,30 & 1,35 & 0,06 & 0,05 & $1,10-1,55$ & $1,20-1,55$
\end{tabular}

G1 $\mathbf{n}=10$ : Não $n=5, \operatorname{Sim} n=5 ;$ G2 $\mathbf{n}=10$ : Não $n=3$, Sim $n=7$.

Grupo ( $p=0,005)$; Alt. Exames $(p=0,004)$; Lado $(p=0,349)$.

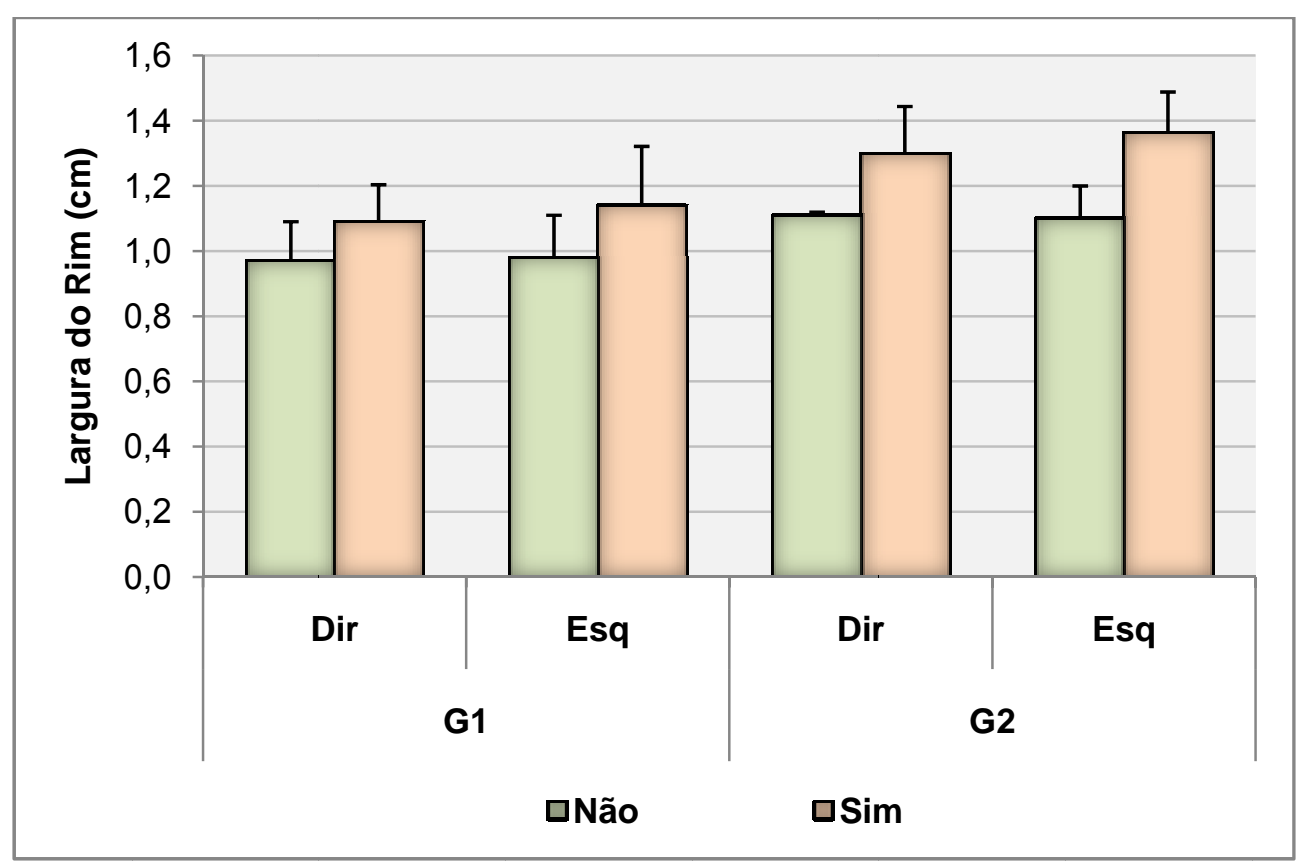

Gráfico 8 - Valores referentes à largura $(\mathrm{cm})$ dos rins direito e esquerdo de Callithrix jacchus com alteração nos exames (sim) e sem alteração nos exames (não) dos grupos 1 e 2 
Em relação à morfologia renal (mensuração anatômica) o peso (g) dos rins direito e esquerdo variou de acordo com as tabelas 10 e 11 e gráficos 9 e 10 (valores do peso renal - Anexo D):

Tabela 10 - Valores referentes ao peso $(\mathrm{g})$ dos rins direito e esquerdo de Callithrix jacchus machos (M) e fêmeas (F) dos grupos 1 e 2 - Goettingen - 2009 e 2006

\section{PESO DOS RINS}

\begin{tabular}{cccccccc}
\hline \hline \multicolumn{2}{c}{ Média \pm DP } & \multicolumn{2}{c}{ Mediana } & \multicolumn{2}{c}{ EP } & \multicolumn{2}{c}{ Mínimo - Máximo } \\
\hline \hline RD & RE & RD & RE & RD & RE & RD & RE
\end{tabular}

\begin{tabular}{llllllllll}
\hline \hline \multirow{2}{*}{$\mathbf{G} 1$} & $\mathbf{M}$ & $1,55 \pm 0,82$ & $1,70 \pm 0,77$ & 1,35 & 1,46 & 0,37 & 0,35 & $0,70-2,92$ & $0,77-2,73$ \\
\cline { 2 - 9 } & $\mathbf{F}$ & $2,26 \pm 0,74$ & $1,93 \pm 0,49$ & 2,47 & 2,03 & 0,37 & 0,24 & $1,20-2,90$ & $1,25-2,40$ \\
\hline \multirow{2}{*}{$\mathbf{G} 2$} & $\mathbf{M}$ & $1,59 \pm 0,34$ & $1,52 \pm 0,28$ & 1,70 & 1,50 & 0,15 & 0,13 & $1,10-1,95$ & $1,10-1,79$ \\
\cline { 2 - 9 } & $\mathbf{F}$ & $2,00 \pm 0,68$ & $1,92 \pm 0,68$ & 2,40 & 2,30 & 0,30 & 0,30 & $1,12-2,62$ & $1,01-2,53$ \\
\hline \hline
\end{tabular}

G1 $\mathbf{n}=10$ : Machos $n=5$, Fêmeas $n=5$; G2n = 10: Machos $n=5$, Fêmeas $n=5$.

Grupo $(p=0,772)$; Sexo $(p=0,141)$; Lado $(p=0,255)$.

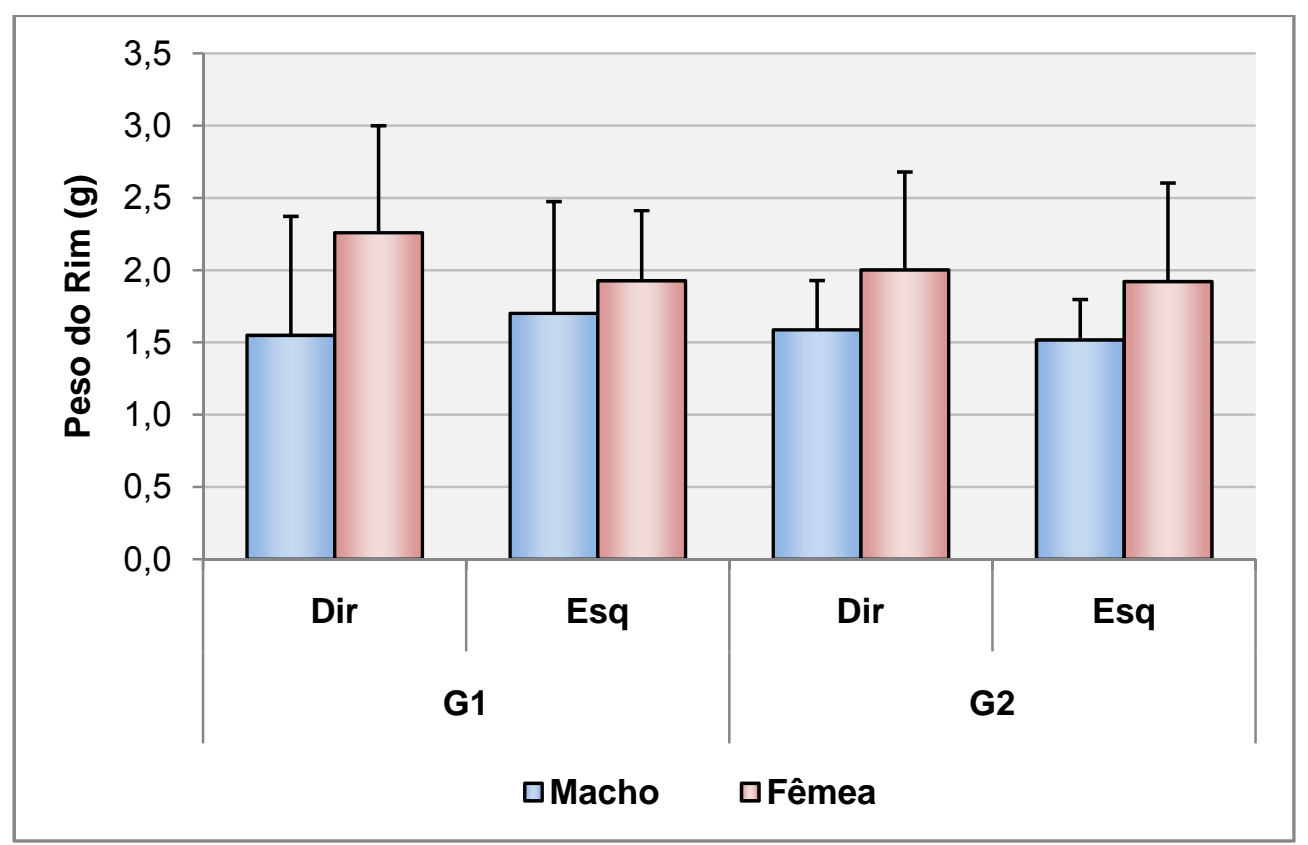

Gráfico 9 - Valores referentes ao peso $(\mathrm{g})$ dos rins direito e esquerdo de Callithrix jacchus machos e fêmeas dos grupos 1 e 2 
Tabela 11 - Valores referentes ao peso (g) dos rins direito e esquerdo de Callithrix jacchus com alteração nos exames (sim) e sem alteração nos exames (não) dos grupos 1 e 2 Goettingen - 2009 e 2006

\section{PESO DOS RINS}

\begin{tabular}{cccccccccc}
\hline \hline \multicolumn{2}{c}{ Média \pm DP } & \multicolumn{2}{c}{ Mediana } & \multicolumn{2}{c}{ EP } & & \multicolumn{2}{c}{ Mínimo - Máximo } \\
\hline \hline RD & RE & RD & RE & RD & RE & RD & RE \\
\hline $1,52 \pm 0,94$ & $1,36 \pm 0,54$ & 1,25 & 1,29 & 0,48 & 0,27 & $0,70-2,90$ & $0,77-2,07$ \\
\hline $2,14 \pm 0,69$ & $2,16 \pm 0,48$ & 2,36 & 2,22 & 0,31 & 0,21 & $1,35-2,92$ & $1,46-2,73$ \\
\hline $1,22 \pm 0,19$ & $1,16 \pm 0,19$ & 1,12 & 1,10 & 0,11 & 0,11 & $1,10-1,43$ & $1,01-1,38$ \\
\hline $2,04 \pm 0,45$ & $1,96 \pm 0,44$ & 1,95 & 1,79 & 0,17 & 0,17 & $1,39-2,62$ & $1,44-2,53$
\end{tabular}

G1 $\mathbf{n}=10:$ Não $n=5, \operatorname{Sim} n=5 ; \mathbf{G 2 n}=10$ : Não $n=3, \operatorname{Sim} n=7$.

Grupo ( $p=0,437)$; Alt. Exames $(p=0,008)$; Lado $(p=0,408)$.

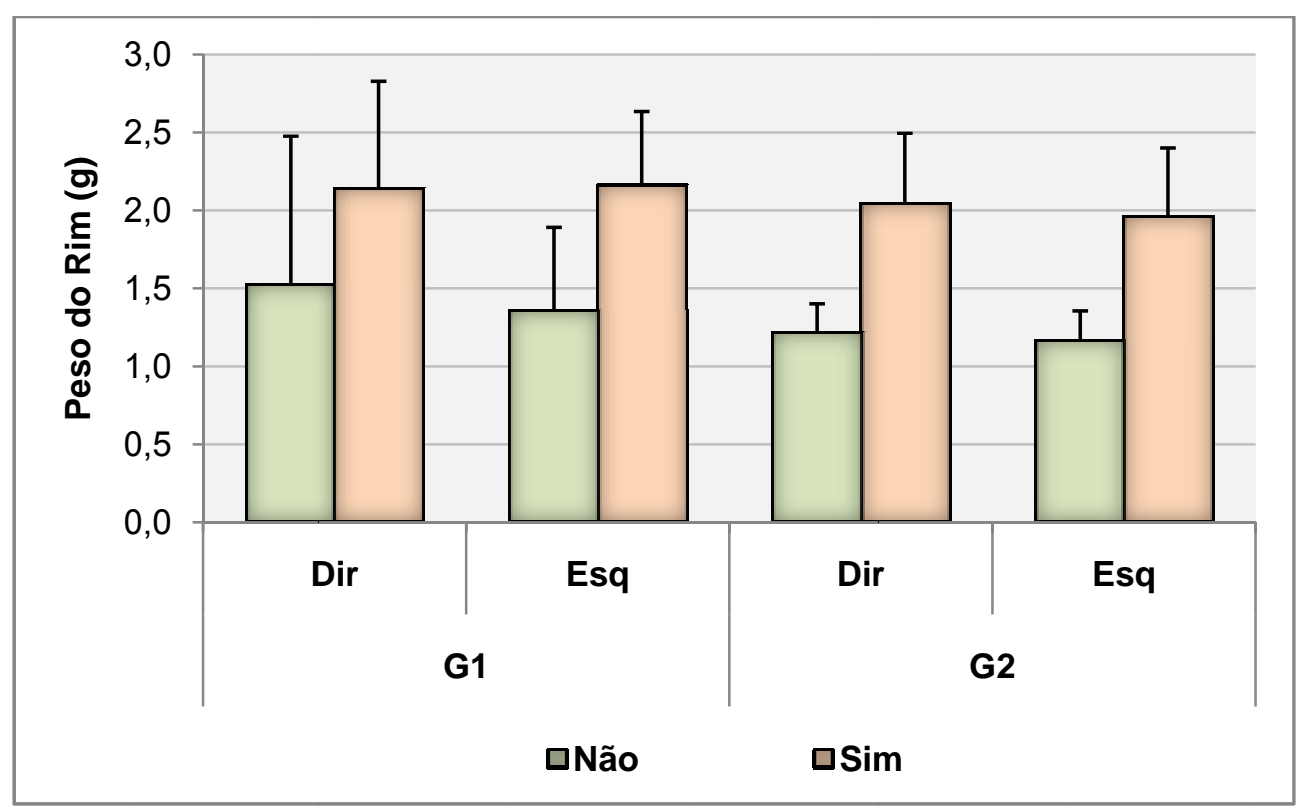

Gráfico 10 - Valores referentes ao peso $(\mathrm{g})$ dos rins direito e esquerdo de Callithrix jacchus com alteração nos exames (sim) e sem alteração nos exames (não) dos grupos 1 e 2 
Em relação à morfologia renal (mensuração anatômica) o volume $\left(\mathrm{cm}^{3}\right)$ dos rins direito e esquerdo variou de acordo com as tabelas 12 e 13 e gráficos 11 e 12 (valores do volume renal - Anexo D):

Tabela 12 - Valores referentes ao volume $\left(\mathrm{cm}^{3}\right)$ dos rins direito e esquerdo de Callithrix jacchus machos (M) e fêmeas (F) dos grupos 1 e 2 - Goettingen - 2009 e 2006

\begin{tabular}{|c|c|c|c|c|c|c|c|c|c|}
\hline & \multicolumn{8}{|c|}{ VOLUME DOS RINS } \\
\hline & & \multicolumn{2}{|c|}{ Média \pm DP } & \multicolumn{2}{|c|}{ Mediana } & \multicolumn{2}{|c|}{ EP } & \multicolumn{2}{|c|}{ Mínimo - Máximo } \\
\hline & & RD & RE & RD & RE & RD & RE & RD & RE \\
\hline \multirow{2}{*}{ G 1} & M & $3,14 \pm 2,21$ & $3,4 \pm 1,65$ & 2,21 & 3,56 & 0,99 & 0,74 & $1,09-6,38$ & $1,09-5,50$ \\
\hline & $\mathbf{F}$ & $3,73 \pm 0,77$ & $3,61 \pm 0,82$ & 4,04 & 3,85 & 0,34 & 0,37 & $2,67-4,50$ & $2,24-4,33$ \\
\hline \multirow{2}{*}{ G 2} & M & $3,19 \pm 0,57$ & $3,04 \pm 0,44$ & 3,31 & 3,05 & 0,26 & 0,19 & $2,22-3,73$ & $2,43-3,61$ \\
\hline & $\mathbf{F}$ & $3,94 \pm 1,02$ & $3,67 \pm 0,87$ & 4,08 & 4,24 & 0,46 & 0,39 & $2,83-5,32$ & $2,64-4,36$ \\
\hline
\end{tabular}

G1 $\mathbf{n}=10$ : Machos $\mathrm{n}=5$, Fêmeas $\mathrm{n}=5$; $\mathbf{G 2 n}=\mathbf{1 0}$ : Machos $\mathrm{n}=5$, Fêmeas $\mathrm{n}=5$.

Grupo $(p=0,990)$; Sexo $(p=0,302)$; Lado $(p=0,632)$.

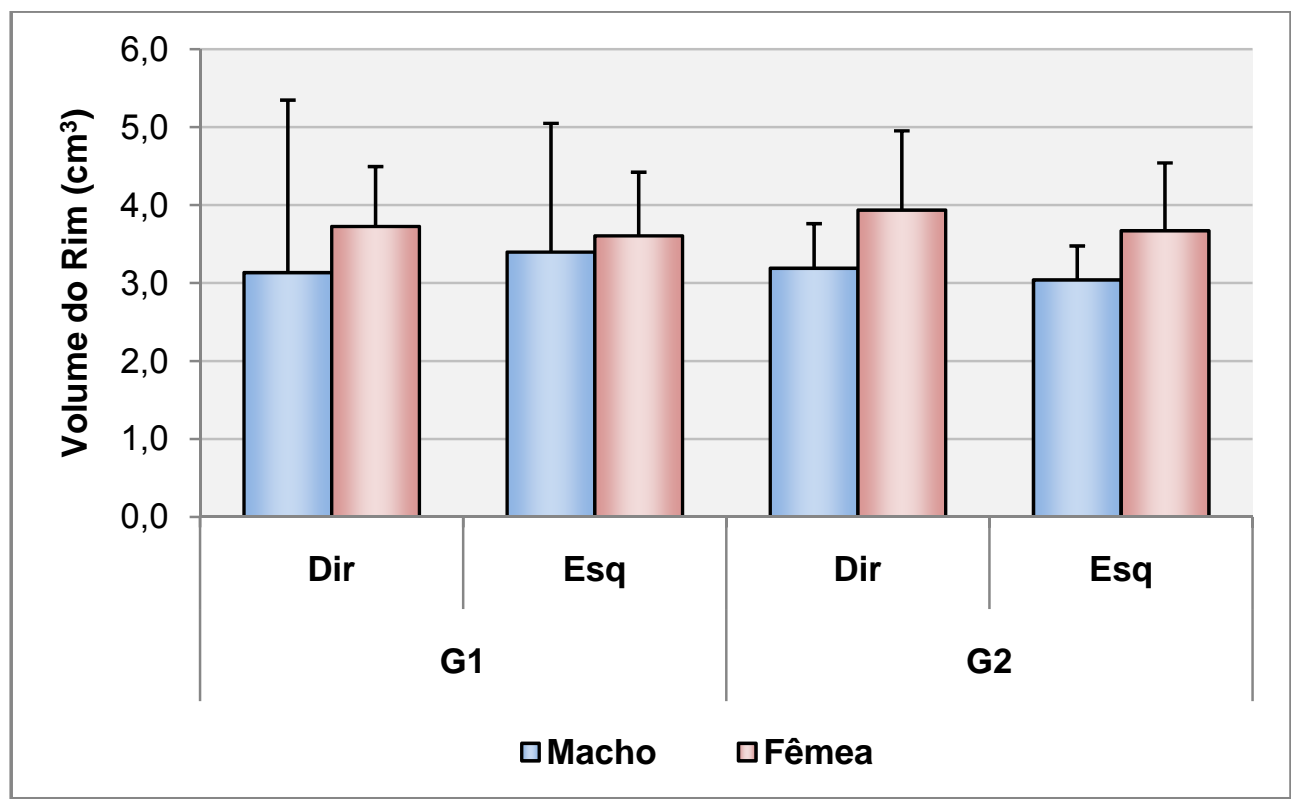

Gráfico 11 - Valores referentes ao volume $\left(\mathrm{cm}^{3}\right)$ dos rins direito e esquerdo de Callithrix jacchus machos e fêmeas dos grupos 1 e 2 
Tabela 13 - Valores referentes ao volume $\left(\mathrm{cm}^{3}\right)$ dos rins direito e esquerdo de Callithrix jacchus com alteração nos exames (sim) e sem alteração nos exames (não) dos grupos 1 e 2 Goettingen - 2009 e 2006

\section{VOLUME DOS RINS}

\begin{tabular}{|c|c|c|c|c|c|c|c|}
\hline \multicolumn{2}{|c|}{ Média \pm DP } & \multicolumn{2}{|c|}{ Mediana } & \multicolumn{2}{|c|}{ EP } & \multicolumn{2}{|c|}{ Mínimo - Máximo } \\
\hline RD & RE & RD & RE & RD & RE & RD & RE \\
\hline
\end{tabular}

\begin{tabular}{llllllllll}
\hline \hline G 1 & Não & $2,68 \pm 1,17$ & $2,68 \pm 1,10$ & 2,67 & 2,67 & 0,52 & 0,49 & $1,09-4,24$ & $1,09-3,85$ \\
\cline { 2 - 8 } & Sim & $4,18 \pm 1,72$ & $4,33 \pm 0,72$ & 4,41 & 4,16 & 0,77 & 0,32 & $1,58-6,38$ & $3,56-5,51$ \\
\hline G 2 & Não & $2,70 \pm 0,43$ & $2,62 \pm 0,19$ & 2,83 & 2,64 & 0,25 & 0,11 & $2,22-3,05$ & $2,43-2,80$ \\
\cline { 2 - 8 } & Sim & $3,93 \pm 0,74$ & $3,67 \pm 0,63$ & 3,73 & 3,61 & 0,28 & 0,24 & $3,26-5,32$ & $2,90-4,36$ \\
\hline \hline
\end{tabular}

G1 $\mathbf{n}=10:$ Não $n=5, \operatorname{Sim} n=5 ;$ G2n = 10: Não $n=3, \operatorname{Sim} n=7$.

Grupo $(p=0,593)$; Alt. Exames $(p=0,006)$; Lado $(p=0,742)$.

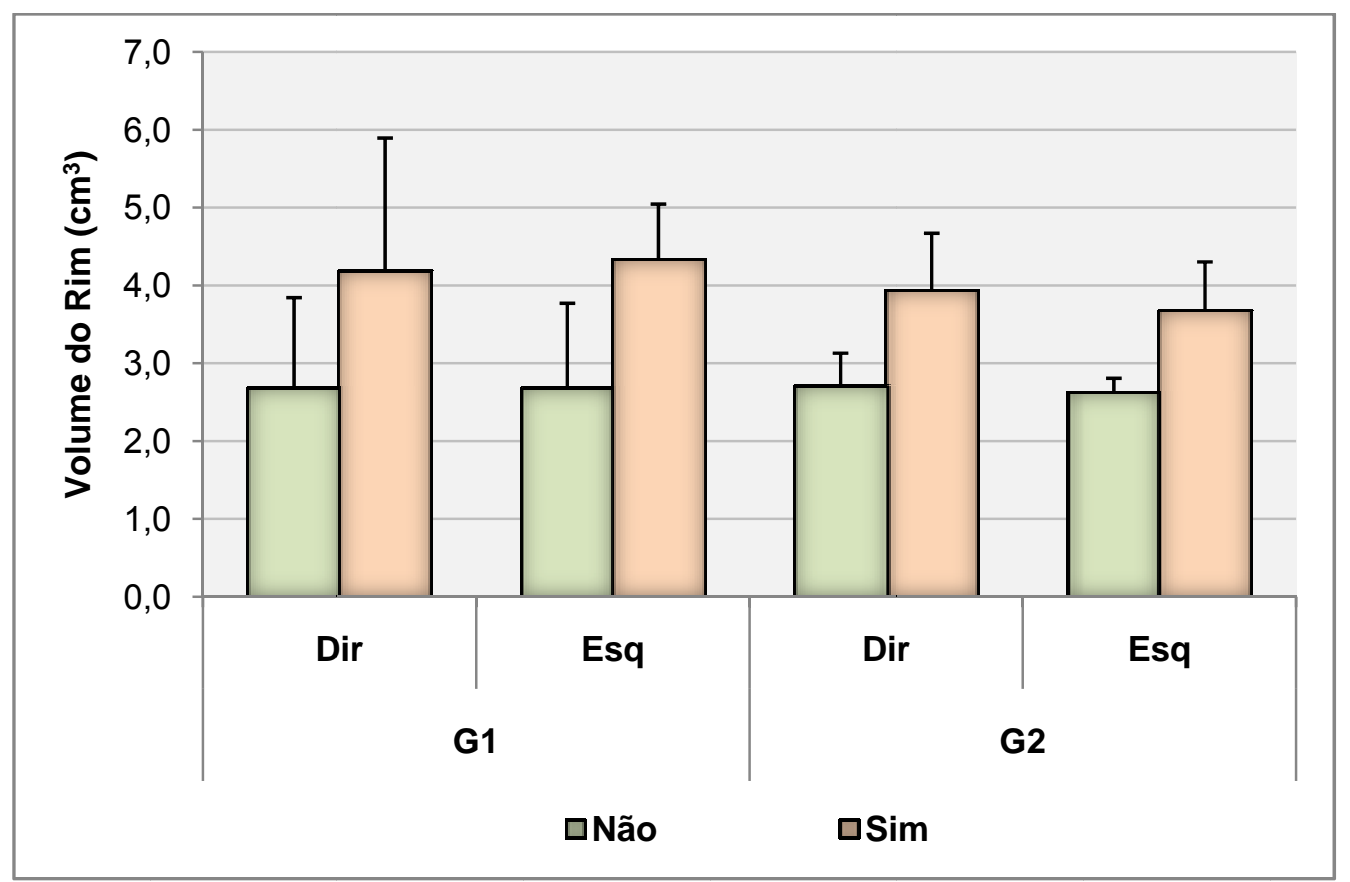

Gráfico 12 - Valores referentes ao volume $\left(\mathrm{cm}^{3}\right)$ dos rins direito e esquerdo de Callithrix jacchus com alteração nos exames ( $\operatorname{sim}$ ) e sem alteração nos exames (não) dos grupos 1 e 2 
As figuras $15,16,17,18,19$ e 20 representam as fotos da necropsia dos Callithrix jacchus deste trabalho e demonstram o posicionamento e a morfologia renal:

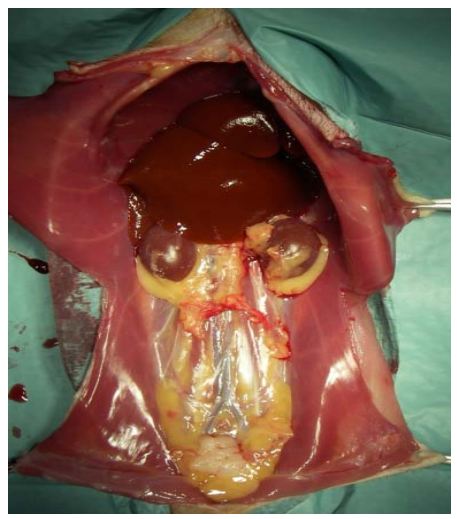

Figura 15 - Necropsia de Callithrix jacchus sem alteração nos exames, demonstrando o tamanho, o posicionamento dos rins e a quantidade de gordura na cavidade abdominal. Animal Southern

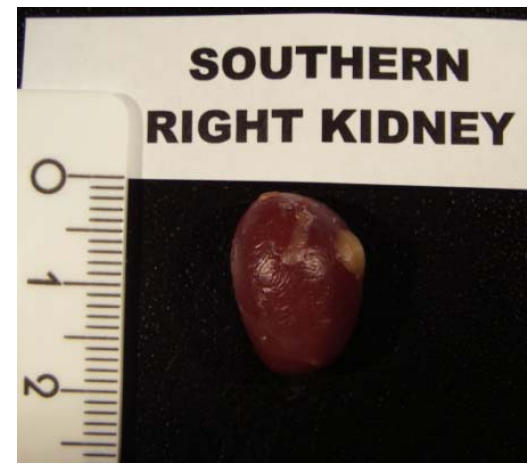

Figura 17 - Rim de Callithrix jacchus sem alteração nos exames, demonstrando tamanho e forma. Animal - Southern

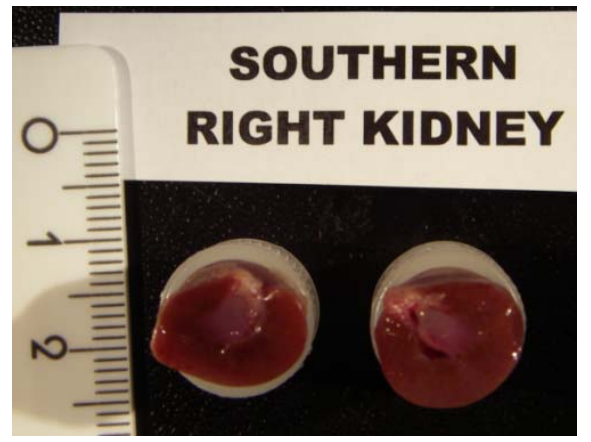

Figura 19 - Rim de Callithrix jacchus sem alteração nos exames, demonstrando morfologia interna. Animal - Southern

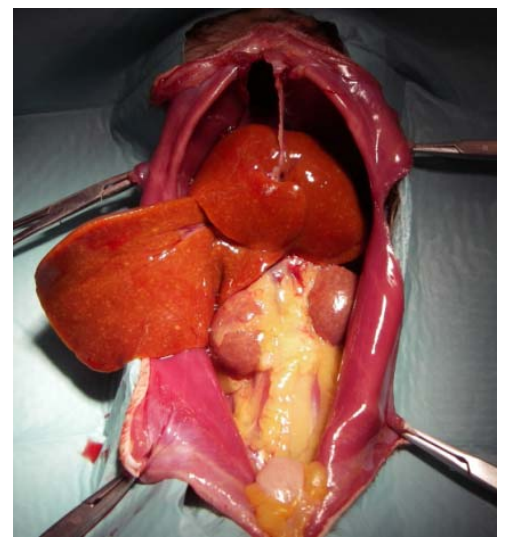

Figura 16 - Necropsia de Callithrix jacchus com alteração nos exames, demonstrando o tamanho, o posicionamento dos rins e a quantidade de gordura na cavidade abdominal. Neste caso o rim direito encontrava-se encoberto pelo fígado aumentado de tamanho. Animal - Karla

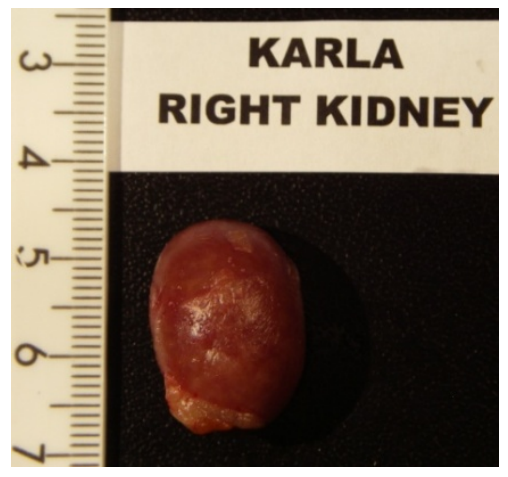

Figura 18 - Rim de Callithrix jacchus com alteração nos exames, demonstrando tamanho e forma. Animal - Karla

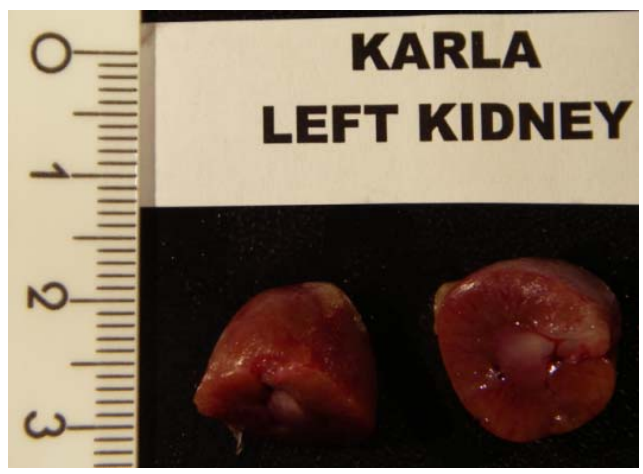

Figura 20 - Rim de Callithrix jacchus com alteração nos exames, demonstrando morfologia interna. Animal - Karla 


\subsection{MORFOMETRIA MICROSCÓPICA RENAL}

Para a microscopia renal as análises também respeitaram as abordagens considerando o fator sexo e a saúde dos animais a exemplo da macroscopia.

$\mathrm{Na}$ morfometria histológica dos rins, em nenhuma das duas abordagens a análise de variância indica haver diferença significativa quando considerado o lado, rim direito e rim esquerdo, para número de glomérulos, densidade e área glomerular $(p>0,05)$.

No primeiro tratamento, quando considerado o sexo dos animais, a análise de variância indica haver diferença significativa entre grupos em relação ao número de glomérulos $(p=0,008)$ e área glomerular $(p=0,001)$, porém a análise de variância não indica haver diferença para número de glomérulos e área glomerular entre sexo $(p>0,05)$.

Para a segunda abordagem, ou seja, quando considerado a sanidade dos animais em relação à morfometria histológica, a análise de variância indica haver diferença significativa na quantidade de glomérulos entre grupos $(p=0,004)$, mas não indica diferença significativa entre animais com alteração nos exames e sem alteração nos exames $(p=0,070)$.

Para área glomerular, considerando ainda a segunda abordagem, a análise de variância indica haver diferença significativa entre grupo 1 e $2(p<0,001)$ e entre animais com alteração nos exames e sem alteração nos exames $(p=0,036)$.

Em nenhuma das análises realizadas para microscopia renal foi verificado efeito de interação entre os fatores considerados (grupo, lado e sexo ou alteração nos exames).

As tabelas 14, 15, 16 e 17 e gráficos 13,14, 15 e 16 expressam os resultados da quantificação glomerular em número e densidade nas abordagens sexo e sanidade dos animais, para os grupos 1 e 2 .

As tabelas 18 e 19 e gráficos 17 e 18 expressam os resultados da mensuração glomerular (área glomerular) para ambas as abordagens e grupos. 
Em relação à histologia renal, a quantidade de glomérulos $\left(\mathrm{n}^{\circ}\right)$ em 30 campos de $1,51 \mathrm{~mm}^{2}$, nos rins direito e esquerdo variou de acordo com as tabelas $14 \mathrm{e} 15 \mathrm{e}$ gráficos 13 e 14 (valores da contagem glomerular - Anexo F):

Tabela 14 - Valores referentes ao número de glomérulos em 30 campos de $1,51 \mathrm{~mm}^{2}$, dos rins direito e esquerdo de Callithrix jacchus machos (M) e fêmeas $(F)$ dos grupos 1 e 2 - São Paulo $-2010$

NÚMERO DE GLOMÉRULOS

\begin{tabular}{|c|c|c|c|c|c|c|c|c|c|}
\hline & & \multicolumn{2}{|c|}{ Média \pm DP } & \multicolumn{2}{|c|}{ Mediana } & \multicolumn{2}{|c|}{ EP } & \multicolumn{2}{|c|}{ Mínimo - Máximo } \\
\hline & & RD & RE & RD & RE & RD & RE & RD & RE \\
\hline \multirow{2}{*}{ G 1} & $\mathbf{M}$ & $161,80 \pm 19,15$ & $170,20 \pm 33,10$ & 164 & 158 & 8,56 & 14,81 & $139-189$ & $139-218$ \\
\hline & $\mathbf{F}$ & $189,80 \pm 27,51$ & $192,20 \pm 24,26$ & 176 & 187 & 12,30 & 10,85 & $163-231$ & $173-234$ \\
\hline \multirow{2}{*}{ G 2} & M & $213,20 \pm 19,28$ & $225,00 \pm 15,15$ & 214 & 225 & 8,62 & 6,77 & $187-233$ & $201-238$ \\
\hline & $\mathbf{F}$ & $200,80 \pm 23,78$ & $201,60 \pm 30,78$ & 188 & 192 & 10,64 & 13,76 & $181-238$ & $174-247$ \\
\hline
\end{tabular}

G1 $\mathbf{n}=10$ : Machos $\mathrm{n}=5$, Fêmeas $\mathrm{n}=5 ; \mathbf{G 2 n}=\mathbf{1 0}$ : Machos $\mathrm{n}=5$, Fêmeas $\mathrm{n}=5$.

Grupo $(p=0,008)$; Sexo $(p=0,688)$; Lado $(p=0,075)$.

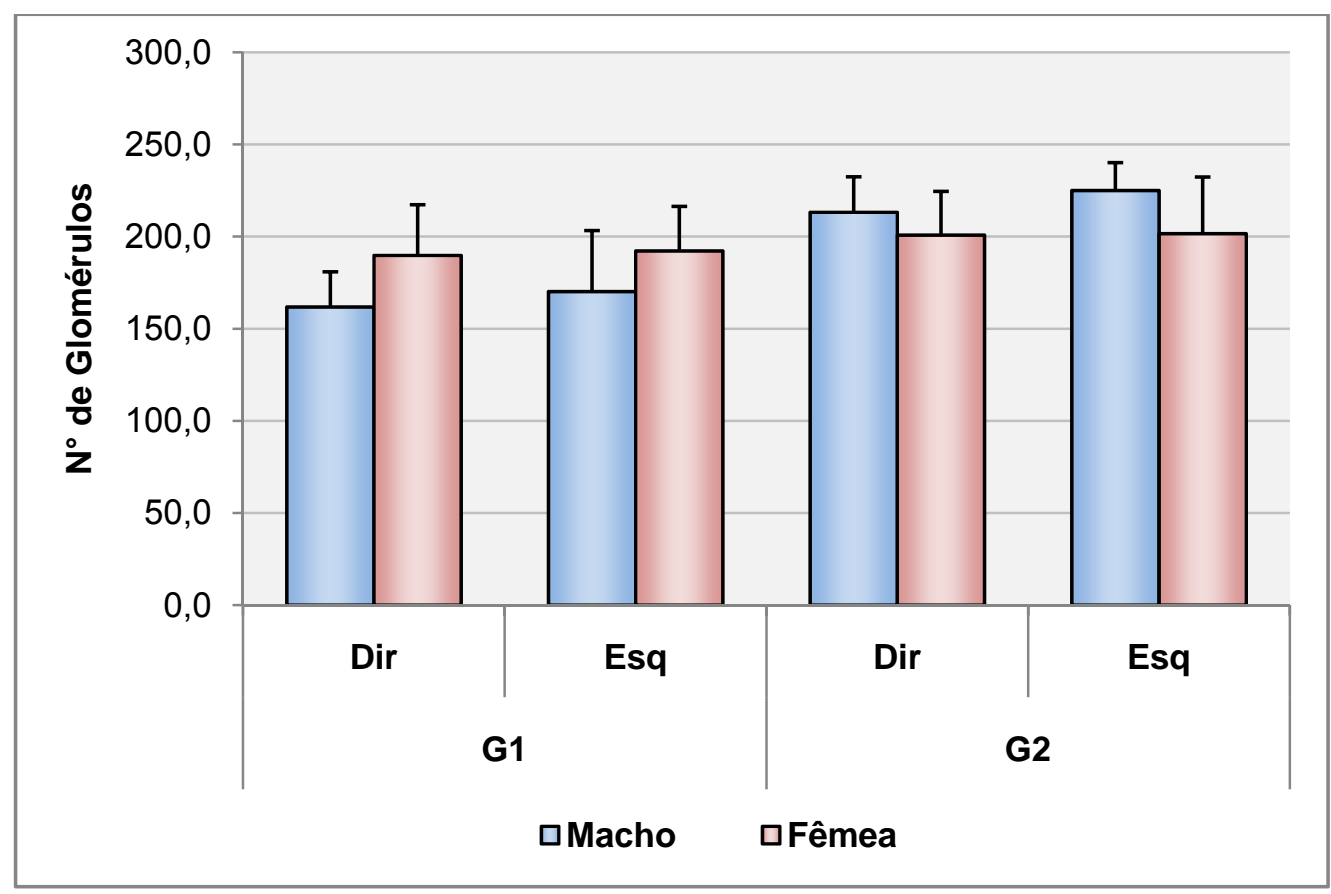

Gráfico 13 - Valores referentes ao número de glomérulos em 30 campos de $1,51 \mathrm{~mm}^{2}$, dos rins direito e esquerdo de Callithrix jacchus machos e fêmeas dos grupos 1 e 2 
Tabela 15 - Valores referentes ao número de glomérulos em 30 campos de $1,51 \mathrm{~mm}^{2}$, dos rins direito e esquerdo de Callithrix jacchus com alteração nos exames (sim) e sem alteração nos exames (não) dos grupos 1 e 2 - São Paulo - 2010

\begin{tabular}{ccccccccc}
\hline \multicolumn{7}{c}{ NÚMERO DE GLOMÉRULOS } \\
\hline \hline \multicolumn{2}{c}{ Média \pm DP } & Mediana & EP & \multicolumn{2}{c}{ Mínimo - Máximo } \\
\hline \hline RD & RE & RD & RE & RD & RE & RD & RE \\
\hline $182,80 \pm 27,4$ & $188,80 \pm 28,47$ & 175 & 189 & 12,25 & 12,73 & $164-231$ & $158-234$ \\
\hline $168,80 \pm 27,21$ & $173,60 \pm 32,13$ & 163 & 178 & 12,17 & 14,37 & $139-204$ & $139-218$ \\
\hline $227,33 \pm 14,36$ & $234,33 \pm 14,84$ & 233 & 238 & 8,29 & 8,57 & $211-238$ & $218-247$ \\
\hline $198,29 \pm 18,03$ & $204,29 \pm 24,96$ & 188 & 201 & 6,81 & 9,44 & $181-230$ & $174-238$ \\
\hline
\end{tabular}

G1 $\mathbf{n}=10$ : Não $n=5$, Sim $n=5 ;$ G2n = 10: Não $n=3, \operatorname{Sim} n=7$.

Grupo $(p=0,004)$; Alt. Exames $(p=0,070)$; Lado $(p=0,102)$.

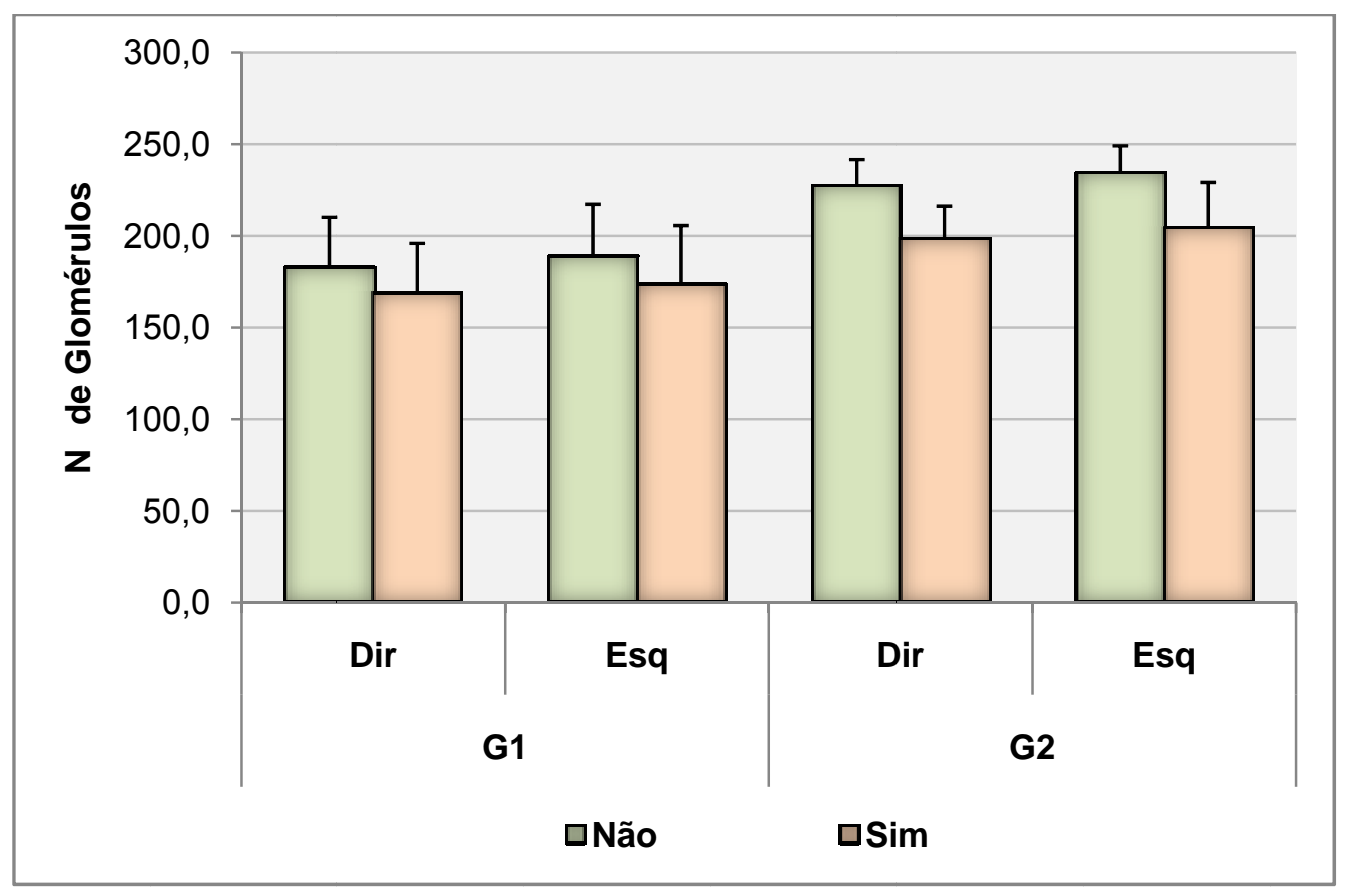

Gráfico 14 - Valores referentes ao número de glomérulos em 30 campos de $1,51 \mathrm{~mm}^{2}$, dos rins direito e esquerdo de Callithrix jacchus com alteração nos exames (sim) e sem alteração nos exames (não) dos grupos 1 e 2 
Em relação à histologia renal, a densidade glomerular $\left(\mathrm{n}^{\circ} / \mathrm{mm}^{2}\right)$ considerando 30 campos de $1,51 \mathrm{~mm}^{2}$, dos rins direito e esquerdo variou de acordo com as tabelas 16 e 17 e gráficos 15 e 16 (valores da densidade glomerular - Anexo F):

Tabela 16 - Valores referentes à densidade glomerular $\left(\mathrm{n}^{\circ} / \mathrm{mm}^{2}\right)$, dos rins direito e esquerdo de Callithrix jacchus machos $(\mathrm{M})$ e fêmeas $(\mathrm{F})$ dos grupos 1 e 2 - São Paulo - 2010

\begin{tabular}{|c|c|c|c|c|c|c|c|c|c|}
\hline & & \multicolumn{8}{|c|}{ DENSIDADE GLOMERULAR } \\
\hline & & \multicolumn{2}{|c|}{ Média \pm DP } & \multicolumn{2}{|c|}{ Mediana } & \multicolumn{2}{|c|}{ EP } & \multicolumn{2}{|c|}{ Mínimo - Máximo } \\
\hline & & RD & RE & RD & RE & RD & RE & RD & RE \\
\hline \multirow{2}{*}{ G 1} & M & $3,56 \pm 0,42$ & $3,75 \pm 0,73$ & 3,61 & 3,48 & 0,19 & 0,33 & $3,06-4,16$ & $3,06-4,80$ \\
\hline & $\mathbf{F}$ & $4,18 \pm 0,61$ & $4,23 \pm 0,53$ & 3,87 & 4,12 & 0,27 & 0,24 & $3,59-5,08$ & $3,81-5,15$ \\
\hline \multirow{2}{*}{ G 2} & $\mathbf{M}$ & $4,69 \pm 0,42$ & $4,95 \pm 0,33$ & 4,71 & 4,95 & 0,19 & 0,15 & $4,12-5,13$ & $4,42-5,24$ \\
\hline & $\mathbf{F}$ & $4,42 \pm 0,52$ & $4,44 \pm 0,68$ & 4,14 & 4,23 & 0,23 & 0,30 & $3,98-5,24$ & $3,83-5,44$ \\
\hline
\end{tabular}

G1 $\mathbf{n}=10$ : Machos $\mathrm{n}=5$, Fêmeas $\mathrm{n}=5 ;$ G2n = 10: Machos $\mathrm{n}=5$, Fêmeas $\mathrm{n}=5$. Grupo $(p=0,008)$; Sexo $(p=0,688)$; Lado $(p=0,075)$.

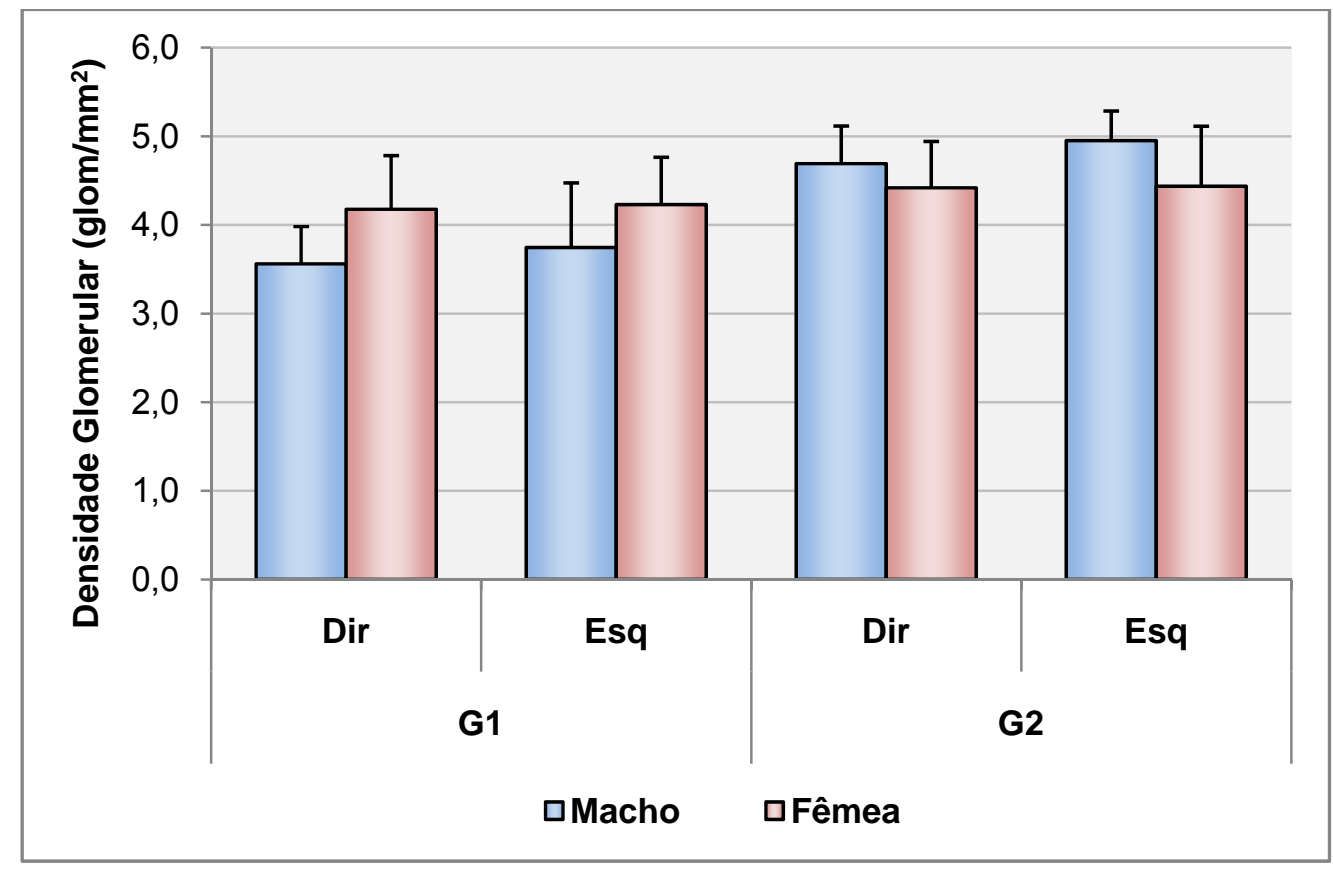

Gráfico 15 - Valores referentes à densidade glomerular $\left(\mathrm{n}^{\circ} / \mathrm{mm}^{2}\right)$, dos rins direito e esquerdo de Callithrix jacchus machos e fêmeas dos grupos 1 e 2 
Tabela 17 - Valores referentes à densidade glomerular $\left(\mathrm{n}^{\circ} / \mathrm{mm}^{2}\right)$, dos rins direito e esquerdo de Callithrix jacchus com alteração nos exames (sim) e sem alteração nos exames (não) dos grupos 1 e 2 - São Paulo - 2010

\begin{tabular}{cccccccc}
\hline \multicolumn{7}{c}{ DENSIDADE GLOMERULAR } \\
\hline \hline \multicolumn{1}{c}{ Média \pm DP } & Mediana & EP & \multicolumn{2}{c}{ Mínimo - Máximo } \\
\hline \hline RD & RE & RD & RE & RD & RE & RD & RE \\
\hline $4,02 \pm 0,60$ & $4,15 \pm 0,63$ & 3,85 & 4,16 & 0,27 & 0,28 & $3,61-5,08$ & $3,48-5,15$ \\
\hline $3,71 \pm 0,60$ & $3,82 \pm 0,71$ & 3,59 & 3,92 & 0,27 & 0,32 & $3,06-4,49$ & $3,06-4,80$ \\
\hline $5,00 \pm 0,32$ & $5,16 \pm 0,33$ & 5,13 & 5,24 & 0,18 & 0,19 & $4,64-5,23$ & $4,80-5,44$ \\
\hline $4,36 \pm 0,40$ & $4,50 \pm 0,55$ & 4,14 & 4,42 & 0,15 & 0,21 & $3,98-5,06$ & $3,83-5,24$
\end{tabular}

G1 $\mathbf{n}=10$ : Não $\mathbf{n}=5, \operatorname{Sim} \mathbf{n}=5 ;$ G2n = 10: Não $n=3, \operatorname{Sim} n=7$.

Grupo $(p=0,004)$; Alt. Exames $(p=0,070)$; Lado $(p=0,102)$.

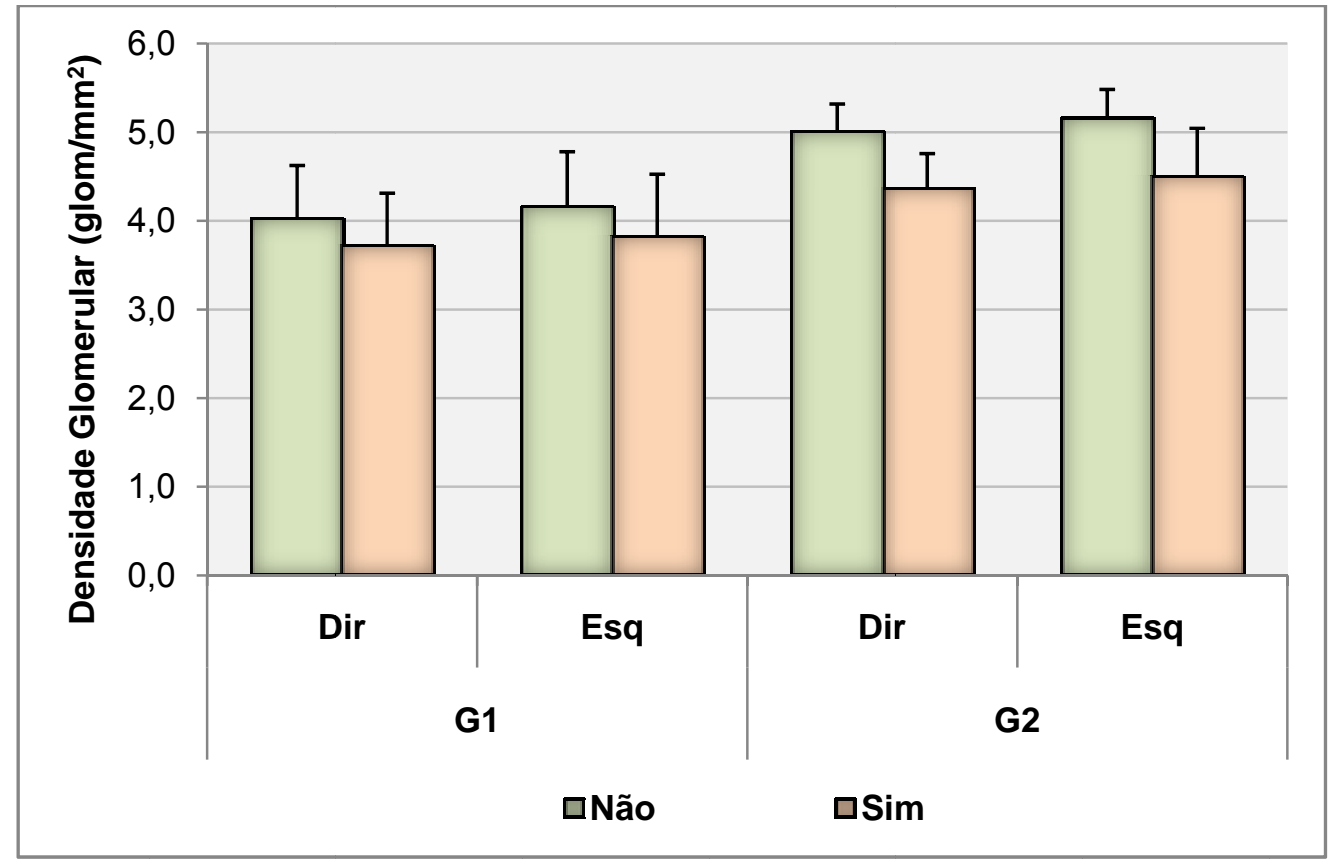

Gráfico 16 - Valores referentes à densidade glomerular $\left(\mathrm{n}^{\circ} / \mathrm{mm}^{2}\right)$, dos rins direito e esquerdo de Callithrix jacchus com alteração nos exames (sim) e sem alteração nos exames (não) dos grupos 1 e 2 
Em relação à morfometria histológica, a área glomerular média $\left(\mu \mathrm{m}^{2}\right)$ de 25 glomérulos mensurados em cada rim, direito e esquerdo, dos Callithrix jacchus dos grupos 1 e 2, variou de acordo com as tabelas 18 e 19 e gráficos 17 e 18 (valores referentes a área glomerular média - Anexo $\mathrm{H}$ ):

Tabela 18 - Valores referentes à área glomerular média $\left(\mu \mathrm{m}^{2}\right)$, dos rins direito e esquerdo de Callithrix jacchus machos (M) e fêmeas (F) dos grupos 1 e 2 - São Paulo - 2010

\begin{tabular}{ccccccccc}
\hline \multicolumn{7}{c}{ ÁREA GLOMERULAR } \\
\hline \hline \multicolumn{2}{c}{ Média \pm DP } & \multicolumn{2}{c}{ Mediana } & \multicolumn{2}{c}{ EP } & \multicolumn{2}{c}{ Mínimo - Máximo } \\
\hline \hline RD & RE & RD & RE & RD & RE & RD & RE \\
\hline $13228 \pm 1942$ & $13863 \pm 1062$ & 13167 & 13882 & 868 & 475 & $10691-16022$ & $12638-15144$ \\
\hline $14556 \pm 2299$ & $14683 \pm 2834$ & 15288 & 14628 & 1028 & 1267 & $10930-17029$ & $10592-18327$ \\
\hline $11740 \pm 1142$ & $11255 \pm 875$ & 11983 & 11118 & 511 & 391 & $10386-13134$ & $10333-12408$ \\
\hline $10874 \pm 1216$ & $11312 \pm 1173$ & 10968 & 11479 & 544 & 525 & $9041-12465$ & $9532-12470$ \\
\hline
\end{tabular}

G1 $\mathbf{n}=10$ : Machos $n=5$, Fêmeas $n=5 ;$ G2n = 10: Machos $n=5$, Fêmeas $n=5$

Grupo $(p=0,001)$; Sexo $(p=0,650)$; Lado $(p=0,456)$.

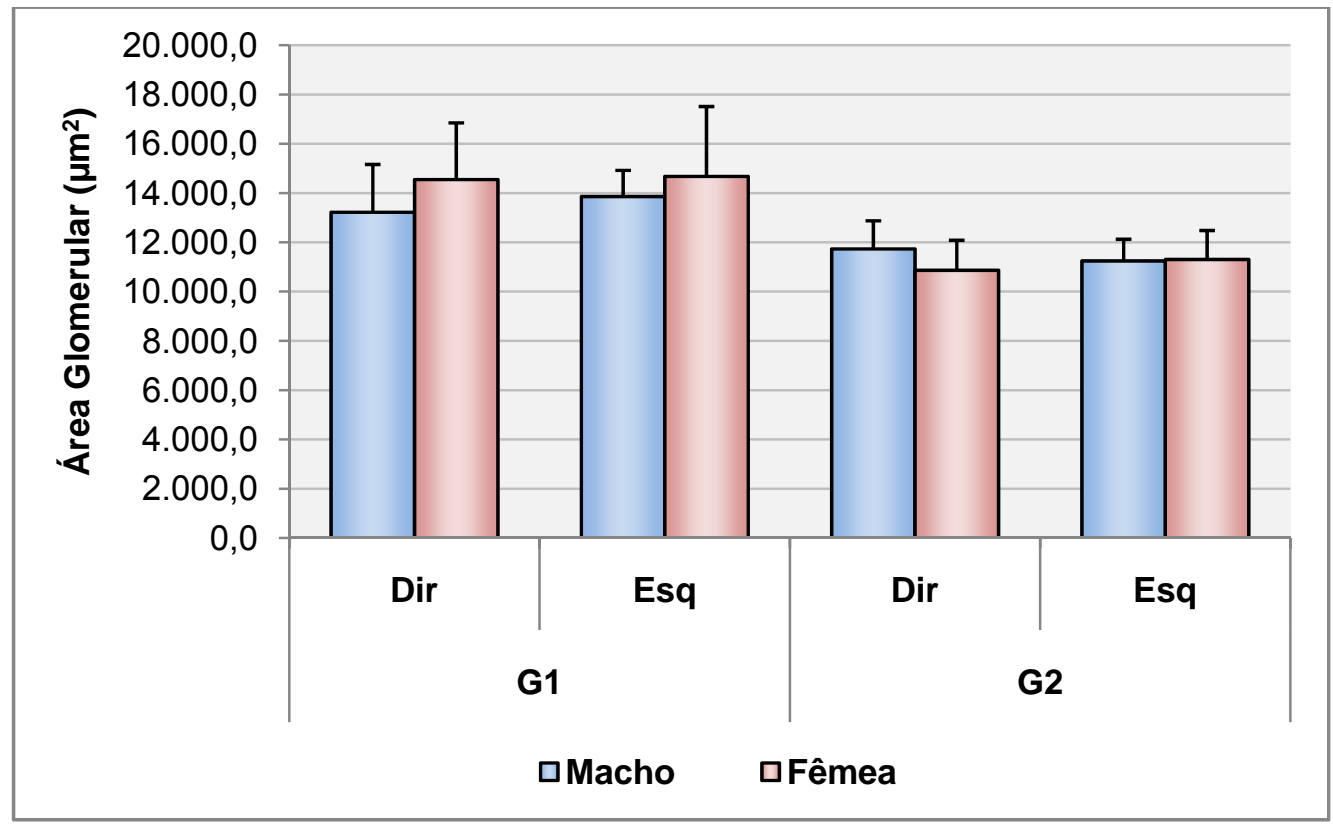

Gráfico 17 - Valores referentes à área glomerular média $\left(\mu \mathrm{m}^{2}\right)$, dos rins direito e esquerdo de Callithrix jacchus machos e fêmeas dos grupos 1 e 2 
Tabela 19 - Valores referentes à área glomerular média $\left(\mu \mathrm{m}^{2}\right)$, dos rins direito e esquerdo de Callithrix jacchus com alteração nos exames (S) e sem alteração nos exames (N) dos São Paulo - 2010 grupos 1 e 2 -

\begin{tabular}{|c|c|c|c|c|c|c|c|c|c|}
\hline & & \multicolumn{8}{|c|}{ ÁREA GLOMERULAR } \\
\hline & & \multicolumn{2}{|c|}{ Média \pm DP } & \multicolumn{2}{|c|}{ Mediana } & \multicolumn{2}{|c|}{ EP } & \multicolumn{2}{|c|}{ Mínimo - Máximo } \\
\hline & & RD & RE & RD & RE & RD & RE & RD & RE \\
\hline \multirow{2}{*}{ G 1} & $\mathbf{N}$ & $13171 \pm 1629$ & $13363 \pm 1689$ & 13167 & 13941 & 729 & 755 & $10930-15288$ & $10592-14654$ \\
\hline & $\mathbf{S}$ & $14614 \pm 2490$ & $15184 \pm 2157$ & 15556 & 15144 & 1114 & 965 & $10691-17029$ & $12638-18327$ \\
\hline \multirow{2}{*}{ G 2} & $\mathbf{N}$ & $10263 \pm 1063$ & $10249 \pm 679$ & 10780 & 10333 & 614 & 392 & $9041-10968$ & $9532-10882$ \\
\hline & $\mathbf{s}$ & $11754 \pm 1006$ & $11727 \pm 715$ & 11983 & 11863 & 380 & 270 & $10386-13134$ & $10553-12470$ \\
\hline
\end{tabular}

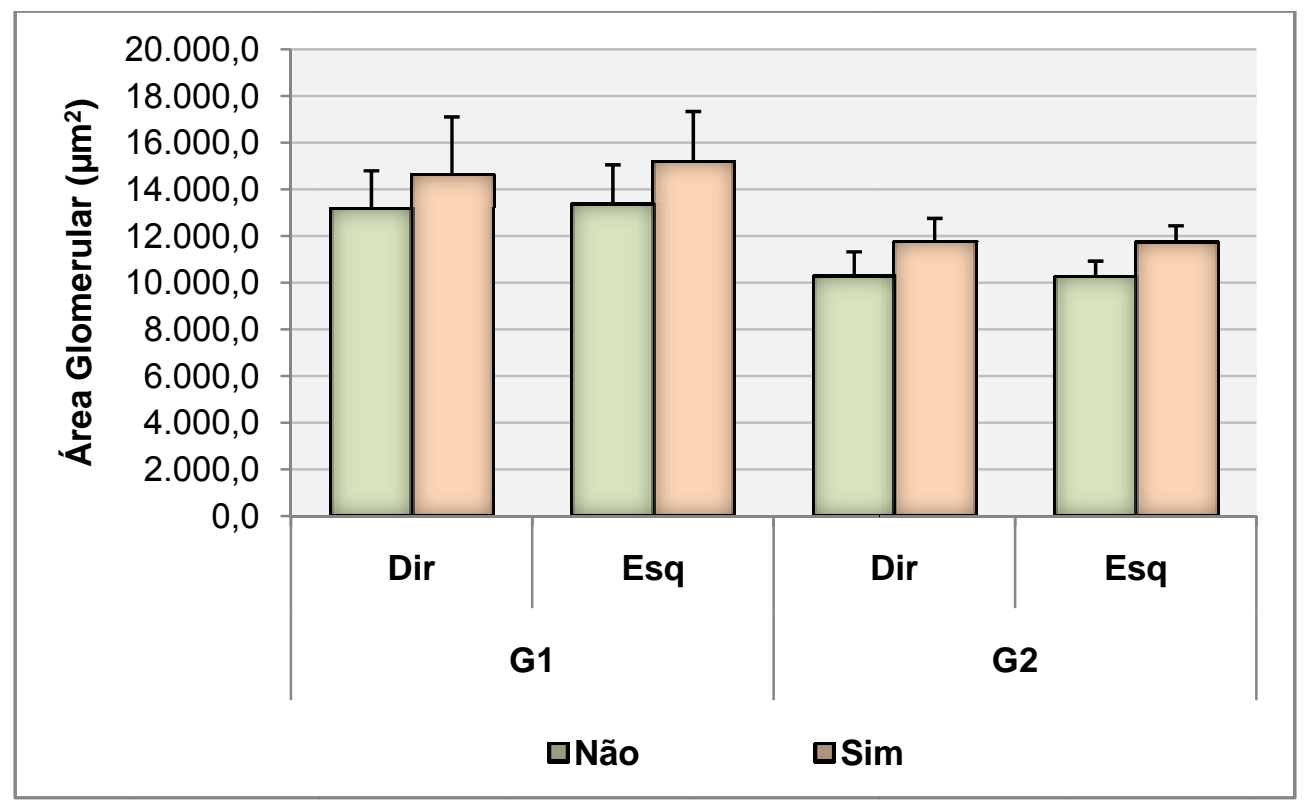

Gráfico 18 - Valores referentes à área glomerular média $\left(\mu \mathrm{m}^{2}\right)$, dos rins direito e esquerdo de Callithrix jacchus com alteração nos exames (sim) e sem alteração nos exames (não) dos grupos 1 e 2 
A distribuição de freqüência (\%) da área glomerular dos rins direito e esquerdo, em relação ao sexo e a saúde dos Callithrix jacchus dos grupos 1 e 2, está representada de acordo com os gráficos 19, 20, 21 e 22:

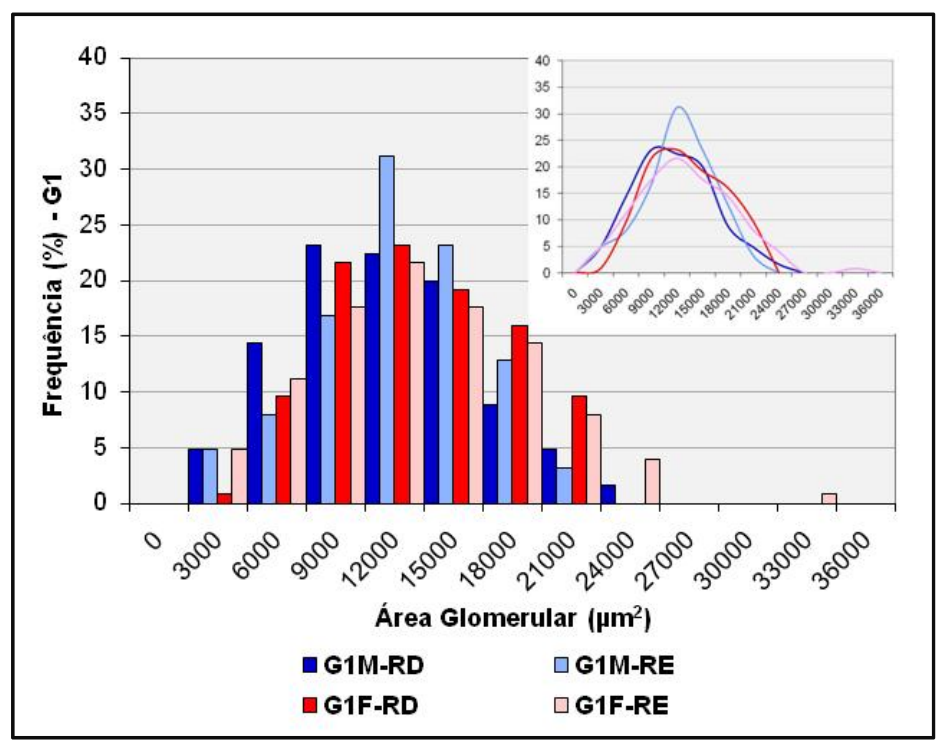

Gráfico 19 - Valores referentes à distribuição de freqüência (\%) da área glomerular média $\left(\mu \mathrm{m}^{2}\right)$, dos rins direito e esquerdo de Callithrix jacchus machos e fêmeas do grupo 1.

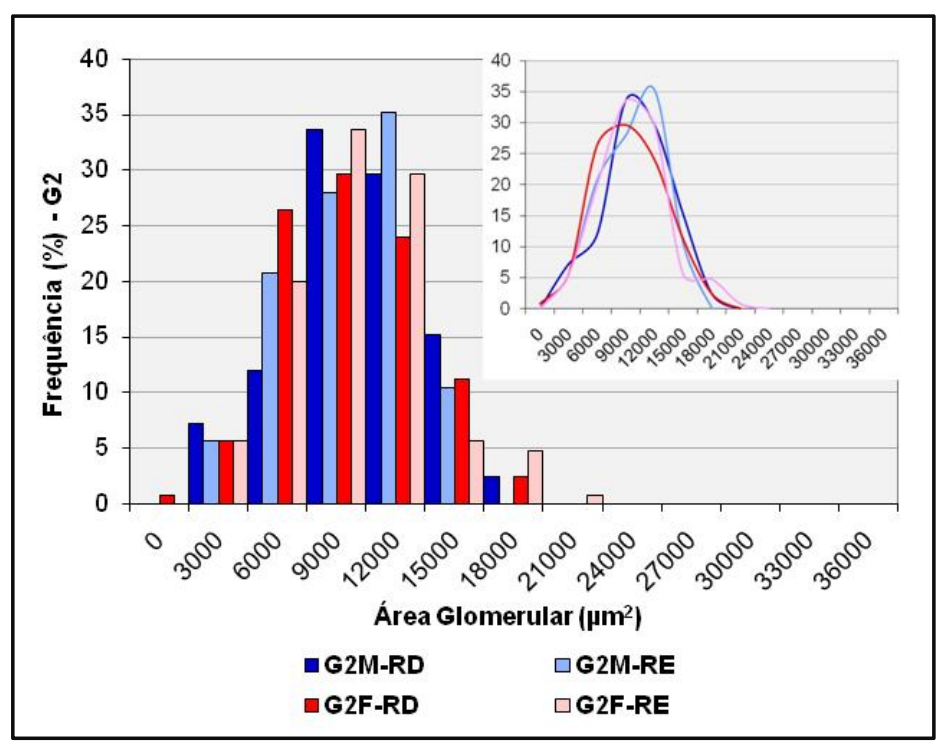

Gráfico 20 - Valores referentes à distribuição de freqüência (\%) da área glomerular média $\left(\mu m^{2}\right)$, dos rins direito e esquerdo de Callithrix jacchus machos e fêmeas do grupo 2. 


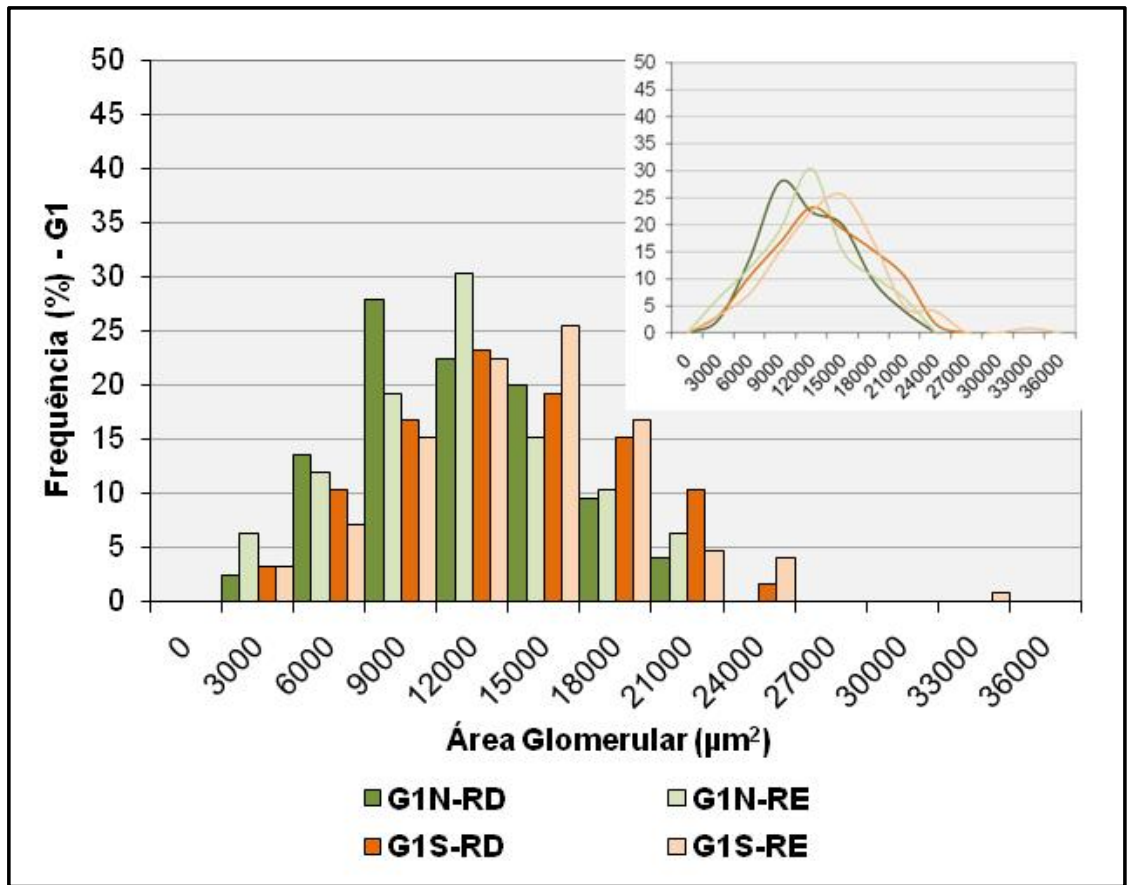

Gráfico 21 - Valores referentes à distribuição de freqüência (\%) da área glomerular média $\left(\mu \mathrm{m}^{2}\right)$, dos rins direito e esquerdo de Callithrix jacchus com alteração nos exames (sim) e sem alteração nos exames (não) do grupo 1.

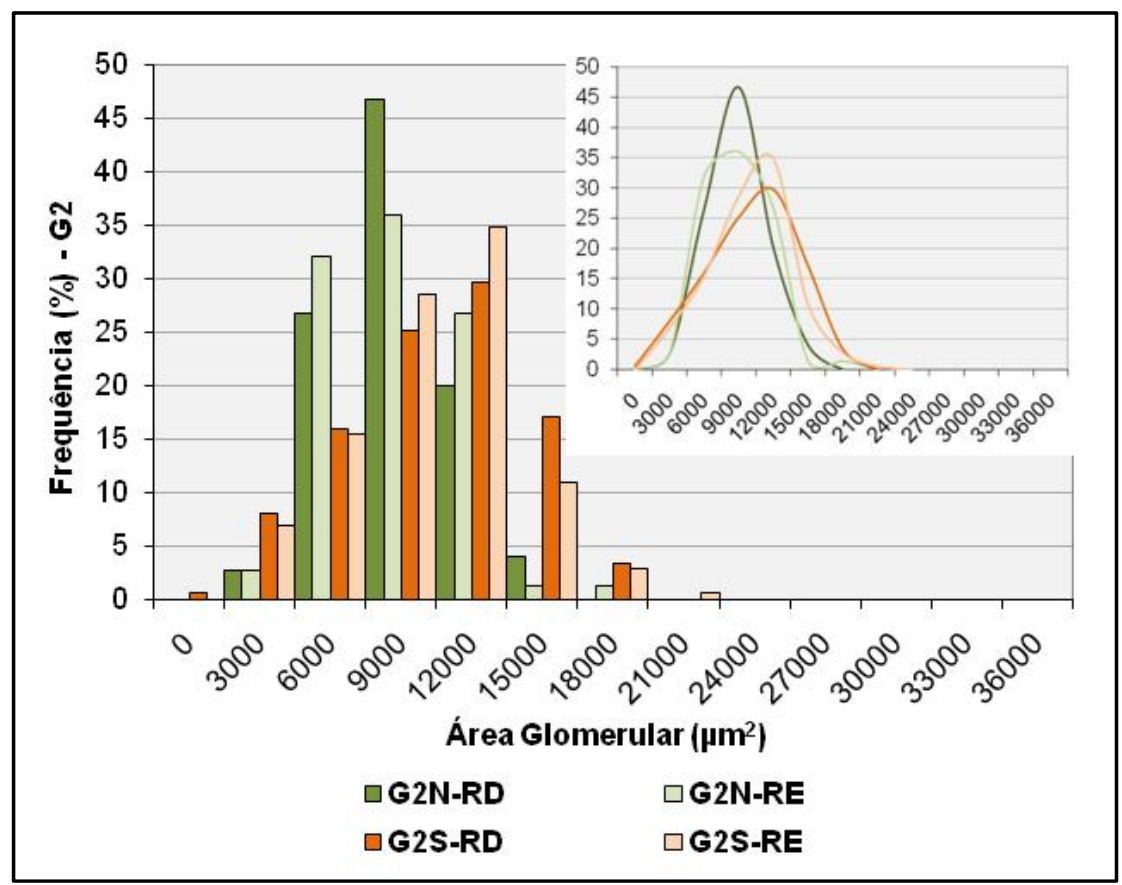

Gráfico 22 - Valores referentes à distribuição de freqüência (\%) da área glomerular média $\left(\mu m^{2}\right)$, dos rins direito e esquerdo de Callithrix jacchus com alteração nos exames (sim) e sem alteração nos exames (não) do grupo 2. 
As figuras 21 e 22 representam os cortes histológicos para quantificação de glomérulos por campo e mensuração da área glomerular dos glomérulos sorteados:

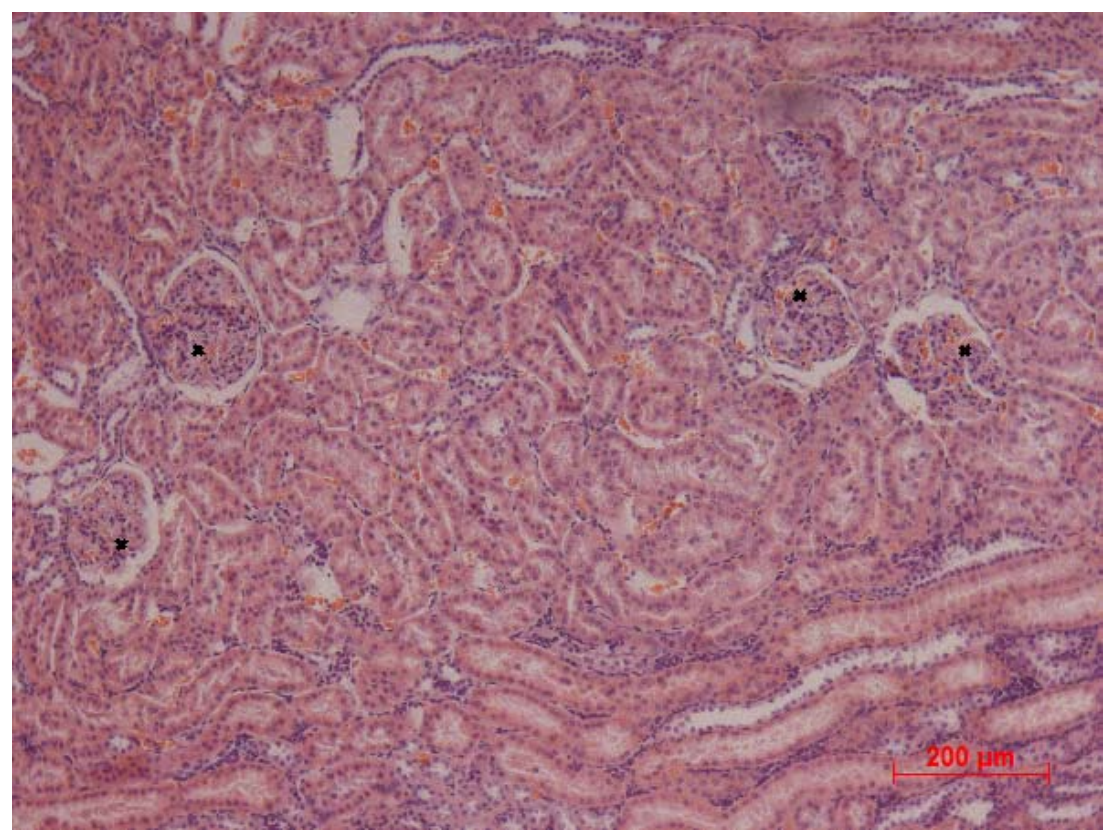

Figura 21 - Corte histológico de rim de Callithrix jacchus demonstrando quantificação glomerular

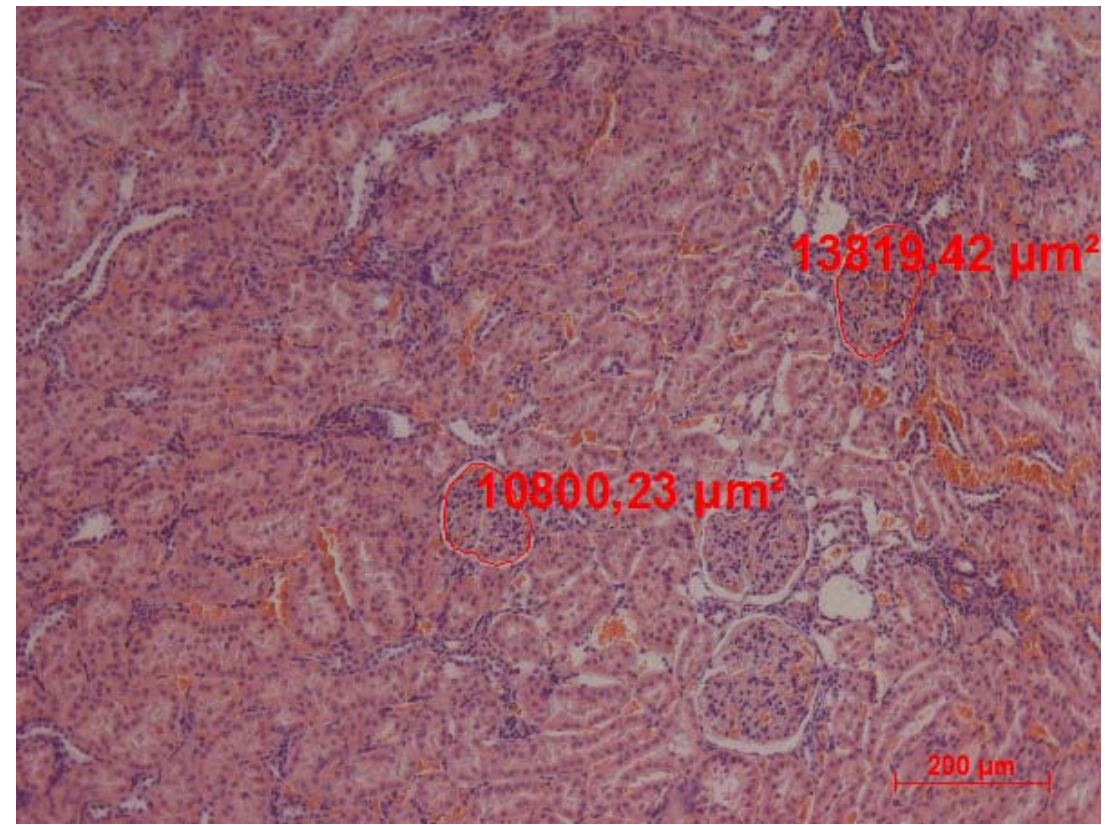

Figura 22 - Corte histológico de rim de Callithrix jacchus demonstrando mensuração da área glomerular 


\section{DISCUSSÃO}

Uma alta incidência de doença renal tem sido descrita em sagüis e micos de varias espécies, incluindo Callithrix jacchus. Estudos mostraram que a nefropatia progressiva, caracterizada por depósitos mesangiais de lgM, proliferação celular mesangial, excesso de matriz mesangial e, finalmente glomeruloesclerose vem acometendo estas espécies em cativeiro (BRACK et al., 1999).

Alguns estudos nos animais do DPZ demonstraram que os animais lá instalados apresentaram algum tipo de alteração renal (BRACK; ROTHE, 1981; GAETSMAN, 1987, BRACK; WEBBER, 1995; BRACK et al., 1999; VALLE, 2008).

A observação do histórico com sinais de doença renal em callitriquídeos motivou o planejamento deste estudo avaliando os dados comparando machos e fêmeas, jovens e adultos, mas também, dados relacionando a sanidade dos animais, com resultados de exames que fossem relevantes sobre a saúde renal destes animais ou que pudessem indicar alterações metabólicas que pudessem influenciar no resultado deste estudo.

Segundo Brack e Weber (1995) as desordens que acometem os rins, começam nos primeiros anos de vida na idade infantil, mas já no primeiro ano de idade afeta cerca de $70 \%$ dos callitriquídeos examinados, portanto em nossos estudos todos os animais até mesmo os mais jovens passaram por exames laboratoriais que pudessem indicar sinais destas desordens e apenas os mais velhos passaram por exames histológicos, devendo-se ao fato de que as alterações histopatológicas são mais evidentes com a cronicidade do processo.

Os exames de proteinúria e hematúria foram realizados para evidenciar sinais de nefropatia. A proteinúria é considerada o primeiro sinal de nefropatia e a hematúria o primeiro achado clínico em $75 \%$ dos humanos nefropatas (PESSEGUEIRO; BARATA; CORREIA, 2003; VASCONCELLOS, PENIDO e VIDIGAL, 2005).

Segundo Valle (2008), em seu estudo com 33 Callithrix jacchus do DPZ, a proteinúria com hematúria podem ser os melhores parâmetros para verificação da condição renal dos animais.

Neste estudo os 12 animais considerados com alteração, apresentaram proteinúria e hematúria com variação entre 1 e 4 cruzes nos exames com fita de 
urina, e proteinúria acima do normal no exame que avalia a razão da concentração de albumina/creatinina na urina.

Gatesman (1987) em um estudo com outras espécies de callitriquídeos também da colônia do DPZ, relatou que a doença renal é evidenciada por hematúria e que a proteinúria e a formação de cilindros estavam presentes em animais aparentemente saudáveis. Potkay (1992) encontrou em outra colônia de callitriquídeos, lesões renais que ocorreram em $90 \%$ dos seus membros, com sinais clínicos variando em hematúria transitória ou contínua com proteinúria e cilindros urinários. Dos 20 animais neste estudo apenas 1 não apresentou alteração nos exames de proteinúria e hematúria, e mesmo os animais considerados sadios em algum momento apresentaram alguma evidência, mesmo discreta de proteína e sangue na urina.

Em relação à bioquímica sérica, os resultados para todos os animais foram considerados normais, apresentando, para uréia e creatinina valores dentro do limite de normalidade segundo Yarbrought et al. (1984), o que demonstra neste estudo, que estes parâmetros não são ideais para identificar possíveis alterações e conseqüentemente, verificar a presença de doença renal nos Callitrihix jacchus. Em contra partida, comparando estes resultados, a urinálise foi considerada mais relevante para auxiliar na divisão dos grupos relacionando a saúde dos animais.

Exames de uréia e creatinina sérica têm sido evidenciados por alguns autores como o teste diagnóstico para a avaliação da doença renal em animais domésticos, como sugeriram Hackendal e Citino (2005), mas em estudos com callitriquídeos estes exames não se mostraram tão eficientes (VALLE, 2008).

Foi realizado exame de curva glicêmica para todos os animais deste estudo, já que as doenças glomerulares em humanos, entre outros fatores podem estar relacionados à diabetes (ALPERS, 2004).

O diagnóstico de diabetes segundo Gross et al. (2002) baseia-se nas alterações da glicose plasmática em jejum ou após uma sobrecarga de glicose e o teste oral de tolerância à glicose é o método de referência, onde a presença de diabetes pode ser considerada quando o valor da glicemia após 2 horas da administração de $75 \mathrm{~g}$ de glicose for $\geq 200 \mathrm{mg} / \mathrm{dl}$, e diminuição da tolerância a glicose quando a taxa for $\geq 140$ e $<200 \mathrm{mg} / \mathrm{dl}$.

Dos 20 Callithrix jacchus deste estudo, 10 apresentaram um pico de glicose plasmática após sobrecarga de glicose maior que $200 \mathrm{mg} / \mathrm{dl}$ e em alguns casos 
chegando a $351 \mathrm{mg} / \mathrm{dl}$, o que nos indica uma tolerância a glicose afetada. Estes resultados corroboram com Shchlumbohm et al. (2005) que relataram animais com alterações na tolerância a glicose, com glicemia de 237,99 $\pm 48,46$, e animais intolerantes à glicose, com glicemia de $356,53 \mathrm{mg} / \mathrm{dl} \pm 34,77$, em ambas as situações após a sobrecarga de glicose.

As doenças glomerulares constituem alguns dos maiores problemas em nefrologia, podendo ser glomerulonefrites primárias ou secundárias as quais afetaram a estrutura glomerular, estas alterações podem estar associadas a alguma doença dentre elas a diabetes (ALPERS, 2004). Em decorrência destes fatores 10 animais entre 6 e 8 anos de idade foram submetidos a exame histológico onde 9 apresentaram alterações baseado no escore total, mas todos apresentaram algum grau de glomerulonefrite variando de escore 1 a 3 , e destes 10, apenas 2 não apresentaram tolerância à glicose alterada e 3 não apresentaram alteração na urinálise.

Idealmente estes testes deveriam detectar anormalidades cedo o possível para que uma terapia pudesse ser instaurada e com isso prevenir a morbidade e a mortalidade associada à doença renal (VALLE, 2008), mas estes resultados mostram que apenas um teste não é suficiente para detectar alterações renais e a correlação entre seus resultados pode ser mais eficiente, ou ainda que estas alterações possam ser relativas a um conjunto de alterações metabólicas, como por exemplo, variações nutricionais e alterações no metabolismo da glicose.

A partir destes dados as análises que se seguiram foram realizadas considerando sexo, idade, saúde dos animais e quando comparados aspectos relativos aos rins, foram considerados os lados (direito e esquerdo).

Quando comparados o peso dos animais jovens e adultos, macho e fêmeas, a média apresentada para cada um destes grupos não foi significativamente diferente. Estes resultados corroboram com Araújo et al. (2000) e Boere et al. (2005) que realizaram estudos com outras colônias de callitriquídeos e também não verificaram diferenças entre machos e fêmeas.

Podemos dizer ainda que a média de peso encontrada nestes animais do DPZ $(422,45 \mathrm{~g} \pm 59,83)$ é semelhante com as médias encontradas por estes autores quando se trata de animais de cativeiro, mas segundo Diniz (1997), o Araújo et al. (2000) e Valle (2008) é maior quando comparada com animais de vida livre. 
Foi relatado por Araújo et al. (2000) em estudo com 243 indivíduos, que em vida livre os machos pesaram entre 282,8 a $352 \mathrm{~g}$ e as fêmeas pesaram entre 281,6 a $362,4 \mathrm{~g}$ e em cativeiro os machos pesaram entre 317,1 a $378,1 \mathrm{~g}$ e as fêmeas pesaram entre 309,3 a 410,1g, e Valle et al. (2005) em estudo com 33 callitriquídeos do DPZ relataram que os animais com peso superior a $400 \mathrm{~g}$ chegava a $70 \%$ dos animais do estudo, e que segundo Diniz (1997) o peso em vida livre não passa de $400 \mathrm{~g}$.

Apesar de não haver diferença significativa $(p=0,082)$, neste estudo, quando comparado o peso dos animais sem alteração nos exames $(394 \mathrm{~g} \pm 62,43)$ com o peso dos animais com alteração nos exames $(441,41 \mathrm{~g} \pm 52,17)$, existe uma indicação de diferença que mostra que os animais alterados são mais pesados individualmente, podendo ser considerados, em relação ao padrão normal da espécie, obesos, o que poderia explicar as alterações nos exames de glicemia e conseqüentemente nos testes urinários.

Em estudo comparando cães obesos com cães magros, Henegar et al. (2001) encontraram mudança nos peso dos rins e alterações estruturais no parênquima renal de cães obesos, mostrando que uma dieta com alto teor de gordura provocou alterações vasculares que refletiram em alterações estruturais e funcionais dos rins. Estas alterações também foram encontradas neste estudo já que os animais que apresentaram alteração nos exames laboratoriais apresentaram também maior peso corpóreo, além de apresentarem maior tamanho (comprimento, altura e largura), peso e volume dos rins e ainda, maior área glomerular, em contraste com os animais sem alterações nos exames.

De maneira geral à macroscopia, os rins direito e esquerdo dos callitriquídeos deste estudo não diferiram em relação à idade ou sexo, mas se apresentaram maiores em suas mensurações anatômicas (comprimento, altura e largura) além de mais pesados e em conseqüência, com maior volume nos animais que apresentaram alterações nos exames $(p<0,05)$.

Em contraste com os resultados de Gaschen, Menninger e Schuurman (2000), que através de exames ultrassonográficos em Macaca fascicularis, relataram que as formas dos rins direito e esquerdo não são idênticas, Hill (1999) realizou estudos com 136 fêmeas de macacos rhesus (Macaca mulatta), que apesar da diferença de idade peso dos animais e mensurações anatômicas do esqueleto, estas fêmeas, possuíam rins de tamanho similar. O mesmo ocorreu neste estudo, onde às 
mensurações macro e microscópicas houve similaridade bilateral entre os rins para todos os animais.

Sampaio e Araújo (2002) obtiveram medidas lineares de 35 cães adultos (18 fêmeas e 17 machos) com idade entre 2 e 6 anos, através de exames ultrassonográficos. Os animais foram divididos em três grupos de acordo com o peso corporal (3,1 a 10,0 kg; 10,1 a 20,0 kg e 20,1 a 45,0 kg) e as medidas lineares compreenderam comprimento $(C)$, largura $(L)$ e espessura $(E)$, e o volume renal foi calculado a partir das medidas lineares utilizando-se a fórmula para o volume de um elipsóide. Os valores médios encontrados para os três grupos foram, respectivamente: comprimento $(4,73 ; 6,09$ e 7,13cm), largura $(2,81 ; 3,44$ e $3,95 \mathrm{~cm})$, espessura $\left(2,43 ; 3,00\right.$ e 3,58cm) e volume $\left(17,98 ; 33,36\right.$ e 53,81 $\left.\mathrm{cm}^{3}\right)$. As dimensões dos rins esquerdo e direito e de machos e fêmeas foram equivalentes.

Em estudo com Callithrix jacchus juvenis e adultos em cativeiro, Wadsworth, Budgett e Forster (1981) relataram que o peso renal dos machos variou entre 0,794 e 2,381g (média de 1,648g) e das fêmeas entre 1,106 e 2,636g (média de 1,755g), obtendo uma variação semelhante a deste estudo como demonstrou a tabela 10 e o gráfico 9, do ítem 4 (Resultados).

A doença renal pode estar associada ao tamanho dos rins. As nefrites interticiais crônicas muitas vezes resultam em diminuição do tamanho dos rins, mas condições como pielonefrite aguda, doença policística, hidronefrose, neoplasias, amiloidose e nefrite glomerular podem levar ao aumento do órgão (BARR; HOLT; GIBBS, 1990; KEALY; SAMPAIO; ARAÚJO, 2002; MCALLISTER, 2005).

Outro fator que pode provocar aumento no tamanho, peso e volume dos rins é a hiperglicemia, o que pode explicar os resultados obtidos quando comparado as mensurações anatômicas dos rins com o fator saúde dos animais.

Em estudos com ratos diabéticos Christiansen, Stødkilde-Jørgensen e Flyvbjerg (1997) relatam que os animais que não obtiveram tratamento apresentaram um aumento de volume renal quando mensurados através de Ressonância Magnética in vivo, e um aumento do peso renal in vitro, quando comparados com animais controles não-diabéticos. Em outro estudo Christiansen et al. (1997), após a indução da diabetes os animais apresentaram aumento dos rins em 4 dias e após 30 dias este aumento chegava a 73\%, com aumento do córtex (63\%) e medula (69\%), sem alterações no volume da pelve. Após tratamento com administração de insulina houve redução abrupta do volume renal para $21 \%$, volume 
do córtex para $27 \%$ e volume da medula para $18 \%$, e após 4 dias todos os três parâmetros eram similares com aqueles vistos nos animais não-diabéticos controle.

Wirta et al. (1996) estudaram 150 pacientes humanos com diabetes não insulino-dependentes (NIDD) utilizando um grupo controle de indivíduos não diabéticos. Eles relatam que a taxa de filtração glomerular é elevada em pacientes NIDD iniciais e que rins em pacientes diabéticos para qualquer nível de falência renal são maiores do que rins de indivíduos não-diabéticos. Foi encontrada uma relação direta entre tamanho dos rins no início da doença e a taxa de filtração glomerular após 6 anos.

Os resultados mostrados na microscopia revelam uma diferença na quantidade de glomérulos e conseqüentemente na densidade glomerular quando comparado a idade dos animais, ou seja, os animais mais jovens (grupo 1) apresentaram menor número de glomérulos que os animais mais velhos (grupo 2). Porém os resultados para as mensurações da área glomerular foram inversamente proporcionais aos resultados da quantificação glomerular, onde os animais mais jovens apresentaram uma superfície de área glomerular maior que os animais mais velhos. Em ambas as mensurações, ou seja, tanto para a quantificação quanto para a mensuração da área glomerular, os resultados não foram significativamente diferentes para machos e fêmeas ou para rim direito e esquerdo.

MacNamara et al. (2009) realizaram estudo com humanos em países do continente Africano que consistiu na associação entre idade, superfície corpórea, com número de glomérulos e volume glomerular individual (IGV). Para tal, dividiram 24 senegaleses homens em dois grupos com 12 indivíduos cada, separados por idade de 20 a 30 anos e 50 a 70 anos. Não foram encontradas diferenças significativas em relação à quantidade de glomérulos nos grupos, mas foi relatado que rins com menos de 1 milhão de néfrons apresentaram média de IGV significativamente maior que em rins com mais de 1 milhão néfrons, e a escala reduzida de indivíduos dentro IGVs foi inversamente proporcional, correlacionado com o número total de glomérulos.

Os resultados da quantificação e mensuração glomerular deste trabalho interagem com os relatados de McNamara et al. (2009) pois ambos os estudos mostraram que a relação número de glomérulos com tamanho glomerular é inversamente proporcional. 
Outro dado importante é quando levamos em consideração a sanidade dos animais. Os animais com alteração nos exames apresentaram uma área glomerular maior que os animais sem alteração nos exames e, apesar de não existir diferença significativa $(p=0,070)$, existe a indicação de que animais com alteração nos exames apresentem menor quantidade de glomérulos e com isso menor densidade glomerular.

Em ratos de 3 meses de idade submetidos a uma restrição alimentar de $50 \%$ intra-uterina houve diminuição do número de néfrons com diâmetro glomerular aumentado, o que sugere hipertrofia compensatória que pode ser caracterizada como um evento inicial de dano glomerular. Os resultados também mostraram redução na taxa de filtração glomerular, maior porcentagem de glomérulos com esclerose e, estudos de imunohistoquímica mostraram aumento da expressão de desmina em glomérulos, sugerindo lesão podócitos (REGINA et al., 2001).

Alterações no metabolismo como a hiperglicemia é uma causa potencial importante de alterações glomerulares. A redução no número de néfrons está associada com a hipertrofia glomerular compensatória e susceptibilidade aumentada à progressão da doença renal. A exposição intra-uterina à hiperglicemia leva a um déficit glomerular, com conseqüentes problemas renais (AMRI et al., 1999; GROSS; AMANN; RITZ, 2005). Além disso, há alteração da função renal na prole de mães insulino-dependentes, com diabetes mellitus (MUGHAL et al. 2005).

Segundo Valle (2008) os Callithrix jacchus do DPZ recebem uma dieta que diverge da dieta natural desta espécie e em comparação com outros centros de primatologia, os animais do DPZ apresentaram mais alterações morfológicas renais.

Os resultados da morfometria macro e microscópica, aliados aos resultados dos exames laboratoriais e histológicos, podem estar associados a algum tipo de alteração orgânica de caráter metabólico e ou nutricional, em virtude de alguns estudos demonstrem que existe associação entre alterações renais e nutricionais, principalmente em uma fase muito jovem da vida, e também associam estas alterações renais às doenças metabólicas, como a diabetes. 


\section{CONCLUSÃO}

A partir da análise dos resultados obtidos podemos concluir que:

O peso corpóreo dos animais do DPZ, apesar de acima da média prevista na literatura, não apresentou diferença significativa em relação à idade $(p=0,454)$, sexo $(p=0,170)$ e saúde dos animais $(p=0,082)$, apesar de denotar uma indicação de diferença, mostrando que os animais com alteração nos exames tem peso maior $(441 \mathrm{~g} \pm 52,17)$ que os animais com alteração nos exames $(394 \mathrm{~g} \pm 62,43)$.

Na mensuração anatômica, não houve diferença no comprimento, altura, peso e volume dos rins, em relação à idade, sexo ou lado $(p>0,05)$, a exceção da largura que não apresentou diferença em relação ao sexo e lado, mas apresentou diferença em relação à idade $(p=0,004)$.

Ainda para a mensuração anatômica, em todos os parâmetros mesurados, houve diferença significativa $(p<0,05)$, em relação à saúde dos animais, onde os animais com alteração nos exames apresentaram um rim de maior tamanho (comprimento, altura e largura), mais pesado e com maior volume do que os animais sem alteração nos exames.

Na morfometria microscópica, não foram observadas diferenças significativas entre rim direito e esquerdo e machos e fêmeas, em relação à quantificação e mensuração da área glomerular ( $p>0,05)$, mas foram observadas, para estes mesmos parâmetros, diferenças entre idade dos animais, onde animais mais jovens (grupo 1) apresentaram menor número de glomérulos quantificados ( $p=0,004$ ) porém com maior área glomerular $(p<0,001)$ e o inverso ocorreu para os animais mais velhos (grupo 2). Em relação à saúde dos animais a área glomerular média foi maior para animais com alteração nos exames $(p=0,036)$ e apesar de não haver diferença significativa ( $p=0,070$ ), existe uma indicação de que o número de glomérulos quantificados em animais com alteração nos exames é menor que em animais sadios, tanto no grupo $1(168,80 \pm 27,21 ; 182,80 \pm 27,4)$ como no grupo 2 $(198,29 \pm 18,03 ; 227,33 \pm 14,36)$. 


\section{REFERÊNCIAS}

ABBOTT, D. H.; BARNETT, D. K.; COLMAN, R. J.; YAMAMOTO, M. E.; SCHULTZDARKEN, N. J. Aspects of common marmoset basic biology and life history important for biomedical research. Comparative Medicine, v. 53, n. 4, p 339-350, 2003.

ABLETT, M. J.; COULTHARD, A.; LEE, R. E. J. RICHARDSON, D. L.; BELLAS, T.; OWEN, J. P.; KEIR, M. J.;BUTLER, T. J. How reliable are ultrasound measurements of renal length in adults? The British Journal of Radiology, v. 68, n. 814, p. 10871089, 1995.

AGARWAL, I.; KIRUBAKARAN, C.; MARKANDEYULU, V.; SELVAKUMAR, D. Quantitation of proteinuria by spot urine sampling. Indian Journal of Clinical Biochemistry, v. 19, n. 2, p. 45-47, 2004.

ALPERS, C. E. The kidney. In: KUMAR, V.; ABBAS, A. K.; FAUSTO, N. Robbins and Cotran pathologic basis of disease. 7. ed. Philadelphia: Elsevier, 2004. 1525 p.

AMRI, K.; FREUND, N.; VILAR, J.; MERLET-BENICHOU, C.; LELIEVREPEGORIER, M. Adverse effects of hyperglycemia on kidney development in rats: in vivo and in vitro studies. Diabetes, v. 48,n. 11, p. 2240-2245, 1999.

ANDRADE, A.; PINTO, S. C.; OLIVEIRA, R. S. Animais de laboratório: criação e experimentação. Rio de Janeiro: Fiocruz, 2002. 388 p.

ARAÚJO, A.; ARRUDA, M. F.; ALENCAR, A. I.; ALBUQUERQUE, F.;

NASCIMENTO, M. C.; YAMAMOTO, M. E. Body weight of wild and captive common marmosets (Callithrix jaccus). International Journal of Primatology, v. 21, n. 2, p. 317-324, 2000.

AUGHEY, E.; FRYE, F. L. Urinary system. In: histology. lowa: lowa State University Press, 2001. p. 137-148.

Comparative veterinary

AURICCHIO, P. Primatas do Brasil. São Paulo: Terra Brasilis, 1995. 168 p.

BANKS, W. J. Sistema urinário. In: ed. São Paulo: Manole, 1991. p. 481-498. . Histologia veterinária aplicada. 2. 
BARR, F. J.; HOLT, P. E.; GIBBS, C. Ultrasonographic measurement of normal renal parameters. Journal of Small Animal Practice, v. 31,n. 4, p. 180-184, 1990.

BEUCHAT, C. A. Body size, medullary thickness, and urine concentrating ability in mammals. American Journal of Physiology, v. 258, n. 2, p. 298-308, 1990.

BOERE, V.; PINHEIRO, E. C.; SILVA, I. O.; PALUDO, G. R.; CANALE, G.; PIANTA, T.; WELKER, A.; ROCHA-DE-MOURA, R. C. Comparison between sex and age class on some physiological thermal, and hematological índices of cerrado's marmoset (Callithrix penicillata). Journal of Medical Primatology, v. 34,n.3, p. 156162, 2005.

BRACK, M.; ROTHE, H. Chronic tubulointerstitial nephritis and wasting disease in marmosets (Callithrix jacchus). Veterinary Pathology, v. 18, n. 1, p. 45-54, 1981. Supplement 6.

BRACK, M.; SCHROEDER, C.; FOOKE, M.; SCHLUMBERGER, W. IgM/lgA nephropathy in callitrichids: antigen studies. Nephron, v. 82, n. 3, p. 221-231, 1999.

BRACK, M.; WEBER, M. Ultrastructural and mesangial alterations in Callitrichid IgM nephropathy (Primates: Platyrrhina). Nephron, v. 69, n. 3, p. 286-292, 1995.

CHRISTIANSEN, T.; RASCH, R.; STØDKILDE-JØRGENSEN H.; FLYVBJERG A. Relationship between MRI and morphometric kidney measurements in diabetic and non-diabetic rats. Kidney International, v. 51, n. 1, p. 50-56, 1997.

CHRISTIANSEN, T.; STØDKILDE-JØRGENSEN, H.; FLYVBJERG A. Magnetic resonance imaging as a monitor of kidney enlargement and regression in experimental diabetes in rats. Journal of Endocrinology, v. 153, n. 2, p. 193-198, 1997.

COIMBRA-FILHO, A. F.; SILVA, R. R.; PISSINATTI, A. Sobre a dieta de Callithrichidae em cativeiro. Revista Biotérios, v. 1, p. 83-93, 1981.

COTRAN, R. S.; KUMAR, V.; ROBBINS, S. L. Robbins patologia estrutural e funcional. 5. ed. Rio de Janeiro: Guanabara Koogan, 1996. 1404 p.

DIAZ, G. B.; OJEDA, R. A. Kidney structure and allometry of Argentine desert rodents. Journal of Arid Environments, v. 41, n. 4, p. 453-461, 1999. 
DINIZ, L. S. M. Primatas em cativeiro: manejo e problemas veterinários: enfoque para espécies neotropicais. São Paulo: Ícone, 1997, 196 p.

DOUGLAS-DENTON, R. N.; MCNAMARA, B. J.; HOY, W. E.; HUGHSON, M. D.; BERTRAM, J. F.Does nephron number matter in the development of kidney disease? Ethnicity \& Disease, v. 16, S2-40, S2-45, Winter 2006. Suppl 2

DYCE, K. M.; SACK, W. O.; WENSING, C. J. G. Tratado de anatomia veterinária. 3. ed. Rio de Janeiro: Elsevier, 2004, 872 p.

ELLENPORT, C. R. Aparelho urogenital do carnívoro. In: ROSENBAUM, C. E.; GHOSHAL, N. G.; HILLMANN, D. (Ed.). GETTY, R. Anatomia dos animais domésticos. 5. ed. Rio de Janeiro: Guanabara, 1986. v. 2, p. 1481-1493.

EMAMIAN, S. A.; NIELSON, M. B.; PEDERSON, J. F. Intraobserver and interobserver variations in sonographic measurements of kidney size in adult volunteers. Acta Radiologica, v.36, n. 4, p.399-401, 1995.

FELKAI, C. S.; VÖRÖS, K.; VRABÉLY, T.; KARSAI, F. Ultrasonographic determination of renal volume in the dog. Veterinary Radiology and Ultrasound, v.33, n. 5, p.292-296, 1992.

FINCO, D. R.; STILES, N. S.; KNELLER, S. K.; LEWIS, R. E.; BARRETT, R.B. Radiologic estimation of kidney size of the dog. Journal of the American Veterinary Medical Association, v.159, n. 8, p.995-1002, 1971.

FORREST, L. J.; OBRIEN, R. T.; TREMELLING, M. S.; STEINBERG, H.; COOLEY, A. J.; KERLIN, R. L. Sonographic renal findings in 20 dogs with leptospirosis. Veterinary Radiology and Ultrasound, v. 39, n. 4, p.337-340, 1998.

GASCHEN, L.; MENNINGER, K.; SCHUURMAN, H.- J. Ultrasonography of the normal kidney in the cynomolgus monkey (Macaca fascicularis): morphologic and Doppler findings. Journal of Medical Primatology, v. 29, n. 2, p. 76-84, 2000.

GATESMAN, T. J. A preliminary clinical investigation using simple urological techniques in determining urinary tract disease in a colony of callitrichidae. Primate Report, v. 16, p. 75-83, 1987. 
GROSS, J. L.; SILVEIRO, S. P.; CAMARGO, J. L.; RECHELT, A. J.; AZEVEDO, M. J. Diabetes Melito: diagnóstico, classificação e avaliação do controle glicêmico. Arquivos Brasileiros de Endocrinologia e Metabologia, v. 46, n. 1, p. 16-26, 2002.

GROSS, M. L.; AMANN, K.; RITZ E. Nephron number and renal risk in hypertension and diabetes. Journal of the American Society of Nephrology, v. 16, p. S27-S29, 2005. Suppl. 1.

GUIMARÃES, M. A. B. V. Contribuição para o estudo da colheita e avaliação de sêmen do macaco-prego (Cebus apella) Erxleben, 1777. 41 f. Dissertação (Mestrado em Reprodução Animal) - Faculdade de Medicina Veterinária e Zootecnia, Universidade de São Paulo, São Paulo, 1994.

HACKENDAHL, N. C.; CITINO, S. B. Radiographic kidney measurement in captive cheetahs (Acionyx jubatus). Journal of Zoo and Wildlife Medicine, v. 36, n. 2, p. 321-322, 2005.

HENEGAR, J. R.; BIGLER, S. A.; HENEGAR, J. R.; TYAGI, S. C.; HALL, J. E. Functional and structural changes in the kidney in the early stages of obesity. Journal of the American Society of Nephrology, v. 12, n. 6, p. 1211-1217, 2001.

HILL, L. R.; HESS, K. R.; STEPHENS, L. C.; TINKEY, P. T.; PRICE, R. E. Comparison of kidney weight and volume to select anatomical parameters in the adult female rhesus monkey (Macaca mullata). Journal of Medical Primatology, v. 28, n. 2, p. 67-72, 1999.

HORACEK, M. J.; EARLE, A. M.; GILMORE, J. P. The renal microvasculature of the monkey: an anatomical investigation. Journal of Anatomy, v. 148, p. 205-231, 1986.

HRICAK, H.; LIETO, R. P. Sonographic determination of renal volume. Radiology, v. 148, n. 1, p. 311-312, 1983.

HUGHSON, M. D.; JOHNSON, K.; YOUNG, R. J.; HOY, W. E.; BERTRAM, J. F. Glomerular size and glomerulosclerosis: relationships to disease categories, glomerular solidification, and ischemic obsolescence. American Journal of Kidney Diseases, v. 39, n. 4, p. 679-688, 2002.

JONES, T. B.; RIDDICK, L. R.; HARPEN, M. D.; DUBUISSON, R. L.; SAMUELS, D. Ultrasonograhic determination of renal mass and renal volume. Journal of Medical Ultra Sound, v. 2, n. 4, p.151-154, 1983. 
JONES, T. C.; HUNT, R. D.; KING, N. W. Patologia veterinária, 6 ed. Manole: São Paulo, 2000. 1415 p.

JUNQUEIRA, L. C.; CARNEIRO, J. Histologia básica. 11. ed. Guanabara Koogan: Rio de Janeiro, 2008. 524 p.

KAMBHAM, N.; MARKOWITZ, G. S.; VALERI, A. M.; LIN, J.; D'AGATI, V. D. Obesity-related glomerulopathy: an emerging epidemic. Kidney International, v. 59, n. 4, p. 1498-1509, 2001.

KEALY, J. K.; MCALLISTER, H. The Abdomen. In: KEALY, J. K.; MCALLISTER, H. Diagnostic radiology \& ultrasonography of the dog and cat. 4.ed. St. Louis, Missouri: Elsevier Saunders, 2005. p. 21-168.

KONIG, H. E.; LIEBICH, H. G. Anatomia dos animais domésticos: texto e atlas colorido. Porto Alegre: Artmed, 2004. V. 2.

MAHAFFEY, M. B.; BARBER, D. L. Radiographic and ultrasonographic evaluation of the urinary tract. In: STONE, E. A.; BARSANTI, J. A. Urologic surgery of the dog \& cat. Philadelphia: Lea \& Febiger, 1992. Cap. 6, p. 53-79.

MCNAMARA, B. J.; DIOUF, B.; HUGHSON, M. D.; HOY, W. E.; BERTRAM, J. F. Associations between age, body size and nephron number with individual glomerular volumes in urban West African males. Nephrology Dialysis Transplantation, v. 24, n. 5, p. 1500-1506, 2009.

MIRAGLIA, T.; ROSSI, R.; MOREIRA, E. Data on the kidneys of the marmoset (Callithrix jacchus). Acta Anatomica, v. 69, n. 2, p. 274-281, 1968.

MUGHAL, M. Z.; EELLOO, J. A.; ROBERTS, S. A.; SIBARTIE, S.; MARESH, M.; SIBLEY, C. P.; ADAMS, J. E. Intrauterine programming of urinary calcium and magnesium excretion in children born to mothers with insulin dependent diabetes mellitus. Archives of Disease in Childhood Fetal Neonatal, v. 90, n. 4, p. F332336. 2005.

NEUSSER, M.; STANYON, R.; BIGONI, F.; WIENBERG, J.; MULLER, S. Molecular cytotaxonomy of New World Monkeys (Platyrrhini) - comparative analysis of five species by multicolor chromosome painting gives evidence for a classification of Callimico goeldii within the family of Callitrichidae. Cytonegenetics and cell genetics, v 94, n.3-4, p 206-15, 2001. 
OLIVEIRA, A. L.; MALAGUEÑO, E.; TELLES, A. M. S.; MADRUGA, M. H.;

SANTANA, J. V. Experimental schistosomiasis in the common marmoset Callithrix jacchus. Revista da Sociedade Brasileira de Medicina Tropical, v. 37, n. 3, p. 222-228, 2004.

OWENS, J. M.; BIERY, D. N. Radiographic interpretation for the small animal clinician. 2. ed. Baltimore: Willians \& Wilkins, 1998. 308 p.

PESSEGUEIRO, P.; BARATA, C.; CORREIA, J. Doença de Berger: proposta de algoritmo terapêutico e factores preditivos de insuficiência renal crônica. Acta Médica Portuguesa, v. 16, p. 261-266, 2003.

POTKAY, S. Diseases of the Callitrichidae: a review. Journal of Medical Primatology, v. 21, n. 4,p. 189-236, 1992.

RAVEN, H. C.; ATKINSON, W. B.; ELFTMAN, H.; HILL, J. E.; SCHULTZ, A. H.; STRAUS JR, W. L.; WASHBURN, S. L. In: GREGORY. W. K. (Ed.). The anatomy of the gorilla: the studies of Henry Cushier Raven. New York: Columbia University Press,1950. p. 200-201.

REECE, W. O. Anatomia e fisiologia dos animais domésticos. 3 ed. São Paulo: Roca, 2008. 468 p.

REGINA, S.; LUCAS, R.; MIRAGLIA, S. M.; ZALADEK, G. F.; MACHADO, C. T. Intrauterine food restriction as a determinant of nephrosclerosis. American Journal of Kidney Diseases, v. 37, n. 3, p. 467-476, 2001.

RUIZ-MIRANDA, C. R.; AFFONSO, A. G.; MORAIS, M. M.; VERONA, C. E.; MARTINS, A.; BECK B. Behavioral and ecological interactions between reintroduced Golden Lion Tamarins (Leotonpithecus Rosália, Linnaeus 1766) and introduced marmosets (Callithrix spp, Linnaeus 1758) in Brazil's Atlantic Coast Forest fragments. Brazilian Archives of Biology and Technology, v. 49, n. 1, p. 99-109, 2006.

SAMPAIO, K. M. O. R.; ARAÚJO, R. B. Ultra-sonografia de características lineares e estimativas do volume de rins de cães. Arquivo Brasileiro de Medicina Veterinária e Zootecnia, v. 54, n. 3, p. 248-254, 2002. 
SCHAEFFTER, C. O. D. Aspectos ultra-sonográficos de rins de macacos prego (Cebus sp.). 1996. 61 f. Dissertação (Mestrado em Anatomia dos Animais Domésticos) - Faculdade de Medicina Veterinária e Zootecnia, Universidade de São Paulo, São Paulo, 1996.

SCHLUMBOHM, C.; ARMSTRONG, V.; BECKER, T.; NAYUDU, P. Hypertrilyceridemia and glucose intolerance in common marmoset monkeys. Diabetes und Stoffwechsell, p. 44, res.PB7, 2005. Supplement 1. Apresentado no Satellite Symposium of the of the $1^{\text {st }}$ International Congress on "Prediabetes and the Metabolic Syndrome", 2005, Dresden.

SCHMIDT-NIELSEN, B.; O'DELL, R. Structure and concentrating mechanism in the mammalian kidney. American Journal of Physiology, v. 200, p. 1119-1124, 1961.

SCHNEIDER, H.; ROSENBERG, A. L. Molecules, morphology and platyrrhine systematics. In: NORCONK, A. L.; ROSENBERG, P. A.; GARBER, P. A. (Ed.).

Adaptive radiations of neotropical primates. New York: Plenum Press, 1966. p. 319.

STEVENSON, M. F.; RYLANDS, A. B. The marmosets, Genus Callithrix. In: MITTERMEIER, R. A.; RYLANDS, A. B.; COIMBRA-FILHO, A.; FONSECA, A. B. (Ed.). Ecology and behavior of neotropical primates. Contagem: Littera Maciel, 1988. v. 2, p. 131-222.

TISHER. C. C.; MADSEN, K. M. Anatomy of the kidney. In: BRENNER, B. M.; RECTOR, F., C. (Ed.). The kidney. 5. ed. Philadelphia: Saunders Company, 1996. v. 1, p. 3-71.

VALLE, C. M. R. Estudo morfofuncional de rins de primatas Callithrix jacchus em cativeiro. $158 \mathrm{f}$. Tese (Doutorado em Ciências), Faculdade de Medicina Veterinária e Zootecnia, Universidade de São Paulo, São Paulo, 2008.

VALLE, C. M. R.; VALLE, R. R.; EITNER, F.; SCHLUMBOHM, C.; CARVALHO, R. A.; SCHOENMANN, U.; BOMBONATO, P. P.; NAYUDU, P. L. The development of a non-invasive differential diagnostic for nephropathy, glucose intolerance and enteritis in captive Callithrix jacchus. Primate Report, v. 72, n. 1, p. 47-48, 2005.

VASCONCELLOS, L. S.; PENIDO, M. G. M.; VIDIGAL, P. G. Importância do dimorfismo eritrocitário na investigação da origem da hematúria: revisão da literatura. Jornal Brasileiro de Patologia e Medicina Laboratorial, v. 41, n. 2, p. 83-94, 2005. 
WADSWORTH, P. F.; BUDGETT, D. A.; FORSTER, M. L. Organ weight data in juvenile and adult marmosets (Callithrix jacchus). Laboratory Animals, v.15, n. 4, p. 385-388, 1981.

WIRTA, O.; PASTERNACK, A.; LAIPPALA, P.; TURJANMAA, V. Glomerular filtration rate and kidney size after six years disease duration in non-insulin-dependent subjects. Clinical Nephrology, v. 45, n. 1, p. 10-17, 1996.

YARBROUGHT, L. W.; TOLLETT, J. L.; MONTREY, R. D.; BEATTIE, R. J. Serum biochemical, hematological and body measurement data for common marmosets (Callithrix jacchus jacchus). Laboratory Animal Science, v. 34, n. 3, p. 276-280, 1984. 
Anexo A - Protocolo de coloração para Hematoxilina-Eosina, diafanização e montagem das lâminas.

Antes de iniciar o processo de desparafinização, indica-se que as lâminas permaneçam por 2 horas em estufa à $60^{\circ} \mathrm{C}$ para derreter e escorrer o excesso de parafina.

1. Xilol I- 5 minutos

2. Xilol II - 5 minutos

3. Álcool $100 \%-3$ minutos

4. Álcool $90 \%-3$ minutos

5. Álcool $70 \%-3$ minutos

6. Água corrente -3 minutos

7. Hematoxilina - 3 minutos

8. Água corrente - 10 minutos

9. Álcool ácido - bem rápido

10. Água corrente - 10 minutos

11. Eosina - 15 segundos

12. Água - 1 mergulho

13. Álcool $95 \%$ - 1 mergulho

14. Álcool $100 \%$ - 1 mergulho

15. Álcool $100 \%-3$ minutos

16. Álcool Xilol - 3 minutos

17. Xilol I - 3 minutos

18. Xilol II - 3 minutos

19. Montagem das lâminas

20. Secagem -2 dias 
Anexo B - Divisão dos grupos de estudo.

Gupo 1: G1 (Animais de 1 a 3 anos de idade)

\begin{tabular}{c|c}
\hline Machos & Fêmeas \\
\hline \hline Alessio & Jette \\
\hline Honoris & Arucha \\
\hline Asko & Aladine \\
\hline Isotop & Aschenputtel \\
\hline Geram & Vulkana \\
\hline
\end{tabular}

Gupo 2: G2 (Animais de 6 a 8 anos de idade)

\begin{tabular}{c|c}
\hline Machos & Fêmeas \\
\hline \hline Atlas & Ariberta \\
\hline Zigeuner & Blanche \\
\hline Klemens & Nicoletta \\
\hline Southern & karla \\
\hline Epson & Hagebutte \\
\hline
\end{tabular}


Anexo C - Dados referentes ao sexo, idade (anos), peso (g) e ausência ou presença de alteração nos exames dos animais dos grupos 1 e 2 .

\begin{tabular}{c|c|c|c|c|c}
\hline Grupo & Nome & Sexo & Idade & Peso g & $\begin{array}{c}\text { Alteração nos } \\
\text { Exames }\end{array}$ \\
\hline \hline 1 & Alessio & M & 1,0 & 464 & SIM \\
\hline 1 & Honoris & M & 2,0 & 420 & SIM \\
\hline 1 & Asko & M & 2,5 & 360 & SIM \\
\hline 1 & Isotop & M & 2,5 & 319 & NÃO \\
\hline 1 & Geram & M & 3,0 & 420 & NÃO \\
\hline 1 & Jette & F & 1,0 & 477 & NÃO \\
\hline 1 & Arucha & F & 2,0 & 453 & SIM \\
\hline 1 & Aladine & F & 2,0 & 403 & NÃO \\
\hline 1 & Aschenputtel & F & 2,5 & 365 & NÃO \\
\hline 2 & Vulkana & F & 3,0 & 440 & SIM \\
\hline 2 & Atlas & M & 6,5 & 404 & SIM \\
\hline 2 & Klgeuner & M & 7,0 & 422 & SIM \\
\hline 2 & Southern & M & 7,0 & 425 & SIM \\
\hline 2 & Epson & M & 8,0 & 407 & NÃO \\
\hline 2 & Ariberta & F & 6,0 & 552 & SIM \\
\hline 2 & Blanche & F & 6,0 & 301 & SIM \\
\hline 2 & Nicoletta & F & 6,5 & 460 & NÃO \\
\hline 2 & karla & F & 8,0 & 513 & SIM \\
\hline 2 & Hagebutte & F & 8,0 & 454 & SIM \\
\hline
\end{tabular}


Anexo D - Valores da mensuração anatômica, comprimento, altura, largura $(\mathrm{cm})$, volume $\left(\mathrm{cm}^{3}\right)$ e peso $(\mathrm{g})$, dos rins direito e esquerdo dos animais do grupo 1 e 2.

\begin{tabular}{|c|c|c|c|c|c|c|c|c|c|c|c|}
\hline Grupo & Nome & Comp. RD & Alt. RD & Larg. RD & Vol. RD & Peso RD & Comp. RE & Alt. RE & Larg. RE & Vol. RE & Peso RE \\
\hline 1 & Alessio & 2,10 & 1,40 & 1,15 & 4,41 & 1,35 & 2,00 & 1,45 & 1,20 & 4,16 & 2,22 \\
\hline 1 & Honoris & 2,50 & 1,50 & 1,10 & 6,38 & 2,92 & 2,20 & 1,80 & 1,10 & 5,51 & 2,73 \\
\hline 1 & Asko & 1,20 & 1,90 & 0,90 & 1,58 & 1,49 & 1,80 & 1,90 & 0,90 & 3,56 & 1,46 \\
\hline 1 & Isotop & 1,30 & 0,85 & 0,80 & 1,09 & 0,70 & 1,15 & 1,30 & 0,80 & 1,09 & 0,77 \\
\hline 1 & Geram & 1,60 & 1,10 & 1,10 & 2,21 & 1,29 & 1,80 & 1,20 & 0,90 & 2,67 & 1,33 \\
\hline 1 & Jette & 1,90 & 1,25 & 1,00 & 3,19 & $\mathrm{xXX}$ & 2,00 & 1,25 & 1,00 & 3,53 & $x x x$ \\
\hline 1 & Arucha & 1,90 & 1,75 & 1,10 & 4,04 & 2,58 & 2,10 & 1,40 & 1,10 & 4,33 & 1,99 \\
\hline 1 & Aladine & 1,80 & 1,20 & 0,90 & 2,67 & 1,20 & 1,65 & 1,00 & 1,10 & 2,24 & 1,25 \\
\hline 1 & Aschenputtel & 2,10 & 1,40 & 1,05 & 4,24 & 2,90 & 2,00 & 1,35 & 1,10 & 3,85 & 2,07 \\
\hline 1 & Vulkana & 2,10 & 1,40 & 1,20 & 4,50 & 2,36 & 2,00 & 1,20 & 1,40 & 4,08 & 2,40 \\
\hline 2 & Atlas & 1,80 & 1,30 & 1,30 & 3,31 & 1,95 & 1,85 & 1,20 & 1,20 & 3,22 & 1,79 \\
\hline 2 & Zigeuner & 1,88 & 1,05 & 1,30 & 3,26 & 1,39 & 1,70 & 1,30 & 1,25 & 2,89 & 1,50 \\
\hline 2 & Klemens & 1,91 & 1,21 & 1,19 & 3,44 & 1,70 & 1,76 & 1,22 & 1,29 & 3,05 & 1,44 \\
\hline 2 & Southern & 1,65 & 0,96 & 1,12 & 2,22 & 1,10 & 1,64 & 1,10 & 1,20 & 2,43 & 1,10 \\
\hline 2 & Epson & 1,95 & 1,40 & 1,10 & 3,73 & 1,80 & 1,90 & 1,10 & 1,45 & 3,61 & 1,76 \\
\hline 2 & Ariberta & 2,00 & 1,25 & 1,55 & 4,40 & 2,4 & 2,01 & 1,20 & 1,55 & 4,36 & 2,39 \\
\hline 2 & Blanche & 1,85 & 1,00 & 1,11 & 2,83 & 1,12 & 1,75 & 1,10 & 1,10 & 2,64 & 1,01 \\
\hline 2 & Nicoletta & 1,80 & 1,30 & 1,10 & 3,05 & 1,43 & 1,80 & 1,20 & 1,00 & 2,80 & 1,38 \\
\hline 2 & karla & 2,20 & 1,40 & 1,40 & 5,32 & 2,44 & 2,00 & 1,30 & 1,45 & 4,32 & 2,30 \\
\hline 2 & Hagebutte & 2,00 & 1,35 & 1,25 & 4,08 & 2,62 & 2,00 & 1,35 & 1,35 & 4,24 & 2,53 \\
\hline
\end{tabular}


Anexo E - Representação esquemática dos formulários para contagem glomerular

\begin{tabular}{|c|c|c|c|c|c|}
\hline & & Lâmina & Corte & Campo & $\mathbf{N}^{\circ}$ de Glomérulos \\
\hline & & & & 1 & \\
\hline & & & 1 & 2 & \\
\hline & & 1 & & 3 & \\
\hline & & 1 & & 4 & \\
\hline & & & 2 & 5 & \\
\hline & & & & 6 & \\
\hline & & & & 7 & \\
\hline & & & 3 & 8 & \\
\hline & & $?$ & & 9 & \\
\hline & & 2 & & 10 & \\
\hline & & & 4 & 11 & \\
\hline & & & & 12 & \\
\hline & & & & 13 & \\
\hline & & & 5 & 14 & \\
\hline Animal & $\begin{array}{l}\text { Rim Direlto ou } \\
\text { Fsquerdo }\end{array}$ & 3 & & 15 & \\
\hline & & $\checkmark$ & & 16 & \\
\hline & & & 6 & 17 & \\
\hline & & & & 18 & \\
\hline & & & & 19 & \\
\hline & & & 7 & 20 & \\
\hline & & 1 & & 21 & \\
\hline & & 4 & & 22 & \\
\hline & & & 8 & 23 & \\
\hline & & & & 24 & \\
\hline & & & & 25 & \\
\hline & & & 9 & 26 & \\
\hline & & 5 & & 27 & \\
\hline & & $\checkmark$ & & 28 & \\
\hline & & & 10 & 29 & \\
\hline & & & & 30 & \\
\hline & & & & Total & \\
\hline & & & & Média / Campo & \\
\hline
\end{tabular}


Anexo $\mathrm{F}$ - Valores referentes à contagem glomerular em 30 campos, média de glomérulos por campo, área do campo $\left(\mathrm{mm}^{2}\right)$ e densidade glomerular (glomérulos $/ \mathrm{mm}^{2}$ ) dos rins direito e esquerdo dos animais do grupo 1 e 2 .

\begin{tabular}{r|l|r|r|r|r|r|r|r|r}
\hline Grupo & \multicolumn{1}{|c|}{ Nome } & Sexo & $\begin{array}{c}\text { GIm. } \\
\text { RD }\end{array}$ & $\begin{array}{c}\text { GIm. } \\
\text { RE }\end{array}$ & $\begin{array}{c}\text { G/C. } \\
\text { RD }\end{array}$ & $\begin{array}{c}\text { G/C. } \\
\text { RE }\end{array}$ & A/C & $\begin{array}{c}\text { D. Glm. } \\
\text { RD }\end{array}$ & $\begin{array}{c}\text { D. GIm. } \\
\text { RE }\end{array}$ \\
\hline \hline 1 & llessio & M & 139 & 139 & 4,63 & 4,63 & 1,515 & 3,06 & 3,06 \\
\hline 1 & Honoris & M & 149 & 146 & 4,97 & 4,87 & 1,515 & 3,28 & 3,21 \\
\hline 1 & Asko & M & 189 & 218 & 6,30 & 7,27 & 1,515 & 4,16 & 4,80 \\
\hline 1 & Isotop & M & 164 & 158 & 5,47 & 5,27 & 1,515 & 3,61 & 3,48 \\
\hline 1 & Geram & M & 168 & 190 & 5,60 & 6,33 & 1,515 & 3,70 & 4,18 \\
\hline 1 & Jette & F & 176 & 173 & 5,87 & 5,77 & 1,515 & 3,87 & 3,81 \\
\hline 1 & Arucha & F & 204 & 187 & 6,80 & 6,23 & 1,515 & 4,49 & 4,11 \\
\hline 1 & Aladine & F & 231 & 234 & 7,70 & 7,80 & 1,515 & 5,08 & 5,15 \\
\hline 1 & Aschenputtel & F & 175 & 189 & 5,83 & 6,30 & 1,515 & 3,85 & 4,16 \\
\hline 1 & Vulkana & F & 163 & 178 & 5,43 & 5,93 & 1,515 & 3,59 & 3,92 \\
\hline 2 & Atlas & M & 187 & 201 & 6,23 & 6,70 & 1,515 & 4,11 & 4,42 \\
\hline 2 & Zigeuner & M & 214 & 238 & 7,13 & 7,93 & 1,515 & 4,71 & 5,24 \\
\hline 2 & Klemens & M & 202 & 223 & 6,73 & 7,43 & 1,515 & 4,44 & 4,91 \\
\hline 2 & Southern & M & 233 & 238 & 7,77 & 7,93 & 1,515 & 5,13 & 5,24 \\
\hline 2 & Epson & M & 230 & 225 & 7,67 & 7,50 & 1,515 & 5,06 & 4,95 \\
\hline 2 & Ariberta & F & 181 & 192 & 6,03 & 6,40 & 1,515 & 3,98 & 4,22 \\
\hline 2 & Blanche & F & 238 & 247 & 7,93 & 8,23 & 1,515 & 5,24 & 5,43 \\
\hline 2 & Nicoletta & F & 211 & 218 & 7,03 & 7,27 & 1,515 & 4,64 & 4,80 \\
\hline 2 & karla & F & 188 & 177 & 6,27 & 5,90 & 1,515 & 4,14 & 3,89 \\
\hline 2 & Hagebutte & F & 186 & 174 & 6,20 & 5,80 & 1,515 & 4,09 & 3,83 \\
\hline & & & & & & & & & \\
\hline
\end{tabular}


Anexo G - Representação esquemática dos formulários para mensuração da área glomerular

\begin{tabular}{|c|c|c|c|c|c|c|c|}
\hline & & $\begin{array}{l}N^{\circ} \text { do } \\
\text { Campo }\end{array}$ & $\begin{array}{l}\text { Contagem } \\
\text { Glomerular }\end{array}$ & $\begin{array}{r}\mathbf{N} \\
\text { Glon }\end{array}$ & $\begin{array}{l}\text { lo } \\
\text { inulo }\end{array}$ & $\begin{array}{c}\mathrm{N}^{\circ} \text { do } \\
\text { Sorteio }\end{array}$ & $\begin{array}{l}\text { Mensuração } \\
\text { Glomerular }\end{array}$ \\
\hline & & 1 & 4 & 1 & 4 & 1 & \\
\hline & & 2 & 6 & 5 & 10 & 8 & \\
\hline & & 3 & 4 & 11 & 14 & & \\
\hline & & 4 & 8 & 15 & 22 & 21 & \\
\hline & & 5 & 5 & 23 & 27 & & \\
\hline & & 6 & 4 & 28 & 31 & & \\
\hline & & 7 & 5 & 32 & 36 & 34 & \\
\hline & & 8 & 5 & 37 & 41 & & \\
\hline & & 9 & 6 & 42 & 47 & $44 ; 47$ & \\
\hline & & 10 & 5 & 48 & 52 & & \\
\hline & & 11 & 5 & 53 & 57 & $54 ; 55$ & \\
\hline & & 12 & 6 & 58 & 63 & $61 ; 63$ & \\
\hline & & 13 & 10 & 64 & 73 & $66 ; 68$ & \\
\hline & Rim Direito & 14 & 10 & 74 & 83 & 77 & \\
\hline Animal & $\begin{array}{c}\text { ou } \\
\text { Fsauerdo }\end{array}$ & 15 & 7 & 84 & 90 & & \\
\hline & & 16 & 10 & 91 & 100 & 96; 99 & \\
\hline & & 17 & 6 & 101 & 106 & & \\
\hline & & 18 & 6 & 107 & 112 & $107 ; 109$ & \\
\hline & & 19 & 8 & 113 & 120 & 114 & \\
\hline & & 20 & 5 & 121 & 125 & & \\
\hline & & 21 & 9 & 126 & 134 & & \\
\hline & & 22 & 5 & 135 & 139 & 135; 136; & \\
\hline & & 23 & 7 & 140 & 146 & & \\
\hline & & 24 & 9 & 147 & 155 & 153 & \\
\hline & & 25 & 12 & 156 & 167 & 163 & \\
\hline & & 26 & 9 & 168 & 176 & 171 & \\
\hline & & 27 & 5 & 177 & 181 & 177 & \\
\hline & & 28 & 7 & 182 & 188 & & \\
\hline & & 29 & 9 & 189 & 197 & 191 & \\
\hline & & 30 & 3 & 198 & 200 & & \\
\hline & & Total & 200 & & & Total & \\
\hline
\end{tabular}


Anexo $\mathrm{H}$ - Valores referentes à média da área glomerular $\left(\mu \mathrm{m}^{2}\right)$ de 25 glomérulos mensurados em cada rim, direito e esquerdo, dos animais do grupo 1 e 2 .

\begin{tabular}{c|l|c|r|r}
\hline Grupo & \multicolumn{1}{|c|}{ Nome } & Sexo & A. GIm. RD & A. Glm. RE \\
\hline \hline 1 & Alessio & M & 10690,86 & 13881,95 \\
\hline 1 & Honoris & M & 16021,84 & 15143,78 \\
\hline 1 & Asko & M & 13769,47 & 12638,30 \\
\hline 1 & Isotop & M & 13167,07 & 14654,13 \\
\hline 1 & Geram & M & 12490,92 & 12997,60 \\
\hline 1 & Jette & F & 13976,55 & 13941,05 \\
\hline 1 & Arucha & F & 17029,13 & 18326,47 \\
\hline 1 & Aladine & $\mathrm{F}$ & 10930,01 & 10591,79 \\
\hline 1 & Aschenputtel & $\mathrm{F}$ & 15287,94 & 14627,87 \\
\hline 1 & Vulkana & $\mathrm{F}$ & 15556,02 & 15928,01 \\
\hline 2 & Atlas & $\mathrm{M}$ & 13133,92 & 12408,12 \\
\hline 2 & Zigeuner & $\mathrm{M}$ & 11983,40 & 11117,93 \\
\hline 2 & Klemens & $\mathrm{M}$ & 12416,77 & 11863,24 \\
\hline 2 & Southern & $\mathrm{M}$ & 10780,12 & 10332,96 \\
\hline 2 & Epson & $\mathrm{M}$ & 10385,96 & 10552,80 \\
\hline 2 & Ariberta & $\mathrm{F}$ & 12464,80 & 12195,16 \\
\hline 2 & Blanche & $\mathrm{F}$ & 9040,52 & 9531,96 \\
\hline 2 & Nicoletta & $\mathrm{F}$ & 10968,28 & 10882,12 \\
\hline 2 & karla & $\mathrm{F}$ & 10925,44 & 11479,36 \\
\hline 2 & Hagebutte & $\mathrm{F}$ & 10969,92 & 12469,92 \\
\hline
\end{tabular}


Anexo I - Valores referentes à bioquímica sérrica (uréia e creatinina $(\mathrm{mg} / \mathrm{dl})$ ) dos animais do grupo 1 e 2 .

\begin{tabular}{c|l|r|r}
\hline Grupo & \multicolumn{1}{|c|}{ Nome } & \multicolumn{1}{c|}{ Uréia } & Creatinina \\
\hline \hline 1 & Alessio & 20,4 & 0,22 \\
\hline 1 & Honoris & 11,5 & 0,16 \\
\hline 1 & Asko & 13,1 & 0,29 \\
\hline 1 & Isotop & 19,2 & 0,47 \\
\hline 1 & Geram & 10,9 & 0,24 \\
\hline 1 & Jette & 17,1 & 0,18 \\
\hline 1 & Arucha & 14,5 & 0,18 \\
\hline 1 & Aladine & 12,8 & 0,21 \\
\hline 1 & Aschenputtel & 7,5 & 0,32 \\
\hline 1 & Vulkana & 13,2 & 0,34 \\
\hline 2 & Atlas & 12,1 & 0,24 \\
\hline 2 & Zigeuner & 20,0 & 0,31 \\
\hline 2 & Klemens & 17,9 & 0,32 \\
\hline 2 & Southern & 19,1 & 0,28 \\
\hline 2 & Epson & 14,7 & 0,32 \\
\hline 2 & Ariberta & 14,3 & 0,33 \\
\hline 2 & Blanche & 16,7 & 0,18 \\
\hline 2 & Nicoletta & 12,5 & 0,26 \\
\hline 2 & karla & 14,5 & 0,31 \\
\hline 2 & Hagebutte & 13,9 & 0,18 \\
\hline
\end{tabular}


Anexo J - Valores de parâmetros urinários, proteína e sangue, mensurados por meio de testes de fita $(+)$, albumina $(\mathrm{mg} / \mathrm{dl})$, creatinina $(\mathrm{mg} / \mathrm{dl})$ e relação albumina/creatinina, mensurados em laboratório, dos 3 exames realizados nos animais do grupo 1.

\begin{tabular}{|c|c|c|c|c|c|}
\hline Nome & Proteína & Sangue & Albumina & Creatinina & Alb/Creat \\
\hline \multirow{3}{*}{ Alessio } & 0 & 0 & 1,21 & 43,53 & 0,028 \\
\hline & 0 & 0 & 1,5 & 31,56 & 0,048 \\
\hline & 2 & 0 & 1,08 & 56,59 & 0,019 \\
\hline \multirow{3}{*}{ Honoris } & 1 & 0 & 5,96 & 94,71 & 0,063 \\
\hline & 3 & 2 & 67,7 & 61,58 & 1,099 \\
\hline & 3 & 0 & 452 & 0,62 & 729 \\
\hline \multirow{3}{*}{ Asko } & 1 & 0 & 2,05 & 85,57 & 0,024 \\
\hline & 1 & 2 & 12,8 & 67,53 & 0,190 \\
\hline & 1 & 0 & 7,97 & 112,6 & 0,071 \\
\hline \multirow{3}{*}{ Isotop } & 1 & 0 & 1,52 & 62,38 & 0,024 \\
\hline & 1 & 0 & 2,53 & 45,07 & 0,056 \\
\hline & 0 & 0 & 1,67 & 71,02 & 0,024 \\
\hline \multirow{3}{*}{ Geram } & 1 & 0 & 0,4 & 93,95 & 0,004 \\
\hline & 1 & 0 & 2,18 & 57,92 & 0,038 \\
\hline & 1 & 0 & 6,81 & 94,97 & 0,072 \\
\hline \multirow{3}{*}{ Jette } & 1 & 0 & 1,67 & 105 & 0,016 \\
\hline & 0 & 0 & 0,78 & 108,4 & 0,007 \\
\hline & 1 & 0 & 1,03 & 97,42 & 0,011 \\
\hline \multirow{3}{*}{ Arucha } & 1 & 0 & 1,42 & 50,48 & 0,028 \\
\hline & 1 & 0 & 3,01 & 156,4 & 0,019 \\
\hline & 2 & 0 & 6,27 & 25,53 & 0,246 \\
\hline \multirow{3}{*}{ Aladine } & 1 & 0 & 6,15 & 192,6 & 0,032 \\
\hline & 1 & 4 & 2,78 & 92,56 & 0,030 \\
\hline & 0 & 1 & 1,51 & 16,96 & 0,089 \\
\hline \multirow{3}{*}{ Aschenputtel } & 1 & 0 & 0,83 & 52,79 & 0,016 \\
\hline & 0 & 0 & 0,73 & 48,9 & 0,015 \\
\hline & 1 & 0 & 0,9 & 123,2 & 0,007 \\
\hline \multirow{3}{*}{ Vulkana } & 1 & 0 & 7,7 & 83,56 & 0,092 \\
\hline & 3 & 2 & 60,1 & 107,4 & 0,560 \\
\hline & 3 & 1 & 274 & 61,87 & 4,429 \\
\hline
\end{tabular}


Anexo $\mathrm{K}$ - Valores de parâmetros urinários, proteína e sangue, mensurados por meio de testes de fita $(+)$, albumina $(\mathrm{mg} / \mathrm{dl})$, creatinina $(\mathrm{mg} / \mathrm{dl})$ e relação albumina/creatinina, mensurados em laboratório, dos 3 exames realizados nos animais do grupo 2.

\begin{tabular}{|c|c|c|c|c|c|}
\hline Nome & Proteína & Sangue & Albumina & Creatinina & Alb/Creat \\
\hline \multirow{3}{*}{ Atlas } & 3 & 1 & 0,41 & 30,14 & 0,014 \\
\hline & 3 & 3 & 39,5 & 62,49 & 0,632 \\
\hline & 3 & 0 & 353 & 54,47 & 6,481 \\
\hline \multirow{3}{*}{ Zigeuner } & 1 & 1 & 11,8 & 63,54 & 0,186 \\
\hline & 1 & 0 & 15,5 & 76,42 & 0,203 \\
\hline & 2 & 0 & 17,2 & 72,27 & 0,238 \\
\hline \multirow{3}{*}{ Klemens } & 3 & 4 & 1,01 & 58,99 & 0,017 \\
\hline & 3 & 2 & 777 & 48,48 & 16 \\
\hline & 3 & 1 & 191 & 48,48 & 3,940 \\
\hline \multirow{3}{*}{ Southern } & 0 & 0 & 0,89 & 28,18 & 0,032 \\
\hline & 1 & 0 & 0,6 & 101,9 & 0,006 \\
\hline & 1 & 0 & 3,39 & 107,6 & 0,032 \\
\hline \multirow{3}{*}{ Epson } & 3 & 2 & 451 & 84,81 & 5,318 \\
\hline & 3 & 3 & 247 & 79,38 & 3,112 \\
\hline & 3 & 1 & 585 & 104,1 & 5,620 \\
\hline \multirow{3}{*}{ Ariberta } & 2 & 0 & 0,24 & 69,87 & 0,003 \\
\hline & 3 & 1 & 64,7 & 59,67 & 1,084 \\
\hline & 3 & 1 & 228 & 95,34 & 2,391 \\
\hline \multirow{3}{*}{ Blanche } & 1 & 0 & 2,43 & 124,1 & 0,020 \\
\hline & 0 & 0 & 1,01 & 65,82 & 0,015 \\
\hline & 1 & 0 & 1,36 & 108,7 & 0,013 \\
\hline \multirow{3}{*}{ Nicoletta } & 0 & 0 & 1,07 & 51,77 & 0,021 \\
\hline & 0 & 0 & 1,92 & 35,93 & 0,053 \\
\hline & 0 & 0 & 1,77 & 43,62 & 0,041 \\
\hline \multirow{3}{*}{ karla } & 3 & 0 & 465 & 100,2 & 4,641 \\
\hline & 3 & 1 & 3,58 & 108,2 & 0,033 \\
\hline & 3 & 1 & 212 & 31,81 & 6,665 \\
\hline \multirow{3}{*}{ Hagebutte } & 3 & 3 & 0,95 & 39,06 & 0,024 \\
\hline & 3 & 1 & 10,9 & 29,77 & 0,366 \\
\hline & 3 & 0 & 88 & 47,86 & 1,839 \\
\hline
\end{tabular}


Anexo L - Valores das taxas de glicose sanguínea $(\mathrm{mg} / \mathrm{dl})$ do exame da curva glicêmica antes da sobrecarga de glicose e 20 minutos após a sobrecarga para sangue venoso $(V)$ e periférico $(P)$, e 10, 40,60, 80, 100, 120 e 140 minutos após a sobrecarga para sangue periférico, dos animais do grupo 1 e 2.

\begin{tabular}{|c|c|c|c|c|c|c|c|c|c|c|c|c|}
\hline Grupo & Nome & Antes (V) & Antes $(\mathrm{P})$ & $10 \mathrm{~m}$ & $20 \mathrm{~m}(\mathrm{~V})$ & $20 \mathrm{~m}(\mathrm{P})$ & $40 \mathrm{~m}$ & $60 \mathrm{~m}$ & $80 \mathrm{~m}$ & $100 \mathrm{~m}$ & $120 \mathrm{~m}$ & $140 \mathrm{~m}$ \\
\hline 1 & Alessio & 203 & 136 & - & 200 & 186 & 246 & 351 & 238 & 172 & 144 & - \\
\hline 1 & Honoris & - & 111 & 139 & - & 136 & 159 & 191 & 174 & 127 & 93 & - \\
\hline 1 & Asko & 170 & 152 & 177 & 199 & 204 & 261 & 284 & 311 & 197 & 185 & - \\
\hline 1 & Geram & 122 & 98 & 111 & 133 & 124 & 159 & 162 & 174 & 130 & 161 & - \\
\hline 1 & Jette & 94 & 96 & 172 & 239 & 228 & 214 & 198 & 219 & 144 & 107 & - \\
\hline 1 & Arucha & 176 & 170 & 272 & 275 & 267 & 249 & 246 & 207 & 175 & - & - \\
\hline 1 & Aschenputtel & - & 135 & 143 & - & 128 & 119 & 116 & 121 & 116 & - & - \\
\hline 1 & Vulkana & 192 & 168 & 233 & 301 & 317 & 294 & 260 & 188 & 166 & - & - \\
\hline 2 & Atlas & 103 & 81 & 79 & 159 & 98 & 111 & 137 & 138 & 124 & 101 & - \\
\hline 2 & Zigeuner & 114 & 127 & 126 & 133 & 117 & 140 & 145 & 166 & 127 & - & - \\
\hline 2 & Klemens & 200 & 171 & 213 & 286 & 244 & 280 & 239 & 241 & 245 & 254 & - \\
\hline 2 & Southern & 132 & 106 & 96 & 85 & 83 & 84 & 97 & 103 & 101 & 108 & - \\
\hline 2 & Nicoletta & - & 106 & 108 & - & 102 & 83 & 92 & 100 & 92 & 80 & - \\
\hline 2 & karla & - & 79 & 141 & - & 167 & 247 & 266 & 248 & 217 & 166 & - \\
\hline 2 & Hagebutte & 97 & 75 & 107 & 180 & 164 & 224 & 268 & 291 & 233 & 219 & 200 \\
\hline
\end{tabular}


Anexo M - Escore morfológico e classificação final (total) do exame histológico dos animais do grupo 2.

\begin{tabular}{l|c|c|c|c|c}
\hline \multicolumn{1}{c|}{ Nome } & Sexo & Glomerulonefrite & Interstício & Túbulo & Total \\
\hline \hline Atlas & $\mathrm{M}$ & 2 & 2 & 1 & 2 \\
\hline Zigeuner & $\mathrm{M}$ & 1 & 1 & 1 & 1 \\
\hline Klemens & $\mathrm{M}$ & 2 & 1 & 1 & 1 \\
\hline Southern & $\mathrm{M}$ & 2 & 1 & 1 & 1 \\
\hline Epson & $\mathrm{M}$ & 2 & 2 & 1 & 2 \\
\hline Ariberta & $\mathrm{F}$ & 2 & 2 & 2 & 2 \\
\hline Blanche & $\mathrm{F}$ & 1 & 1 & 0 & 1 \\
\hline Nicoletta & $\mathrm{F}$ & 1 & 0 & 0 & 0 \\
\hline karla & $\mathrm{F}$ & 2 & 2 & 1 & 2 \\
\hline Hagebutte & $\mathrm{F}$ & 2 & 2 & 2 & 2 \\
\hline
\end{tabular}

